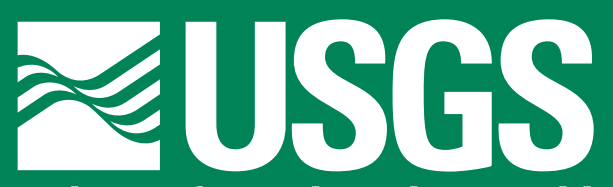

science for a changing world

\title{
User's Manual for Computer Program BASEPLOT
}

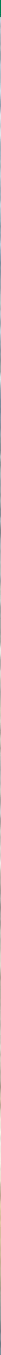

U.S. GEOLOGICAL SURVEY Open-File Report 02-151 


\section{User's Manual for Computer Program BASEPLOT}

By Curtis L. Sanders, Jr.

U.S. Geological Survey

Open-File Report 02-151

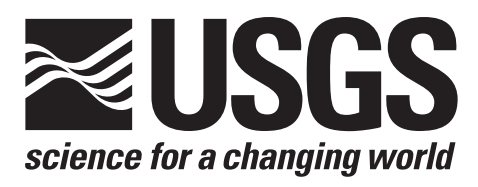

Columbia, South Carolina

2002 


\section{U.S. DEPARTMENT OF THE INTERIOR \\ GALE A. NORTON, Secretary}

U.S. GEOLOGICAL SURVEY

Charles G. Groat, Director

Use of trade, product, or firm names in this publication is for descriptive purposes only and does not imply endorsement by the U.S. Geological Survey

For additional information write to:

District Chief

U.S. Geological Survey

Suite 129

720 Gracern Road

Columbia, SC 29210-7651
Copies of this report can be purchased from:

U.S. Geological Survey

Branch of Information Services

Box 25286

Denver, CO 80225-0286

888-ASK-USGS

Additional information about water resources in South Carolina is available on the internet at http://sc.water.usgs.gov 


\section{CONTENTS}

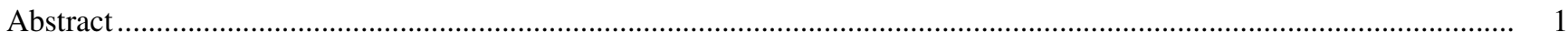

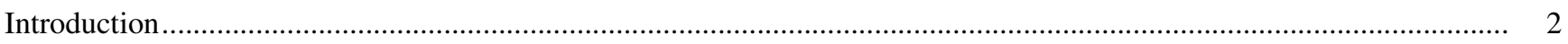

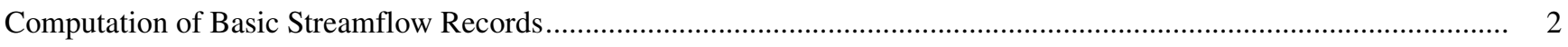

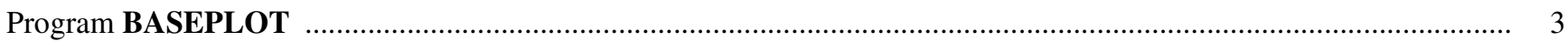

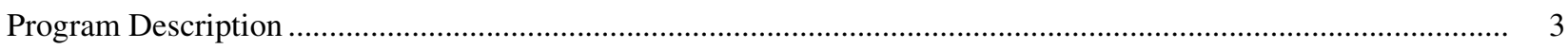

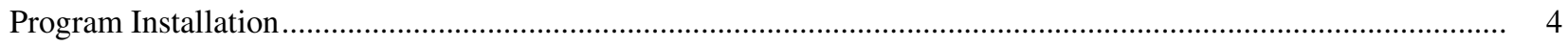

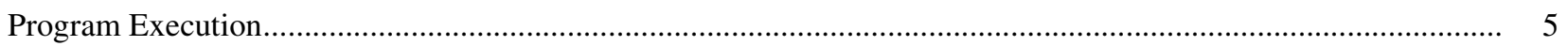

Review of Basic Streamflow Record Computation Using Program BASEPLOT …................................................ 7

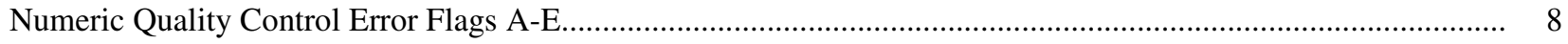

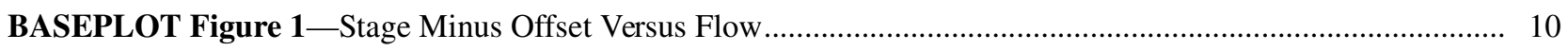

BASEPLOT Figure 2 -Stage Versus Discharge, Low-Water Arithmetic Scale ........................................... 16

BASEPLOT Figure 3-All V-shift Curves for the Retrieved Period ............................................................. 16

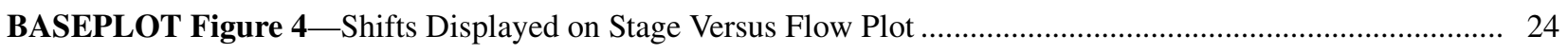

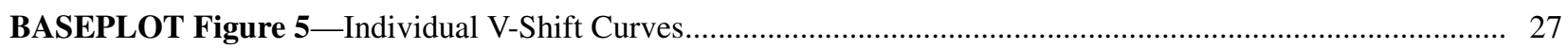

BASEPLOT Figure 6-Hydrograph of Gage Heights, Shifts, and Datum Corrections ...................................... 48

BASEPLOT Table 1-Percent Differences Between Measurements in Prior 4 Years and the Current Ratings....... 53

BASEPLOT Table 2-Measurements, Inspection, V-Shift, and Quality Control Data..................................... 54

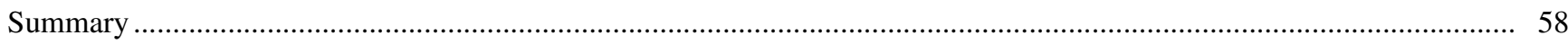

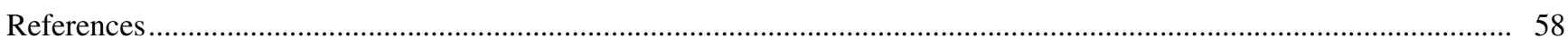

Appendix—Review Checklist for Computer Program BASEPLOT ........................................................................ 59

\section{FIGURES}

1-2. Plots of BASEPLOT Figure 1-Stage minus offset versus discharge for Station 02197310:

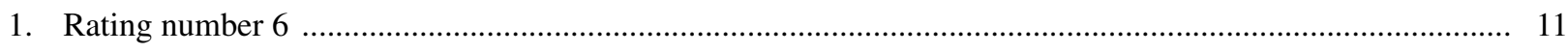

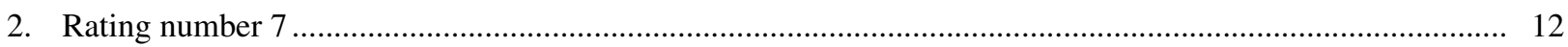

3-4. Plots of BASEPLOT Figure 2-Stage versus discharge, arithmetic scale for Station 02197310:

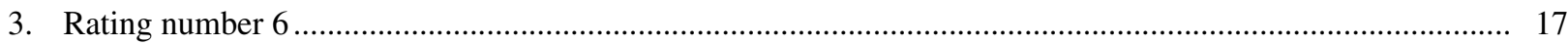

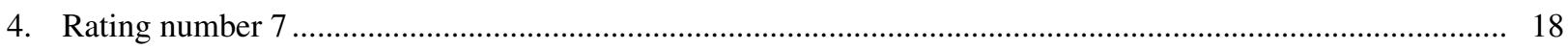

5-6. Plots of BASEPLOT Figure 3-All V-shift curves for retrieved period for Station 02197310:

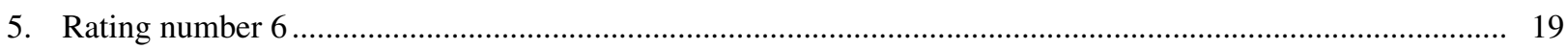

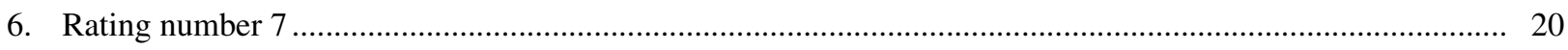

7-8. Plots of BASEPLOT Figure 4-Shifts displayed on stage versus discharge plot for Station 02197310:

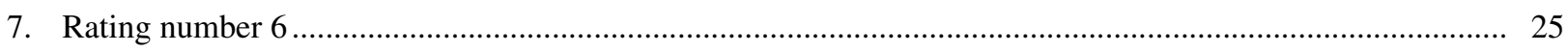

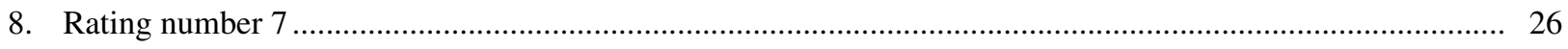

9-12. Plots of BASEPLOT Figure 5-Individual shift curve for Station 02197310, shift of:

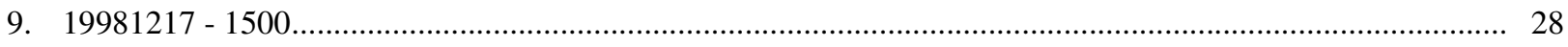

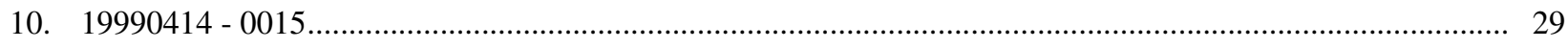

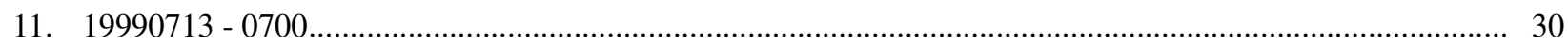


12-24. Plots of BASEPLOT Figure 6-Hydrograph of gage heights, shifts, and datum corrections for Station 02197310:

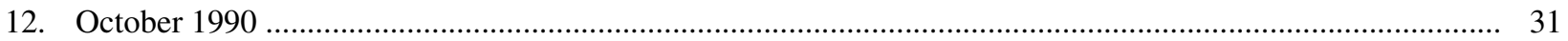

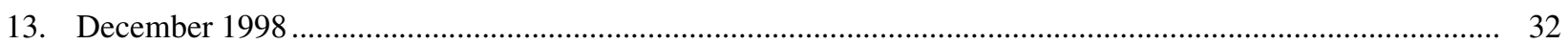

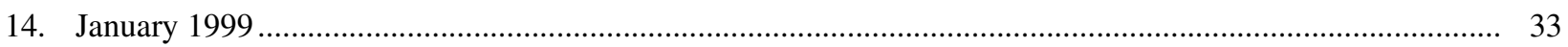

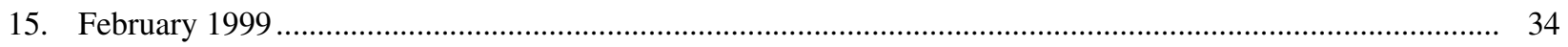

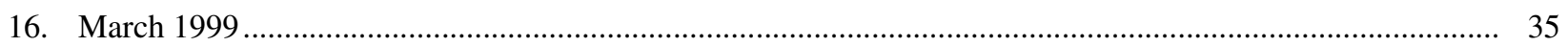

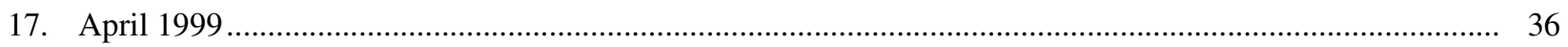

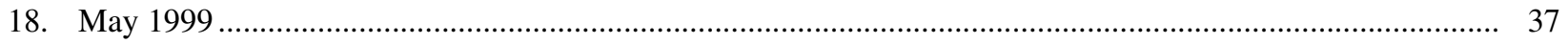

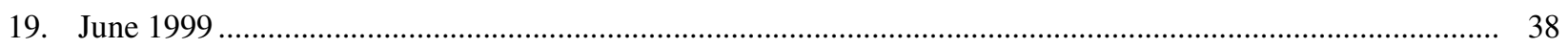

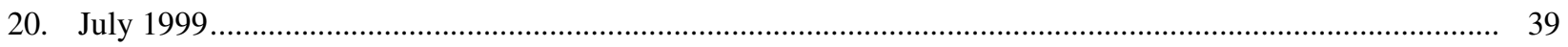

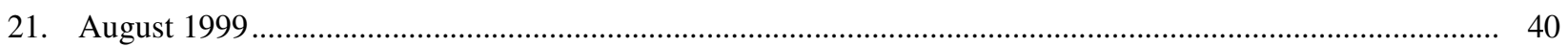

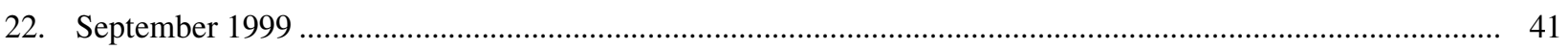

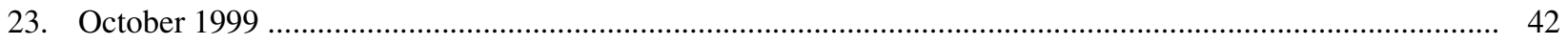

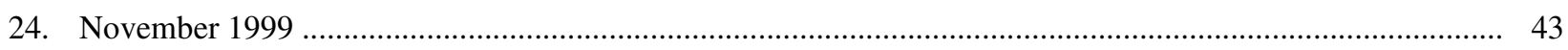

\section{TABLES}

1. BASEPLOT Table 1-Percent differences between measurements made in prior 4 years and the current ratings ....... 14

2. BASEPLOT Table 2-Measurement, V-shift, and quality control data.

\section{CONVERSION FACTORS}

\begin{tabular}{rll}
\hline Multiply & By & To obtain \\
\hline feet $(\mathrm{ft})$ & 0.3048 & meters \\
cubic feet per second $\left(\mathrm{ft}^{3} / \mathrm{s}\right)$ & 0.0283 & cubic meter per second \\
\hline
\end{tabular}




\title{
User's Manual for Computer Program BASEPLOT
}

\author{
By Curtis L. Sanders, Jr.
}

\section{ABSTRACT}

The checking and reviewing of daily records of streamflow within the U.S. Geological Survey is traditionally accomplished by hand-plotting and mentally collating tables of data. The process is time consuming, difficult to standardize, and subject to errors in computation, data entry, and logic. In addition, the presentation of flow data on the internet requires more timely and accurate computation of daily flow records.

BASEPLOT was developed for checking and review of primary streamflow records within the U.S. Geological Survey. Use of BASEPLOT enables users to (1) provide efficiencies during the record checking and review process, (2) improve quality control, (3) achieve uniformity of checking and review techniques of simple stage-discharge relations, and (4) provide a tool for teaching streamflow computation techniques.

The BASEPLOT program produces tables of quality control checks and produces plots of rating curves and discharge measurements; variable shift (V-shift) diagrams; and V-shifts converted to stage-discharge plots, using data stored in the U.S. Geological Survey Automatic Data Processing System database. In addition, the program plots unit-value hydrographs that show unit-value stages, shifts, and datum corrections; input shifts, datum corrections, and effective dates; discharge measurements; effective dates for rating tables; and numeric quality control checks. Checklist/tutorial forms are provided for reviewers to ensure completeness of review and standardize the review process. The program was written for the U.S. Geological Survey SUN computer using the Statistical Analysis System (SAS) software produced by SAS Institute, Incorporated. 


\section{INTRODUCTION}

The checking and reviewing of daily records of streamflow can be a long and tedious process. Traditionally, the checking and review of daily records of streamflow have been done by hand-plotting and mentally collating tables of measurements, datum corrections, and shift corrections on daily value or unit-value hydrographs; reviewing hand-plotted shift curves; and reviewing hand- or computer-drawn stagedischarge ratings. In addition, the traditional checking and review processes are difficult to standardize and subject to errors in computation, data entry, and logic. The presentation of flow data on the internet requires more timely and accurate computation of daily flow records. Therefore, there is a need for computer-generated graphics and numeric quality control checks using computational data stored in the USGS Automatic Data Processing System (ADAPS) (National Water Information System, 1997) to expedite and improve the checking and review processes.

\section{COMPUTATION OF BASIC STREAMFLOW RECORDS}

To understand the review of basic streamflow records using BASEPLOT, an understanding of the computation process is needed. A complete description of the process, as presented by Rantz (1982) and Kennedy (1983), is beyond the scope of this document, but a short description is provided below.

Unit-value gage heights, or stages, are recorded at regular time intervals, such as 15 minutes, at gaging stations on selected streams. The unit-value gage heights are entered in the USGS ADAPS (National Water Information System, 1997) unit-value file.

The gages are serviced, the discharge of the stream is measured, and the inside and outside gage heights at the time of the measurements are recorded at predetermined intervals. Unit-value gage heights are continuously recorded by a recorder: the inside gage height is a reading of gage height independent of the recorder from inside the gaging structure, and the outside gage height is a reading from a gage completely external to the gaging structure. The outside gage measurement, therefore, is not affected by potential mechanical or electronic factors that could affect the measurement of gage heights from within the gaging structure. The measured discharge, inside and outside gage heights, quality of the measurement, and other measurement data are entered in the ADAPS measurement file.

A graphical relation of a reference gage height to measured discharge, called a stage-discharge rating, is developed. The relation typically varies with time, because of variations in the physical characteristics of the stream, such as sediment scouring or filling in the controlling channel. The stage-discharge relation itself can be revised, or temporary changes can be accomplished by "shifting," whereby adjustments are made to the rating by varying gage height corrections with time, or with time and stage. Variations with time and stage are accomplished by variable-shift (V-shift) curves, which relate the shifts to stage. Typically, the shifts or V-shift curves are interpolated with time, or applied during high flows of flood events that could have caused the shift. These shifts and V-shift curves are stored in the ADAPS database.

Because shifts are averaged within the accuracy of the discharge measurements where possible, some residual, in terms of percent of discharge and shift, in feet (ft), may remain. These residual percent differences and residual shifts, in feet, also are entered in the measurement file for each measurement. 
In addition, datums of the recorder, inside gage, and outside gage are periodically verified by levels. Datum corrections as determined by levels, or as determined by comparisons of the recorder, inside, and outside gage heights, are stored in the ADAPS database.

Finally, the recorded unit-value gage heights are adjusted by adding shift and datum corrections, and then applied to the stage-discharge ratings to produce unit-value discharges. Subsequently, the unit-value discharges are aggregated into daily value discharges, both of which are stored in the ADAPS database.

\section{PROGRAM BASEPLOT}

\section{Program Description}

BASEPLOT is a post-processor program that summarizes the computation of basic discharge records using plots, tables, numeric quality control checks, and tutorial checklist forms. The program also can be used as a pre-processor to plot measurements and optimum shifts on unit-value hydrographs to guide initial decisions on application of shifts with time. This report documents installation and execution instructions and provides specific guidance on how to analyze the output produced by BASEPLOT.

BASEPLOT was designed to:

1. Make checking and review of primary flow records more efficient by eliminating the need to handplot information and search through tables of corrections.

2. Improve quality control by graphical representation of data and numeric quality-control checks.

3. Achieve uniformity of checking and review techniques, by standardized graphical representations of computations and checklist forms for review.

4. Provide a tool for teaching streamflow computation techniques by means of graphical visualization of computation methods, program documentation, and tutorials that accompany the checklists.

5. Serve as a repository and implementation vehicle for review techniques being used and developed throughout the USGS.

It is important that each of the review items listed on the checklist forms be checked to ensure a minimal level of uniformity of review techniques and to maximize the usefulness of the program. Specifically, using data stored in the ADAPS database, the BASEPLOT program depicts:

1. Plots of rating curves and discharge measurements.

2. Variable shift (V-shift) diagrams (Rantz, 1982; and Kennedy, 1983).

Note: V-shift diagrams are 3-point relations of gage height to temporary gage height corrections to stage-discharge ratings. Herein, stage and gage height are interchangeably used to describe the elevation of water surfaces being recorded at USGS streamflow gaging stations.

3. V-shifts converted to stage-discharge plots. 
(4) Unit-value hydrographs showing:

(a) Unit-value stage, shifts, and datum corrections.

(b) Input shifts, datum corrections, and effective dates.

(c) Discharge measurements.

(d) Effective dates for rating tables.

(e) Numeric quality control checks.

(5) Tables of numeric quality control checks.

Program BASEPLOT is designed as part of an overall strategy for graphical checking and review of basic surface-water flow records. The suggested sequence of review steps using BASEPLOT is:

1. Review the station analysis for an overall explanation of the computation of records.

2. Review level notes and application of datum corrections.

3. Review field notes and the quality of individual discharge measurements.

4. Review rating plots and error-bar shift plots produced by the ADAPS software to verify that ratings and shifts were derived correctly and logically.

NOTE: The shifts and error limits of the shifts, in units of feet, are plotted against gage height in an error-bar shift plot. The plotted error limits make it easier for the analyst to draw a single V-shift curve through as many measurement shift points as possible.

5. Review basic primary flow computations using unit-value stage, unit-value discharge, measurement, shift correction, datum correction, and stage-discharge rating data stored in the ADAPS database as depicted by the graphic and numeric quality control capabilities of BASEPLOT, in conjunction with a detailed review of the station analysis.

NOTE: A complete discussion of methods of computation of records of continuous streamflow is provided by Rantz (1982) and Kennedy (1983) and is beyond the scope of this report.

6. Verify computed daily value flow data by hydrographic comparison to daily value flow data at index stations, using regression techniques employed by program HYDCOMP (C.L. Sanders, U.S. Geological Survey, written commun., October 2000).

7. Review the Station Manuscript for misspellings and contradictions with the station analysis or previous years records.

\section{Program Installation}

The installation shell script baseplot_install.sh is available for downloading over the Internet from the public anonymous File Transfer Protocol (FTP) server sun1dsccmb.er.usgs.gov (internet address 144.47.8.248) in the directory /pub/baseplot. When the system administrator executes the installation script file baseplot_install.sh with root access from any directory on the SUN computer, it will transfer, install, and create the necessary programs, directories, and links. The BASEPLOT software should be 
installed on the same SUN computer where the USGS ADAPS software and database reside. Program BASEPLOT utilizes the SAS software package marketed by SAS Institute, Inc. (1993). Therefore, at least one copy of the SAS software also needs to be installed on the same SUN computer where the USGS ADAPS software and database reside.

\section{Program Execution}

For each streamflow station, the user must first create a small plot request file (herein called a "b-file"), using vi, emacs, SUN's text editor, or other editor (step 1, below), and then execute the file (step 2, below).

1. Create the b-file as follows. Use the prefix " $b$ " and the station number to name the file, such as "b02197310," for this example. Note that all percent signs, parentheses, commas, quotation marks, and semicolons are necessary.

\%baseplot ('02197310’, 3, 11, 19980901, 19991130,

‘02197310 UPPER THREE RUNS ABOVE RD C AT SAVANNAH RIVER SITE, SC’,

\section{pr,un,oneshiftpl,short);}

The data in parentheses are arguments delivering information to the program, as described below.

Argument no. 1 is the station number in single quotes.

Argument no. 2 is the data descriptor (dd) number for the gage height record in ADAPS.

Argument no. 3 is the dd number for the discharge record in ADAPS.

Argument no. 4 is the begin YYYYMMDD date. Begin two months before the water-year of record being reviewed to display the last shifts and measurements of the previous water-year.

Argument no. 5 is the end YYYMMDD date. End two months after the current water year of record being reviewed to display the first shifts and measurements of the following water-year.

Argument no. 6 is the station number and name in single quotes.

Argument no. 7 is the output destination. Enter "sc" to send plots to the screen. Enter "pr" to send the plots to a printer.

Notes: (1) If the "pr" argument is used, the destination printer is specified when the program is executed by the "baseplot" command.

(2) If the "sc" argument is used, several error messages concerning "unknown printer" will be displayed. These messages can be ignored. 
(3) To go from one plot to another when plots are brought to the terminal screen by the "sc" argument, place the cursor in the plot on the screen, and click the left mouse button. Plots can only be viewed in a successively forward direction.

Argument no. 8 specifies the scaling method to be used for BASEPLOT Figure 6, which is a unit-value hydrograph of gage heights, shifts, and datum corrections. Enter "un" to request that uniform scales be used for the vertical axis for the entire run. Enter "nu" to request that the scales be different for each month. Large gage heights from flood events can compress the gage height scale so much that detail is lost for the lower gage heights. If so, the "nu" option can be used to force a different scale by month, thereby achieving scales that will show more detail for the lower gage heights. Otherwise, the "un" option is recommended, because uniform scaling makes it easier to compare the magnitudes of flood events that may have caused shifts.

Argument no. 9 specifies whether all stage-discharge shift curves in BASEPLOT Figure 4 are plotted on one graph (the argument is "oneshiftpl"), or whether each curve is plotted on a separate graph (the argument is "sevshiftpl"). If too much detail is lost from having several shift curves on one plot, as specified by argument "oneshiftpl," the argument "sevshiftpl" can be used to provide more detail by plotting the curves separately.

Argument no. 10 specifies the extent of annotation of numeric quality checks shown for inspections and measurements on the hydrographs in BASEPLOT Figure 6. If the argument is "short," as shown in the example, or is left off, numeric quality control checks will be annotated on BASEPLOT

Figure 6 only if the checks show that errors may exist. If the argument is "long," the numeric quality control checks will appear even if they do not indicate possible errors. The argument "short" is recommended, because it decreases the amount of over-writing of graphical information on the plots, increases the speed of the review, and emphasizes the location and type of possible errors.

2. Execute the program as follows. To execute the file named "b02197310" type:

\section{baseplot b02197310 pr3 <carriage return>}

where:

b02197310 is the name of the plot-request file.

pr3 is the name of the printer where the plots are to be directed. If the plots are to be printed, do not forget to set argument 7 in the "b-file" to "pr." If the plots are to be directed to the screen (by specifying "sc" in argument 7), the printer name does not have to be included in the above command line. 
Note: Some users like to determine if $\mathrm{V}$-shift curve shapes are reasonable using

BASEPLOT Figures 3 and 4 and to resolve numeric quality control errors in BASEPLOT Table 2 before printing all the remaining figures. This can be done by:

(a) setting argument 7 to "pr" in the "b" file,

(b) leaving off the printer name when executing the "baseplot b02197310"command, and

(c) issuing the following spool commands:

lp plot.ps. 3 plot.ps. 4

lp -ylandscape sas.pgm.lst

\section{REVIEW OF BASIC STREAMFLOW RECORD COMPUTATION USING PROGRAM BASEPLOT}

Forms are provided in the Appendix for each BASEPLOT figure which is produced to serve as a checklist for users. The forms will ensure uniformity and completeness of technique, ensure that the output of BASEPLOT is used as intended, and provide sufficiently detailed tutorials for inexperienced users. A discussion of the analytical methods of BASEPLOT is provided below by detailed explanations of the questions and recommendations presented on the forms. Therefore, an example analysis of Station 02197310, Test River near Testville, S.C., is shown for each item on each form to demonstrate the review steps. Only one form needs to be completed for each of BASEPLOT Figures 1-6, even though each figure may contain multiple plots.

In the following documentation of each form, the question is shown in bold type, and the explanation is shown in italic type. Detailed explanations of the questions are shown in regular type. An underlined " $\underline{ }$ " or " $\mathrm{N}$ " to be circled by the reviewer indicates the preferred answer, if any, to the question. The reviewer should be aware that, in some cases, an answer contrary to the "preferred" answer may be justifiable, in which case, the reviewer should document the justification and continue with the review. Subsequent reviewers can determine if a previous reviewer found problems with the computations by glancing at the underlined "Y $\mathrm{s}$ " and "Ns." In addition, the underlined answers guide inexperienced users toward proper review methods for most analyses.

The forms should not be customized for each district at this time, because the intent is to work toward standardizing the review process for flow records computed from simple stage-discharge relations. If the forms need modification, or new review methods need to be added, please notify personnel responsible for maintenance of BASEPLOT so that the changes can be incorporated into the program.

Some space is reserved on the review checklist forms for reviewer comments. The reviewer should use this space to note what is required to remedy any errors. This space can also be used to document whether or not the required actions were done or the reasons why they were not. Lengthy comments can be made on the reverse side of the forms.

The documentation, forms, and plots are voluminous in order to completely describe the review process and methods. Once familiar with the BASEPLOT program and its output, a reviewer can quickly study the plots and numeric quality control checks, and document recommendations on the forms. In addition, 
BASEPLOT can be used by the hydrographer who computes the streamflow record to check computations. If errors detected by program BASEPLOT are corrected by the person computing the record, a great deal of time and effort will be saved in subsequent reviews.

\section{Numeric Quality Control Error Flags A-E}

BASEPLOT uses the following numeric quality control error flags (A-E):

1. Flag A: The user enters the shift, in feet, to be applied for a measurement into the ADAPS measurement file. This is called the "measurement-file shift." BASEPLOT computes a "unit-value file" shift by subtracting the "computed," datum-corrected unit-value file gage height from the gage height determined by finding the gage height associated with the unit-value discharge at the mid-time of the measurement in the current rating table. If the absolute value of the difference between these two shifts is equal to or larger than $0.01 \mathrm{ft}$, the Error Flag A is raised. If the difference is less than $0.01 \mathrm{ft}$, then the shift applied to the rating for computing the unit-value discharge agrees with the shift that the user intended to apply. This check verifies that:

a. The intended shifts were correctly typed into the ADAPS measurement and shift files.

b. The shift intended by the user agrees with the V-shift curve at the gage height of the measurement.

c. The primary was run using the intended V-shift curve.

d. The application of the shift with stage and(or) time agree with the shift intended by the user at the stage of the measurement.

2. Flag B: The user computes a percent difference between the measured discharge and the rating discharge after the shift is applied, and enters the percent difference into the ADAPS measurement file. This is called the "measurement-file percent difference." BASEPLOT computes a percent difference using the measured discharge and the unit-value discharge at the mid-time of the measurement. This is called the "unit-value file difference." If these two differences disagree by more than 3 percent, Flag B is raised. This check verifies Flag A items 1a-d in terms of percent discharge, rather than feet. If the measured discharge were plotted on a unit-value discharge hydrograph, the unit-value difference is simply the percent difference between the measurement and the unit-value hydrograph discharge. The following warning, posted on the Review Checklist form for BASEPLOT Table 2, should be heeded:

WARNINGS: (a) The two differences may not agree exactly, because the unit-value discharge is taken at the mid-time of the measurement, ignoring the fact that the discharge may not have changed uniformly with time during the measurement or with stationing across the cross section. IF THE DISAGREEMENT IS MORE THAN ABOUT 3 PERCENT AND THERE IS CONSIDERABLE CHANGE OF STAGE DURING THE MEASUREMENT, THEN IGNORE THE QUALITY CONTROL CHECK OF FLAG B.

(b) Also, if the rating is extremely flat, the difference may be more than 3 percent. 
The hourly rate of change of stage during the measurement is presented on BASEPLOT Figures 5 and 6 and in BASEPLOT Table 2. If this rate of change of stage is small and the rating is not extremely flat, the unit-file difference is probably accurate.

3. Flag C: If the unit-value file percent difference is greater than the measurement accuracy in percent ( 5 percent for a "good" measurement or 8 percent for a "fair" measurement), Flag C is raised. No test is applied for measurements rated "poor." If Flag $\mathrm{C}$ is raised, it indicates that the user did not shift within the accuracy of the measurement. It may indicate that the user did not do primary flow computations after shifts were computed and entered in the ADAPS measurement and shift files.

4. Flag D: If the measurement file shift differs from the V-shift curve by more than 0.01 feet, Flag D is raised. If Flag D is not raised, it is a positive indication that an error was NOT found. However, if Flag D is raised an error may not exist for the following reasons presented on the Review Checklist for BASEPLOT Figure 5.

WARNINGS: (1) Currently (June 2002) BASEPLOT does not interpolate from one
v-shift curve to another v-shift curve with time. Therefore, if shift curves
of different shapes are applied on either side of a measurement, the square
may not fall on the v-shift line, even though the shift may have been
applied correctly. If the square does not fall on the v-shift curve for what-
ever reason (including warning 2 below), but ERR flags A and B are
blank, the reviewer is assured that the shift was probably applied properly.
(2) The program assumes that the shift is applied before the measurement. If
the measurement is plotted, but no shift curve is plotted or the square does
not fall on the shift curve, it may mean that the shift was applied shortly
after the measurement instead. DO NOT CHANGE THE TIME OF THE
SHIFT AND RERUN THE PRIMARY JUST TO MAKE FIGURE 5
CORRECT.

(3) If the measurement is not plotted, it may mean that the time of the measurement was not entered in the measurement file and that the measurement file should be corrected.

5. Flag E: If the recorder error (the unit-value gage height at the mid-time of the measurement or time of the inspection minus the measurement or inspection inside gage height) is more than $0.01 \mathrm{ft}$, Flag $\mathrm{E}$ is raised. If the measurement inside gage height were plotted on a unit-value gage height hydrograph, the recorder error is simply the difference between the measurement gage height and the unit-value hydrograph gage height. Flag $\mathrm{E}$ is especially important for insuring that datum corrections detected by inspections are applied.

When Flag E is raised, BASEPLOT also prints out the percent error in discharge that would result from the detected recorder error. If the percent discharge error is less than about 3 percent, a datum correction is probably not warranted. It should be kept in mind that for flat ratings, very small changes in gage height can make very large changes in discharge.

The BASEPLOT forms suggest numeric error limits, such as $0.01 \mathrm{ft}, 3$ percent of discharge, and so forth. These limits were somewhat arbitrarily determined; therefore, the reviewer must use judgement as to whether small excedances of these limits are acceptable. 
The following message appears at the beginning of the form:

Numeric quality control ERR flags A-D can be evaluated in Figures 5 and 6 and in Table 2, depending on the preferences of the reviewer. ERR flag $E$ can be reviewed in Figure 6 or Table 2.

As stated in the message, some numeric quality control checks are redundantly shown in two BASEPLOT figures and one BASEPLOT table. The checks are shown in the plots, because it is useful to evaluate the numeric quality control checks in relation to the shift curve or time and unit-value stage. However, it may be more expedient to resolve possible errors detected by the numeric quality control checks by first inspecting the data and warning flags in BASEPLOT Table 2, as some checks appear in BASEPLOT Table 2 but not in the plots. However, several graphic quality control checks have to be performed on the plots as described in the forms. The graphic and numeric quality control checks are described in detail below.

\section{BASEPLOT Figure 1 - Stage Minus Offset Versus Flow}

(Note: Some confusion may be caused in the following documentation because two types of figure or table numbers are referenced: (1) figure or table numbers produced by BASEPLOT and (2) figure or table numbers of the report. Therefore, if the word "BASEPLOT" precedes the figure in table number, a BASEPLOT figure or table number is being referenced; otherwise, a report figure or table number is being referenced.)

BASEPLOT Figure 1 shows stage-discharge ratings and associated recent measurements (figs. 1 and 2), and is useful for verification of rating table data entry, especially if the stage-discharge rating plot in use has not yet been computer generated. A separate plot is produced for each rating used in the period specified for the retrieval. Reviewers should consider the following items presented on the forms when examining BASEPLOT Figure 1:

1. "Are enough rating points used to define the curvature of the rating?"

If too few stage-discharge points are entered into the ADAPS rating file, interpolation of discharges from the rating will not be accurate. Therefore, the rating must have enough points to define the curvature adequately and should not have the appearance of connected straight-line segments.

Example Analysis: The answer is "yes."

2. "Does the curve show there are no obvious data entry errors?"

Blatant data entry errors may be depicted by sharp spikes, flat places, or other irregularities of the plotted rating.

Example analysis: The answer is "yes." 


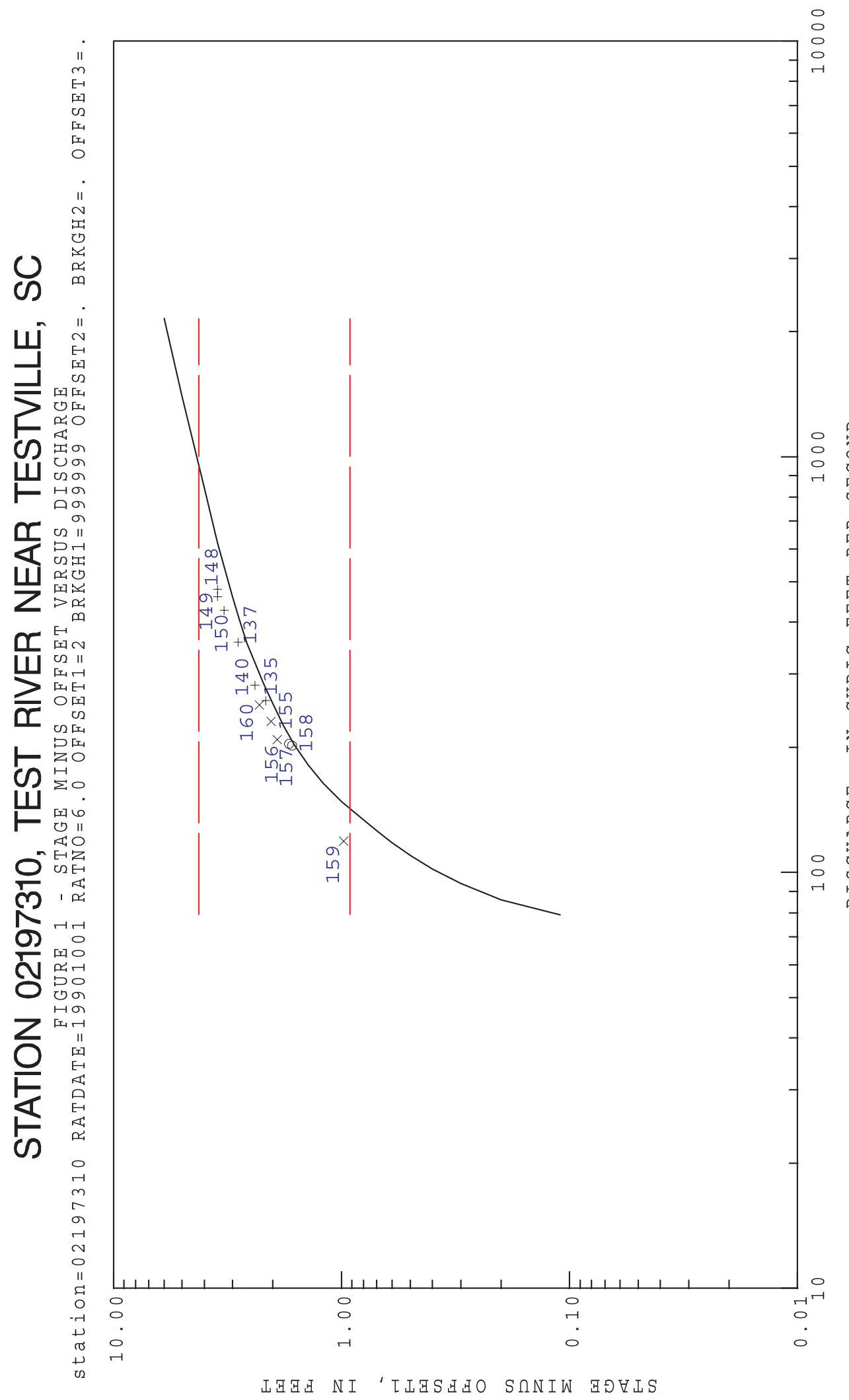

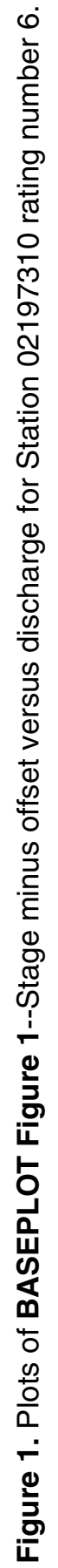



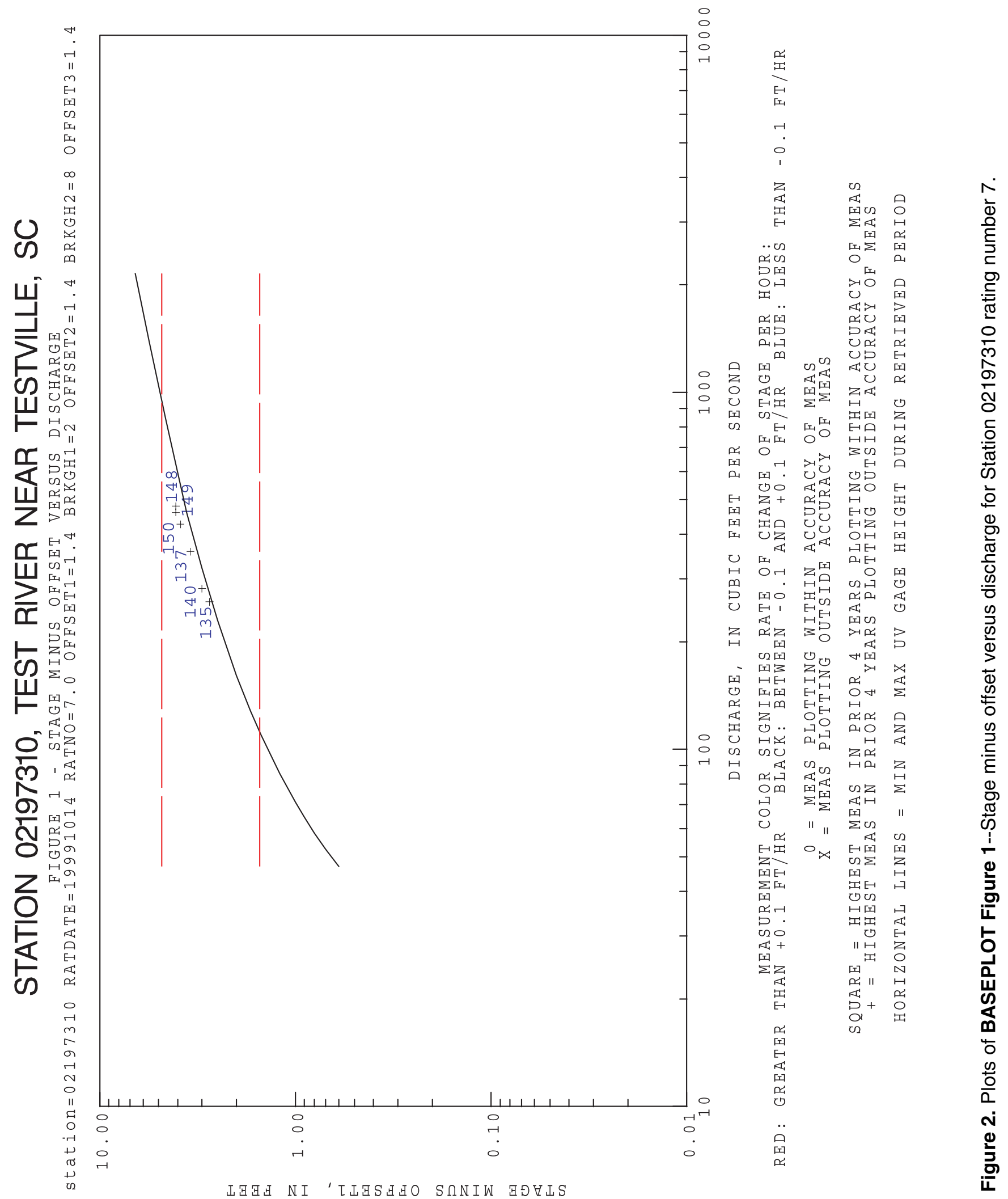


\section{3. "Does the offset adequately straighten the lower part of the curve?"}

The lower part of logarithmic plots of stage-discharge ratings are usually straightened by subtracting an offset value from the recorded gage heights.

Example Analysis: The answer is "no." An offset of 2.0 feet (ft) was applied, when an offset of $0.0 \mathrm{ft}$ or $1.0 \mathrm{ft}$ may have been more appropriate in BASEPLOT Figure 1 (figs. 1 and 2).

4. "Based on the alignment of the $\mathbf{x} /+$ symbols, is it necessary to draw a new rating (especially the high end)?'”

"The " $x$ " and "+" symbols signify measurements that differ from the rating discharge by more than the percentage suggested by the accuracy of the measurements."

Circles represent measurements during the period being reviewed that agree with the current ratings within the accuracy of the measurement, whereas the X's show those that do not agree. Squares (not illustrated) represent measurements (1) that were made in the 4 years prior to the period being reviewed, (2) that are higher than the highest measurement during the period being reviewed, and (3) that agree with the current ratings. The pluses (+) represent measurements in the prior 4-year period that do not agree with the current ratings.

Review of BASEPLOT Figure 1 can be used to determine if new ratings should be drawn. In general, the higher ends of ratings do not shift as much as the lower ends of ratings. Usually, fewer high-flow measurements are obtained than low-flow measurements, because of the periods of high flow are usually short. Therefore, high-flow measurements made in the prior 4-year period are plotted for evaluation. Confidence in the validity of the current rating increases with the number of measurements that agree with the curve. If the high measurements have percent differences that are mostly positive or negative, the reviewer should determine if a new rating should be drawn. The reviewer should inspect these percent differences in BASEPLOT Table 1 (table 1) while reviewing BASEPLOT Figure 1. (See documentation for BASEPLOT Table 1).

Plotting the higher measurements plotted in BASEPLOT Figure 1 and showing their percent differences in BASEPLOT Table 1 saves the time of retrieving, plotting, and computing percent differences of these measurements, and also ensures that the higher previous measurements are evaluated in the review.

Example Analysis: The answer is "yes." All measurements are plotted above the rating curve (figs. 1 and 2), and an average rating curve could be fitted through these measurements. A check should be made to see if the rating in use is justified hydraulically. For example, if there were a solid-rock or weir control at this site, the limiting rating that is drawn might be more appropriate than an average rating. Even though an average rating might be more appropriate, the discharges computed for the current year are considered to be acceptable and would not be revised, because the rating was shifted to all measurements where necessary. 
Table 1. BASEPLOT Table 1-Percent differences between measurements made in prior 4 years and the current ratings

[FT, feet; CFS, cubic feet per second]

\begin{tabular}{|c|c|c|c|c|c|c|c|}
\hline $\begin{array}{c}\text { Date } \\
(1)\end{array}$ & $\begin{array}{c}\text { MEAS } \\
\text { NUMBER } \\
\text { (2) }\end{array}$ & $\begin{array}{c}\text { RATING } \\
\text { NUMBER } \\
\text { (3) }\end{array}$ & $\begin{array}{c}\text { INSIDE } \\
\text { GAGE } \\
\text { HEIGHT } \\
\text { (FT) } \\
(4)\end{array}$ & $\begin{array}{c}\text { MEAS } \\
\text { DISCHARGE } \\
\text { (CFS) } \\
\text { (5) }\end{array}$ & $\begin{array}{c}\text { RATING } \\
\text { DISCHARGE } \\
\text { (CFS) } \\
(6)\end{array}$ & $\begin{array}{c}\text { MEAS } \\
\text { RATED } \\
(7)\end{array}$ & $\begin{array}{c}\text { PERCENT } \\
\text { DIFFERENCE } \\
(8)\end{array}$ \\
\hline 19941025 & 135 & 6.0 & 4.15 & 259.0 & 277.5 & G & -6.7 \\
\hline 19950216 & 137 & 6.0 & 4.84 & 358.0 & 415.7 & G & -13.9 \\
\hline 19950808 & 140 & 6.0 & 4.40 & 282.0 & 320.0 & F & -11.9 \\
\hline 19970110 & 148 & 6.0 & 5.49 & 480.0 & 616.6 & G & -22.2 \\
\hline 19970110 & 149 & 6.0 & 5.49 & 461.0 & 616.6 & G & -25.2 \\
\hline 19970214 & 150 & 6.0 & 5.27 & 427.0 & 543.5 & G & -21.4 \\
\hline 19941025 & 135 & 7.0 & 4.15 & 259.0 & 274.2 & G & -5.6 \\
\hline 19950216 & 137 & 7.0 & 4.84 & 358.0 & 420.9 & G & -14.9 \\
\hline 19950808 & 140 & 7.0 & 44.0 & 282.0 & 322.0 & F & -12.4 \\
\hline 19970110 & 148 & 7.0 & 5.49 & 480.0 & 629.4 & G & -23.7 \\
\hline 19970110 & 149 & 7.0 & 5.49 & 461.0 & 629.4 & G & -26.8 \\
\hline 19970214 & 150 & 7.0 & 5.27 & 427.0 & 549.4 & G & -22.3 \\
\hline
\end{tabular}

NOTE: If all the percent differences are positive or negative, a new rating should be drawn. At least one of the most recent measurements should agree with the rating within the accuracy of the measurement.

\section{5. "Do the rising-stage and falling-stage measurements indicate that a loop rating should be drawn?"}

"Red symbols indicate that stages were rising more than 0.10 feet per hour $(\mathrm{ft} / \mathrm{hr})$ during the measurement. Blue symbols indicate that stages were falling more than $0.10 \mathrm{ft} / \mathrm{hr}$. If several red symbols plot below the rating curve and several blue symbols plot above the rating curve, a loop rating may exist, which might require rate-of-change-of-stage adjustments. If so, check to see if such adjustments were applied to the flow records."

For rivers with large channels and overbank storage areas, a "loop" rating may exist, as indicated by discharge measurements that plot below an average rating on rising stages and above an average rating on falling stages. This is because the flow in a river is a function of slope of the water surface in addition to the stage at the gage. At a given stage, the slope and discharge may be greater on rising stages than on falling stages at the same stage. The slope at a particular stage would be greater on rising stages because the downstream channels and overbank storage areas are filling with flood water as the river rises. The slope would be less at the same stage on falling stages, because the flood wave has passed and the downstream channels and overbank areas have been filled. 
If measurements were obtained at intervals over the rising and falling stages of a flood, they would plot in a counterclockwise "loop" about the average stage-discharge rating. It should be kept in mind that the rating is actually a series of normally shaped curves that are a function of stage and slope. (Note: In BASEPLOT Figures $\mathbf{4}$ and 5, it would be erroneous to connect measurements on one side of the "loop" to measurements on the other side of the "loop" by means of a v-shift crossing the average rating curve.)

If it seems that a "loop" rating exists, the need for and application of rate-of-change-of stage adjustments should be verified if necessary. One way of verifying the need for the adjustment would be to execute BASEPLOT for the period of record and direct the output to the screen to avoid excessive printing of plots. All measurements for the period of record would therefore be plotted in BASEPLOT Figure 1 on the screen. However, be warned that the program may run for a very long time if the entire length of record is requested. The program can be aborted by determining the program identification number (PID) using the "ps -fu username" command, and then issuing the command "kill -9 pid."

Example Analysis: The answer is "no."

\section{Does the range of discharge measurements reasonably cover the range of gage heights that occurred over the review period?}

"If not, describe the range(s) of gage heights for which measurements are needed. The minimum and maximum unit-value gage heights (minus the offset) for the retrieved period are shown as dashed horizontal lines on figure 1. The squares and pluses indicate all the measurements made in the prior 4 years that have discharges higher than the maximum experienced in the current year. Therefore, if the upper part of the rating is not verified by discharge measurements, it means that high flows have not been measured at the station in the last 4 years."

The dashed horizontal lines on BASEPLOT Figure 1 depict the minimum and maximum unitvalue gage height, minus the offset, recorded during the retrieved period. Also, measurements made in the 4 years prior to the retrieved period that are higher than the highest measurement in the retrieved period are plotted to indicate recent high-flow measurements that may have been used to define the upper end of the rating. In particular, the reviewer should determine if enough measurements were made in the retrieved period and the prior 4 years to define the upper end of the rating, and that sufficient measurements were made in the retrieved period to define the lower end of the rating.

Example Analysis: The answer is "yes," with a warning that the rating needs to be re-drawn through the measurements next year, if hydraulically necessary. 


\section{BASEPLOT Figure 2 - Stage Versus Discharge, Low-Water Arithmetic Scale}

BASEPLOT Figure 2 provides an arithmetic-scale plot of the lower three feet of each stage-discharge rating so that the reviewer can evaluate the shape of the rating as flows approach zero flow (which cannot be plotted on logarithmic-scale graphs) or very low flows (figs. 3 and 4).

1. "Does the shape of the rating seem reasonable as it approaches zero flow or very low flows?"

The reviewer should determine if the rating is a straighter line on the arithmetic plot than on the logarithmic plot, as is sometimes the case for stage-discharge ratings at culverts. It is desirable to select scaling (logarithmic or arithmetic) or logarithmic offsets to straighten out rating curves as much as possible. The drawing and extension of ratings by hand is more reproducible from one person to another when the ratings are fairly straight than when the ratings are curved.

The reviewer should be aware that the curve of an arithmetic-scale plot derived from a logarithmic-scale plot will be unavoidably scalloped to some degree. The degree of scalloping can be decreased, but not eliminated, by shortening the interval at which the logarithmic-scale data points are entered into the rating file.

It is highly recommended that estimates of the point of zero flow (PZF) be entered in the measurement file as numbered and dated discharge measurements, rather than being noted as estimates of the PZF's in the "comment" portion of a non-zero flow measurement. If the estimated PZF is entered as a measurement, it will be automatically plotted by BASEPLOT and ADAPS Program RATPLOT, which plots ratings and discharge measurements. If the character " $Z$ " is appended to the measurement number, the measurement can be identified as an estimated PZF in plots and computational programs. A note should be made in the "remarks" data field of the measurement and measurement file describing exactly how the PZF was estimated. On the logarithmic-scale stage-discharge rating in BASEPLOT Figure 1, the minimum discharge scale will be set to 0.001 $\mathrm{ft}^{3} / \mathrm{s}$ by BASEPLOT for zero-flow measurement discharges.

Example Analysis: No zero-flow measurements are plotted, and flows did not approach zero flow during the retrieved period. Without zero-flow measurements, the answer will have to be "yes."

\section{BASEPLOT Figure 3 - All V-shift Curves for the Retrieved Period}

All V-shifts for each rating are shown on BASEPLOT Figure 3 (figs. 5 and 6) to depict the general strategy for applying shifts for the water year. BASEPLOT Figure 3 should be used to quickly evaluate the overall shifting methodology and should not be used for analysis of specific shift curves. 


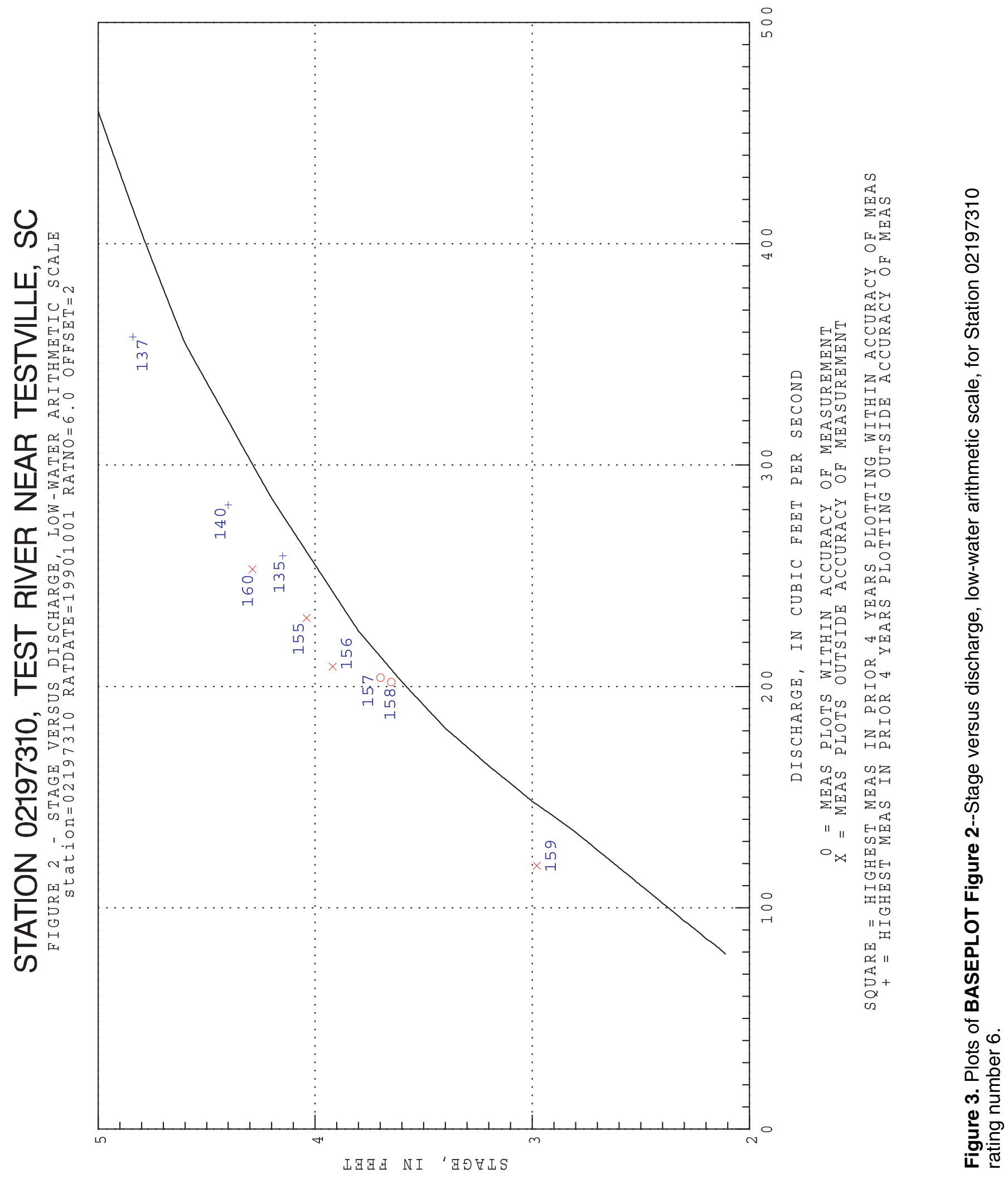




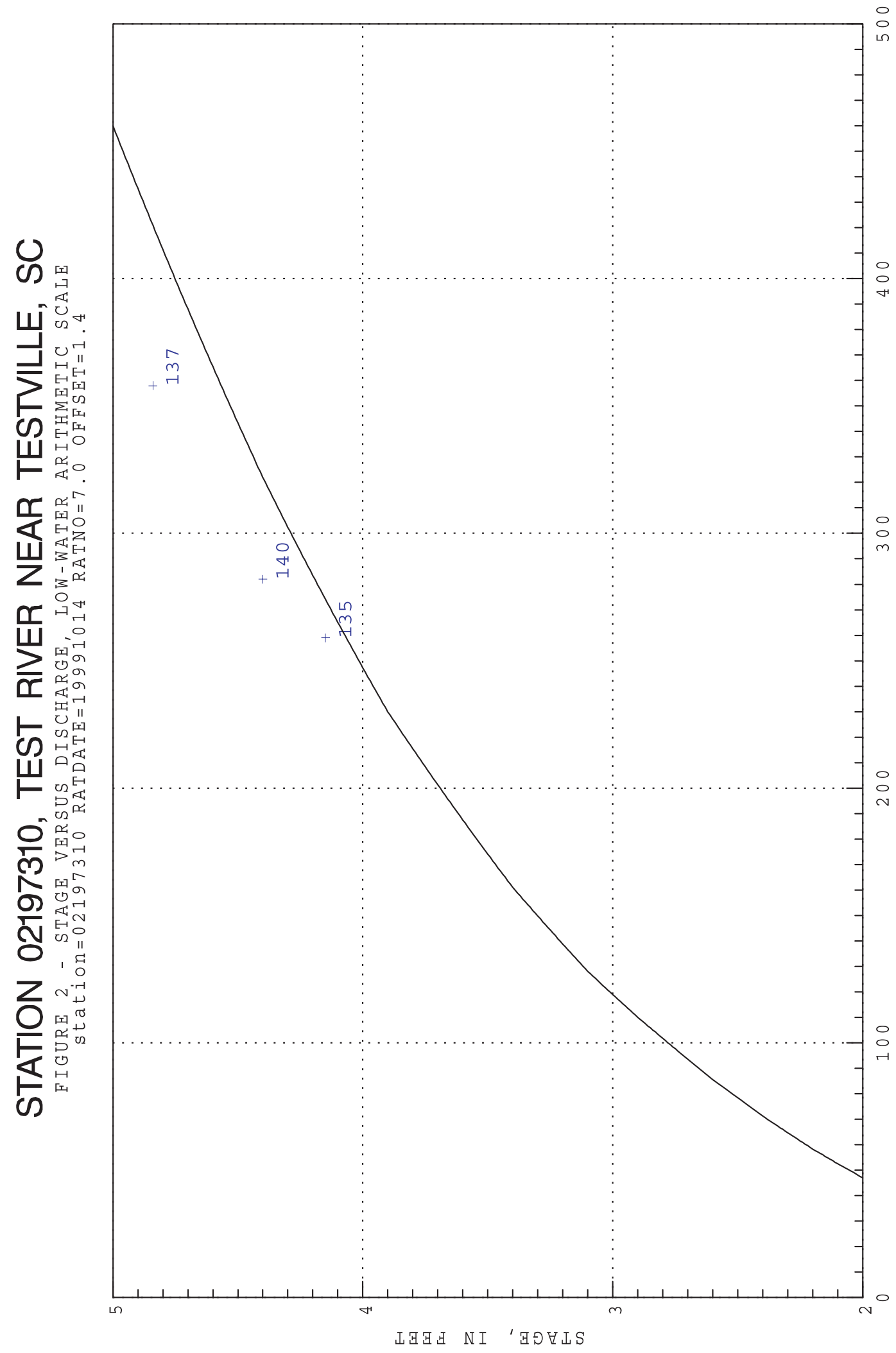

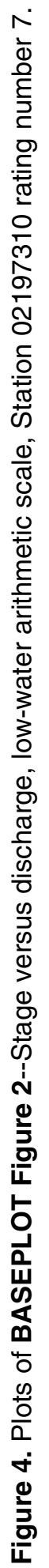




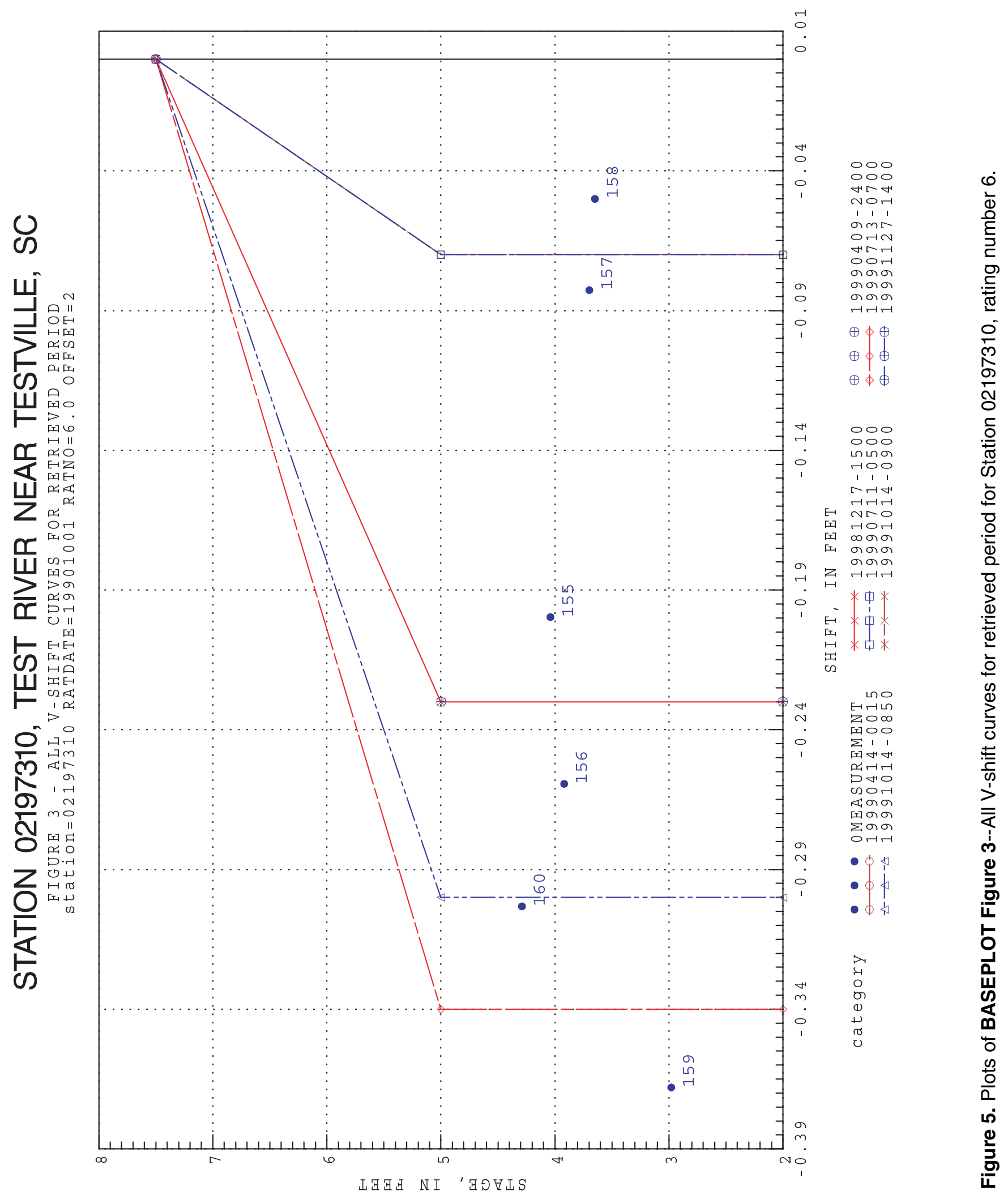




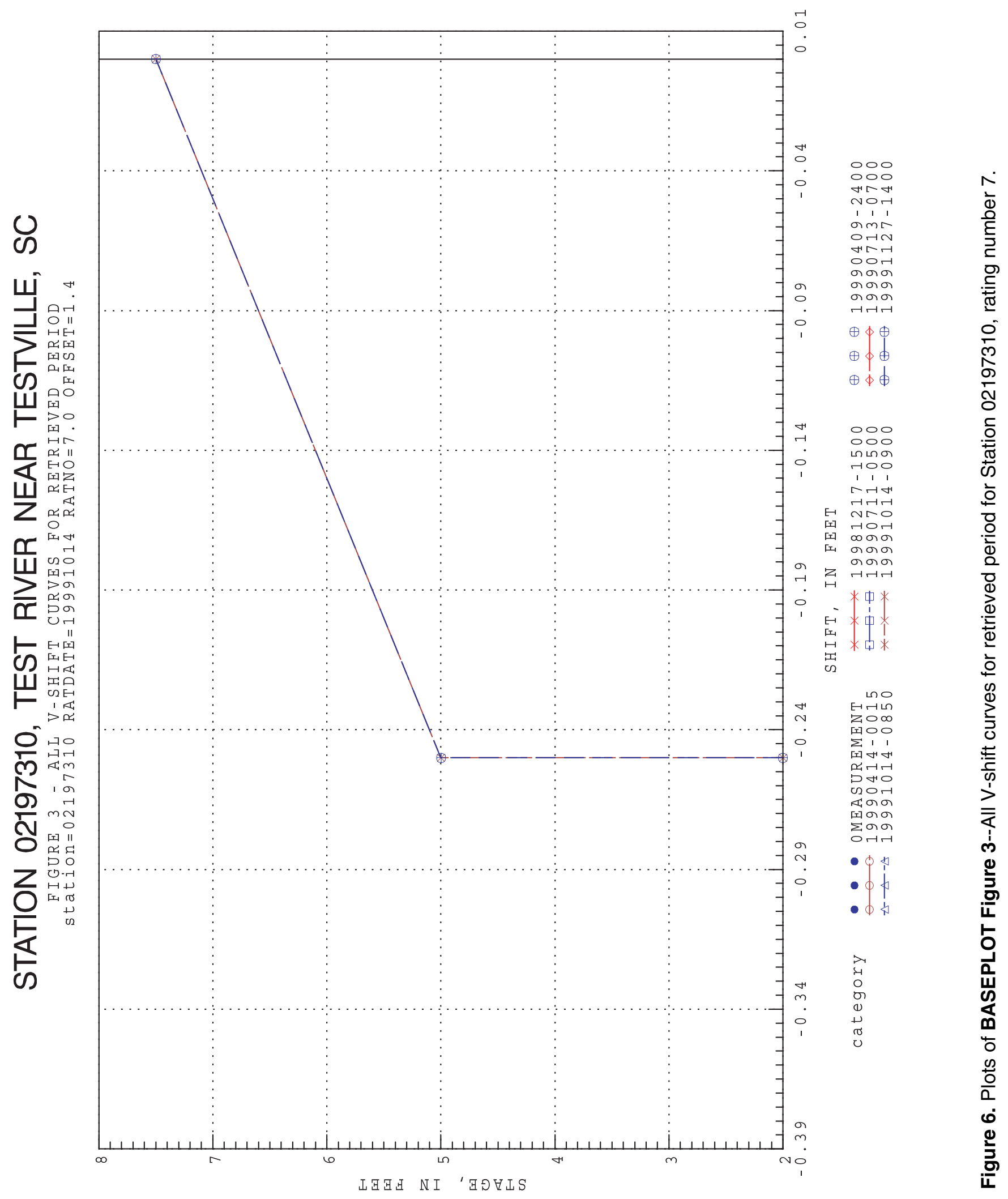




\section{1. "Do all the shift curves form a family of curves sharing a common apex point?"}

"If so, a family of ratings is reasonably assumed to exist about a base rating. If not, the reviewer is put on notice that the shapes must be determined to be reasonable while reviewing Figures 4 and 5."

A valid shifting strategy is to use a single gage height for the apex of the V-shifts and a single gage height for the central point of the V-shifts throughout the year. This assumes a family of ratings moving uniformly about a central base rating. Examine the plots to determine if this strategy was used. If it was not used, the reviewer must determine that the shapes are reasonable while reviewing BASEPLOT Figure 3 (figures 4 and 5).

The proper shape of the V-shift curve should be determined initially as described below (Kennedy, 1983). The following steps should be used:

Step 1. Draw an accurate base stage-discharge rating. For weir or rock-ledge controls, a limiting-flow base rating should be drawn to the right of the measurements, if possible, and not averaging the measurements reflecting trash caught on the control. For shifting channel controls, an average rating through all the latest measurements when the channel is not seriously degrading or aggrading should be drawn. This is usually done by hand, using measurements made in the most recent years of flow measurements.

Step 2. Sketch a rating through the shift measurements plotted on the stage-discharge rating. Shift measurements are those that would agree with the shift curve being developed within the accuracy of the measurements.

Step 3. Determine the shift differences, in feet, between the sketched rating and the base rating at several increments of gage height.

Step 4. Plot these differences on a stage-shift graph, where the measured (not rating) gage height is used as the $y$-axis.

Step 5. Approximate the resulting curved line by two straight-line segments, from which the three V-shift points can be determined. This defines a single V-shift curve.

Step 6. Repeat steps 2-5, using other combinations of measurement data, and determine if average apex and mid-point gage heights can be used for the various combinations of measurements. If so, this verifies the assumption of a family of shift curves about an average stage-discharge relation. Otherwise, the series of curves may demonstrate some other orderly and logical pattern of shift curves. For example, a pattern of shapes may be shown where the apexes of shift curves having larger shifts may be located on the gage-height axis at higher gage heights. Subsequently, the average apex and midpoint gage heights can be used for the apexes and midpoints of shift measurements when there are not enough measurements to re-define the shape of the shift curve.

Once an initial shape or family of shapes has been established, the above processes will have to be repeated only when the V-shift shape has changed. 
An alternative method for determining initial shapes might be to assume a V-shift curve shape and run the ADAPS primary computation program. The next steps would be to run BASEPLOT and look at the BASEPLOT Figure 4 plot to see if the stage-discharge shift ratings look reasonable and blend smoothly into the base stage-discharge rating.

At some stations, it may be that no two or three measurements ever line up enough to draw even one stage-discharge shift curve using the method suggested above. If so, it may be possible to determine a V-shift curve shape by the following procedure:

Step 1. Use equation 1 (Kennedy, 1984) for calculating the logarithmic offset to straighten out the stage-discharge SHIFT curve (not the master stage-discharge curve).

$$
\mathrm{e}=\left(\mathrm{g}_{1} \mathrm{~g}_{2}-\mathrm{g}_{3}^{2}\right) /\left(\mathrm{g}_{1}+\mathrm{g}_{2}-2 \mathrm{~g}_{3}\right)
$$

where e = logarithmic offset of the shift stage-discharge curve, in feet,

$\mathrm{g}_{1}=$ gage height, in feet, at an upper point on the rating curve,

$\mathrm{g}_{2}=$ gage height, in feet, at a lower point on the rating curve, and

$\mathrm{g}_{3}$ = gage height, in feet, at an intermediate point on the rating corresponding to $\mathrm{q}_{3}$, computed by equation 2 :

$$
\mathrm{q}_{3}=\left(\mathrm{q}_{1} \mathrm{q}_{2}\right)^{0.5}
$$

where $\mathrm{q}_{1}=$ discharge, in cubic feet per second, at a gage height of $\mathrm{g}_{1}$, and $\mathrm{q}_{2}=$ discharge, in cubic feet per second, at a gage height of $\mathrm{g}_{2}$.

Step 2. Assume that the V-shift curve is shaped such that the lower segment is a vertical straight line on the V-shift plot.

Step 3. Compute the desired shift, $\mathrm{S}$, using the measurement and the base stage-discharge rating.

Step 4. Determine the gage height, $\mathbf{g}_{1}$, and $\mathbf{q}_{1}$ from the rating at the point where the stagedischarge shift curve would intersect the basic stage-discharge rating curve, assuming a shift of zero.

Step 5. Let $\mathbf{q}_{2}$ be at the lowest discharge of the master stage-discharge rating.

Step 6. Let $\mathrm{g}_{2}$ be the computed shift, $\mathrm{S}$, plus the gage height of the lowest discharge of the master stage-discharge rating.

Step 7. Compute $\mathbf{q}_{\mathbf{3}}$ using equation 2.

Step 8. Let $\mathrm{g}_{3}$ be the computed shift, $\mathrm{S}$, added to the gage height determined by entering the base stage-discharge relation with $\mathbf{q}_{3}$. The initial assumption is that the shift, $\mathrm{S}$, will be to a gage height higher than $\mathrm{g}_{3}$, which may or may not be so, as determined below. 
Step 9. Compute e, the offset for the shift stage-discharge curve using equation 1.

Step 10. Plot the shift stage-discharge curve on $\log -\log$ paper as a straight line using $\mathbf{g}_{1}, \mathbf{q}_{1}, \mathbf{g}_{2}$, $q_{2}, g_{3}$, and $q_{3}$, and the exact offset, $e$.

Step 11. Plot the master stage-discharge curve as a curved line on the same graph. This curvature is already determined in the original development of the base stage-discharge rating curve.

Step 12. Shape the V-shift curve using steps 2-7 discussed in the preceding procedure where enough shift measurements are available to draw a shift stage-discharge shift curve.

Step 13. Check to see that $g_{3}$ is less than the gage height of the midpoint of the newly shaped V-shift curve. If not, another method for shaping the curve will have to be used.

Step 14. Re-plot both stage-discharge curves using the offset originally used for the base stage-discharge rating curve, to see if the shape looks reasonable. If not, another method for shaping the curve will have to be used.

Example Analysis: The answer is "yes."

2. "Are the gage heights for each discharge measurement always used to create the midpoint for each v-shift diagram?"

"If the gage heights of each discharge measurement are always used to create a new midpoint for each $v$-shift diagram, this may mean that the shift curve was not drawn by first sketching a stagedischarge rating through the measurements and then shaping the v-shift curve using the sketched rating or by first doing an error-bar shift plot analysis. The hydrographer may be erroneously assuming that the shape of the curve is instead determined by the date of the measurement. If so, this may mean that the entire shift analysis should be redone."

"WARNING: Use shift diagrams only for the highly variable low-flow end of the rating and for the temporary shifts of the less variable high-flow end of the rating. Do not use shift diagrams to define semi-permanent high-flow ratings. New high-flow ratings are more easily remembered and carried over from one year to the next than high-flow shift curves."

The hydrographer should not always draw a line from the apex of the shift curve directly to the stage and shift of each measurement, unless it is justified. This may mean that the shape of the shift curve is determined by the date and time of the measurement, and not by some change in the hydraulic characteristics of the stream. It may mean that a rating was not sketched through the measurements used for shifting on the stage-discharge curve for determining the proper shape for the shift curve, as described above. In addition, it may mean that the hydrographer did not attempt to get as many measurements as possible on each shift curve by means of the error-bar shift plot. In an error-bar shift plot, the shifts and the error limits of the shifts in units of feet are plotted against gage height. The plotted error limits allow the analyst to draw a shift curve through as many shifts as possible. 
To illustrate the problem with always using the measurement shift as the midpoint of the shift curve without justification, suppose a shift of $+0.10 \mathrm{ft}$ is measured on one day at a gage height of $3.00 \mathrm{ft}$. If the stream is measured the next day, at a gage height of $4.00 \mathrm{ft}$, a shift of $+0.10 \mathrm{ft}$ will likewise probably be measured. By the method being discouraged here, the midpoint of the shift curve would move up from $3.00 \mathrm{ft}$ to $4.00 \mathrm{ft}$, just because the stream was measured at another gage height on another day, and not because of the physical properties of the stream.

V-shift curves should be used only to depict temporary shifts and not to depict semi-permanent rating changes, particularly of the higher ends of the rating curves. The danger in using V-shift curves to represent semi-permanent ratings at the higher ends of the ratings is that the hydrographer will have to remember and carry forward the high-end V-shifts from prior years, and re-analyze the shift using the current and prior measurements. If no high-water measurements are made in the current water year, there may be a tendency to use the latest rating without the V-shift used in preceding years, whereas new high-end ratings are automatically carried forward from one year to the next.

Example Analysis: The answer is "no."

\section{BASEPLOT Figure 4 - Shifts Displayed on Stage Versus Flow Plot}

The base ratings and all the V-shifts as stage-discharge ratings are shown on BASEPLOT FIGURE 4 (figs. 7 and 8). If shift curves are not drawn using sketches of shift stage-discharge ratings as described in the previous section, the stage-discharge shift rating may not blend smoothly into the base stage-discharge rating.

1. "Does the family of shift curves smoothly blend into the master rating curve at reasonable points?"

"If not, the shift curves should be revised to smoothly blend them into the master curve."

Usually, the gage height of the apex of the V-shift curve is selected at a gage height on the rating where flows are breaking out of the main channel into the overbank area and where the curvature of the rating is greatest. It is assumed that the phenomenon that caused the low-water shift will be negligible during high overbank flows. Shift curves should not be drawn to abruptly intersect the master rating, but should be drawn to smoothly merge into them.

Example Analysis: The answer is "yes."

2. "Are the shapes of the shift curves reasonable in comparison with the shape of the master rating curve?"

The shift curve should not depart unreasonably from the base rating curve, and should not be parallel to the base rating curve when the logarithmic scale is used. In general, the shift curve should not cross the master rating curve or other shift curves.

Example Analysis: The answer is "yes." 


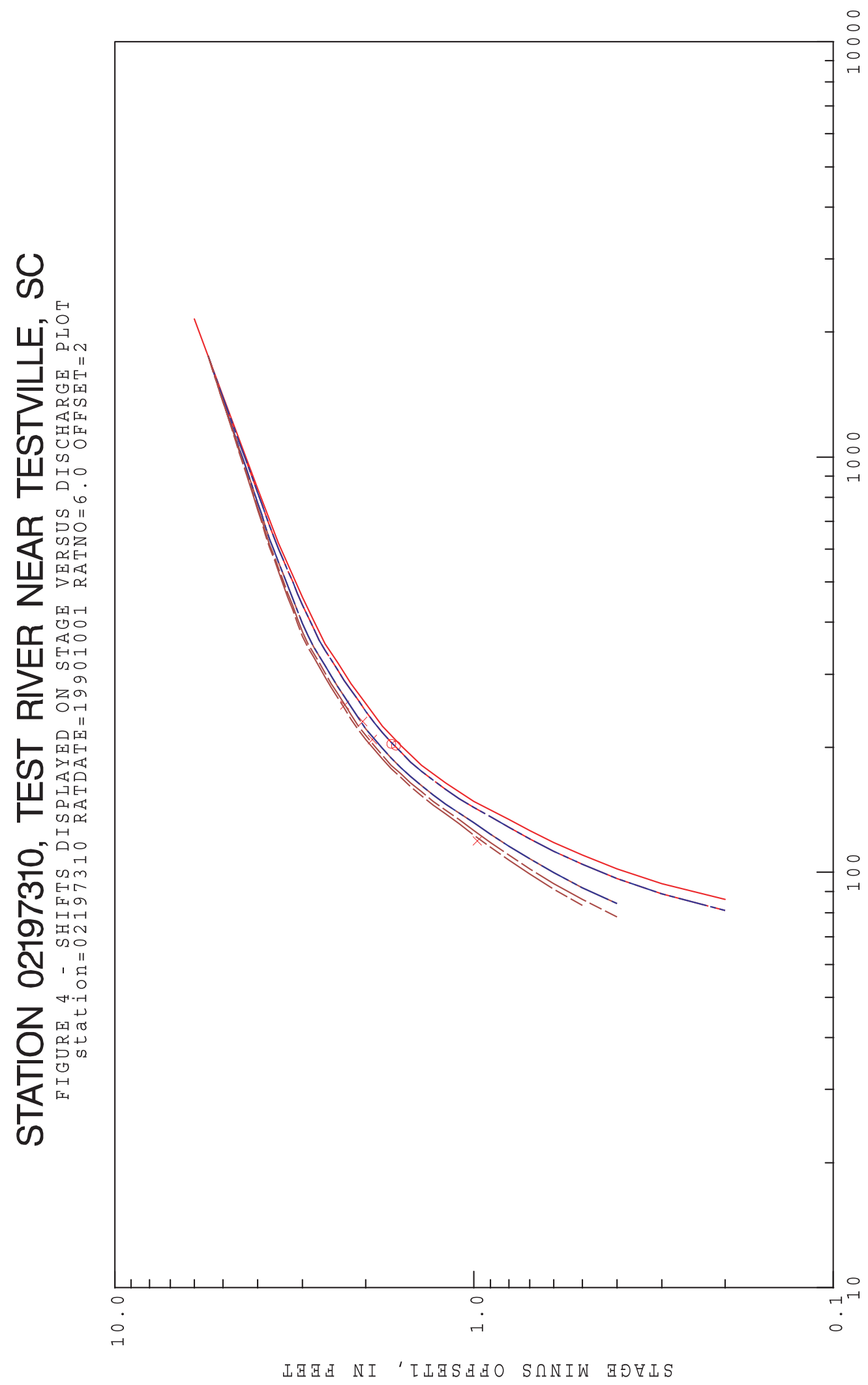

$$
\begin{aligned}
& \text { 잉 } \\
& \text { In } \\
& \begin{array}{rl}
1 & 1 \\
1 & 1 \\
-1 &
\end{array} \\
& \text { rm } \\
& \text { 담 } \\
& \text { 더응 } \\
& \text { कन } \\
& \text { कन } \\
& \text { तना } \\
& \mid
\end{aligned}
$$

$\stackrel{5}{p}$

잉

0 느
$+\infty$

ro

zon

HOH

텅ㅇ

भनन

नून

$\left|\begin{array}{l}1 \\ 1 \\ 1 \\ 1\end{array}\right|$

"I

Oxis

牙

剀

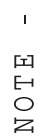



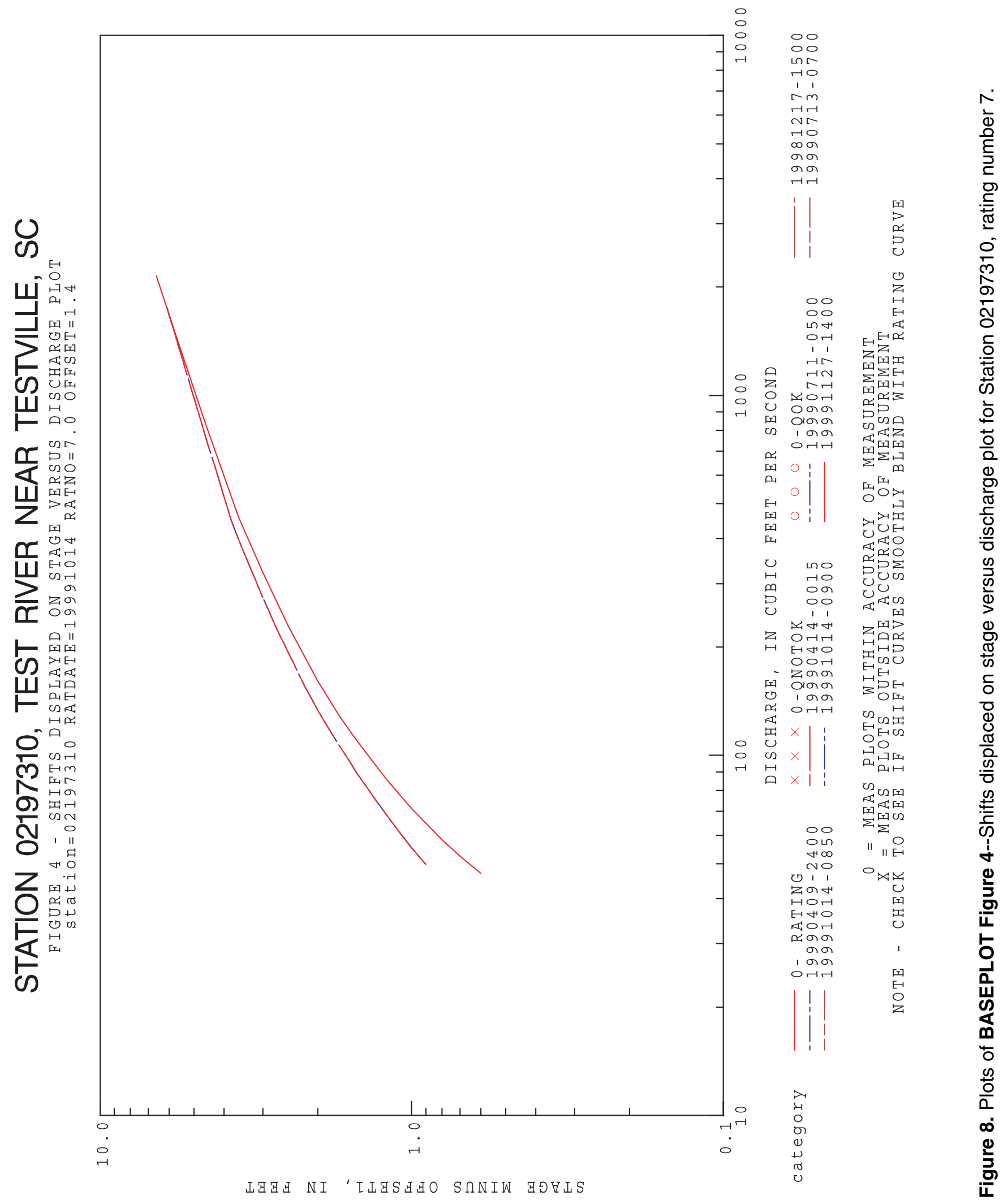


\section{BASEPLOT Figure 5 - Individual V-Shift Curves}

The V-shift curve, the optimum shift, and the shift entered in the ADAPS measurement file are shown on BASEPLOT Figure 5 (figs. 9-11), along with some of the numeric quality control checks. The numeric quality control checks A-D in BASEPLOT Figure 5 are repeated in BASEPLOT Figure 6 (figs. 12-24) and in BASEPLOT Table 2, so quality control checks A-D need to be reviewed only once. The most efficient method for the reviewer would be to review the numeric checks in BASEPLOT Table 2. However, these checks are printed on the BASEPLOT figures because it is useful to see the checks in relation to the V-shift diagrams in BASEPLOT Figure 5, and the timing of measurements, shifts, and unit-value gage heights in BASEPLOT Figure 6. In the checklist for BASEPLOT Table 2, the user is required to acknowledge that possible errors indicated by the numeric quality control error flags have been investigated either in the BASEPLOT figures or BASEPLOT Table 2.

1. "If all the shift curves do not form a family of curves sharing a common apex point, are the shapes physically reasonable, justified by discharge measurements, and the reasoning fully documented in the station analysis?"

If the shift curve crosses the zero-shift line, check to see if measurements on either side of a loop rating were connected. If so, the shift curve is not correct.

In general, the V-shift curve should not cross the zero-shift line, especially if the rating is drawn through measurements on either side of a loop rating (previously discussed). A V-shift curve might cross the zero-shift line if the mid-part of the base rating was drawn too close to measurements that were not representative of the average of the measurements in that range. In this case, a revised average rating should be drawn.

It may be possible for the shift curve to cross the zero-shift line, but the reviewer should ensure that a physical reason does exist, that measurements verify the V-shift curve, and that the reason is documented in the station analysis. An example of a case where the V-shift curve might reasonably cross the zero-shift line would be a stream in a large swamp with a very small main channel, and where backwater conditions might not be the same for the channel as for the swamp.

In general, the V-shift curve should not bend toward the zero shift line at lower gage heights or bend away from the zero shift line at higher gage heights on the assumption that obstructions causing shifts at lower gage heights would not affect flows at higher gage heights. The shapes described above might be warranted if the upper part of the stage-discharge rating is encompassed by the V-shift curve, where a backwater condition might exist when flows are greatly out of banks, but not when flows are within banks. In general, V-shifting should be done for flows within banks, where much variable shifting is usually necessary, and for temporary shifts to high-water ratings. The stage-discharge rating should be re-drawn if several consecutive measurements plot on either side of the high-water rating. A danger in using the $\mathrm{V}$-shift for a semipermanent high-water rating is that there may be a tendency to forget to shift the application during subsequent years when measurements are not available to reinforce that a shift or rating change has occurred.

Example Analysis: The answer is "NA," for "not applicable" because a family of shift curves was drawn sharing a common apex point. 


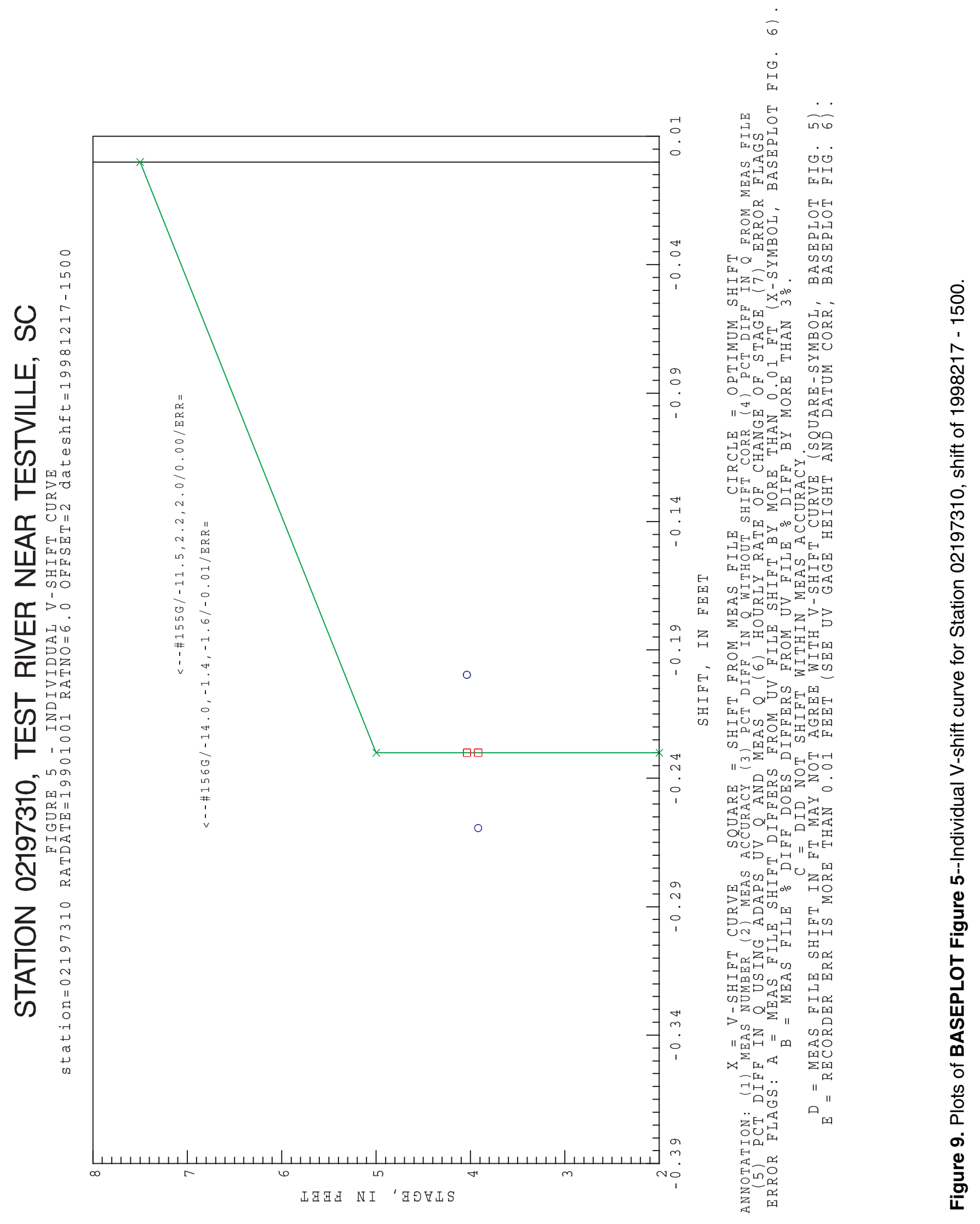




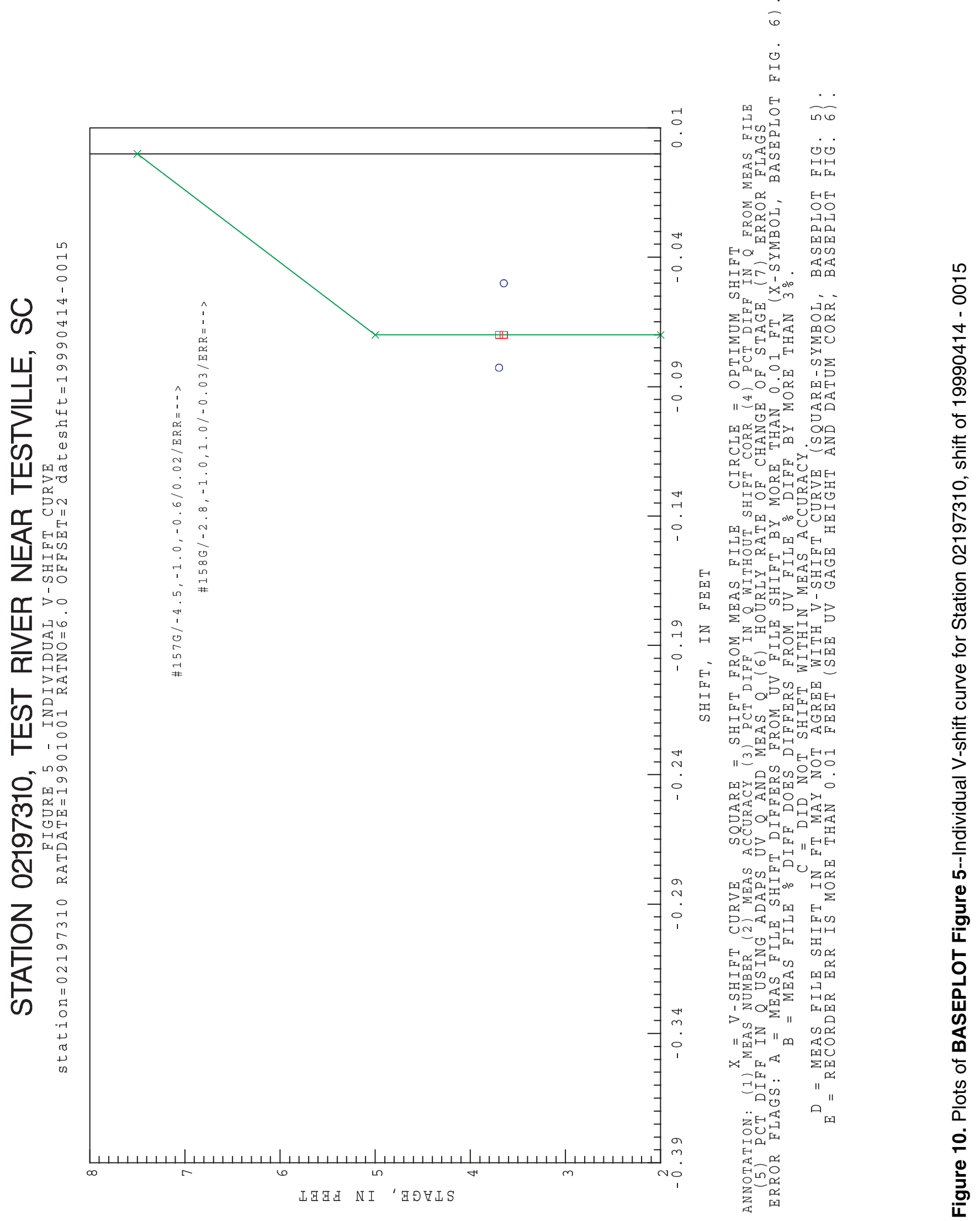




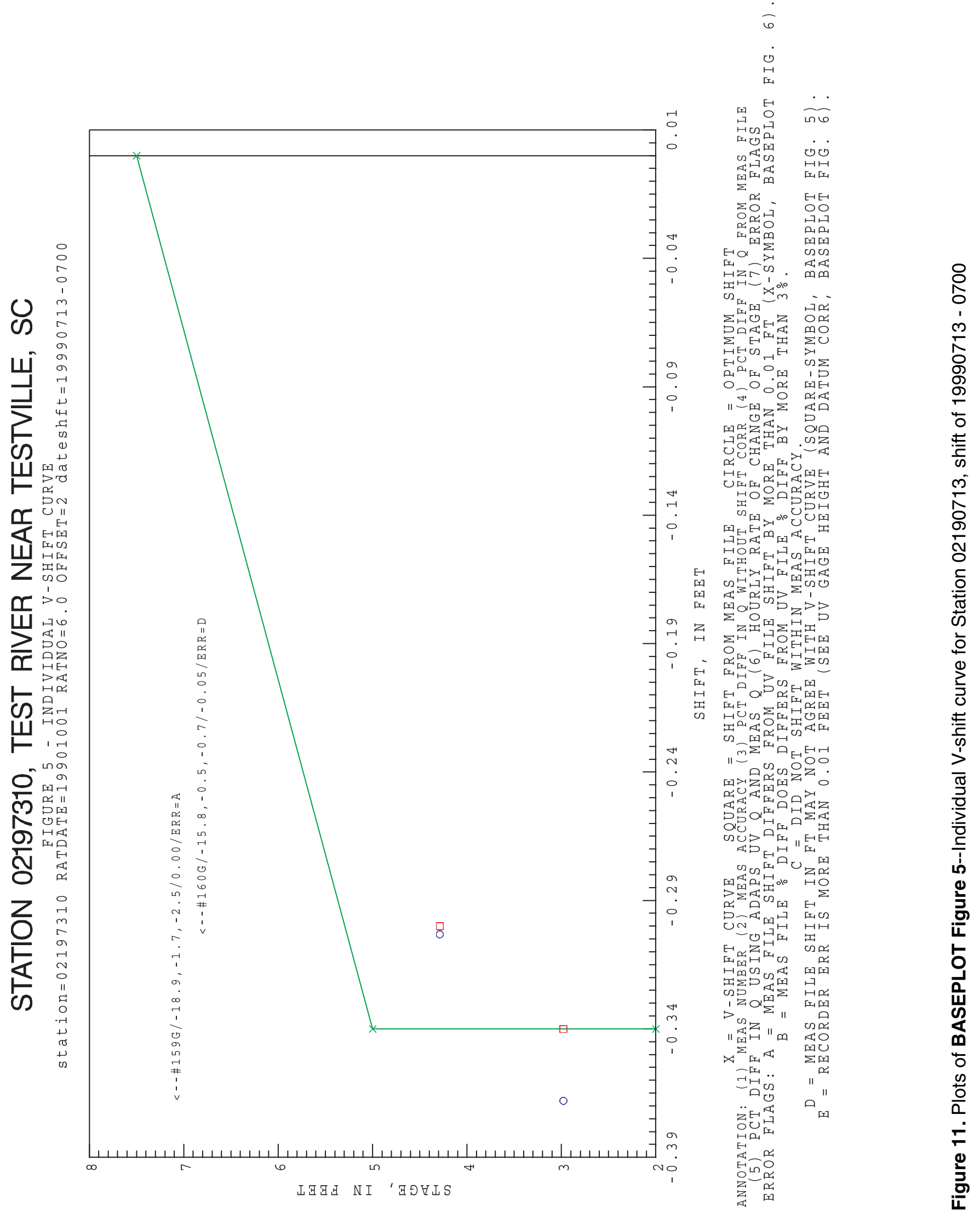




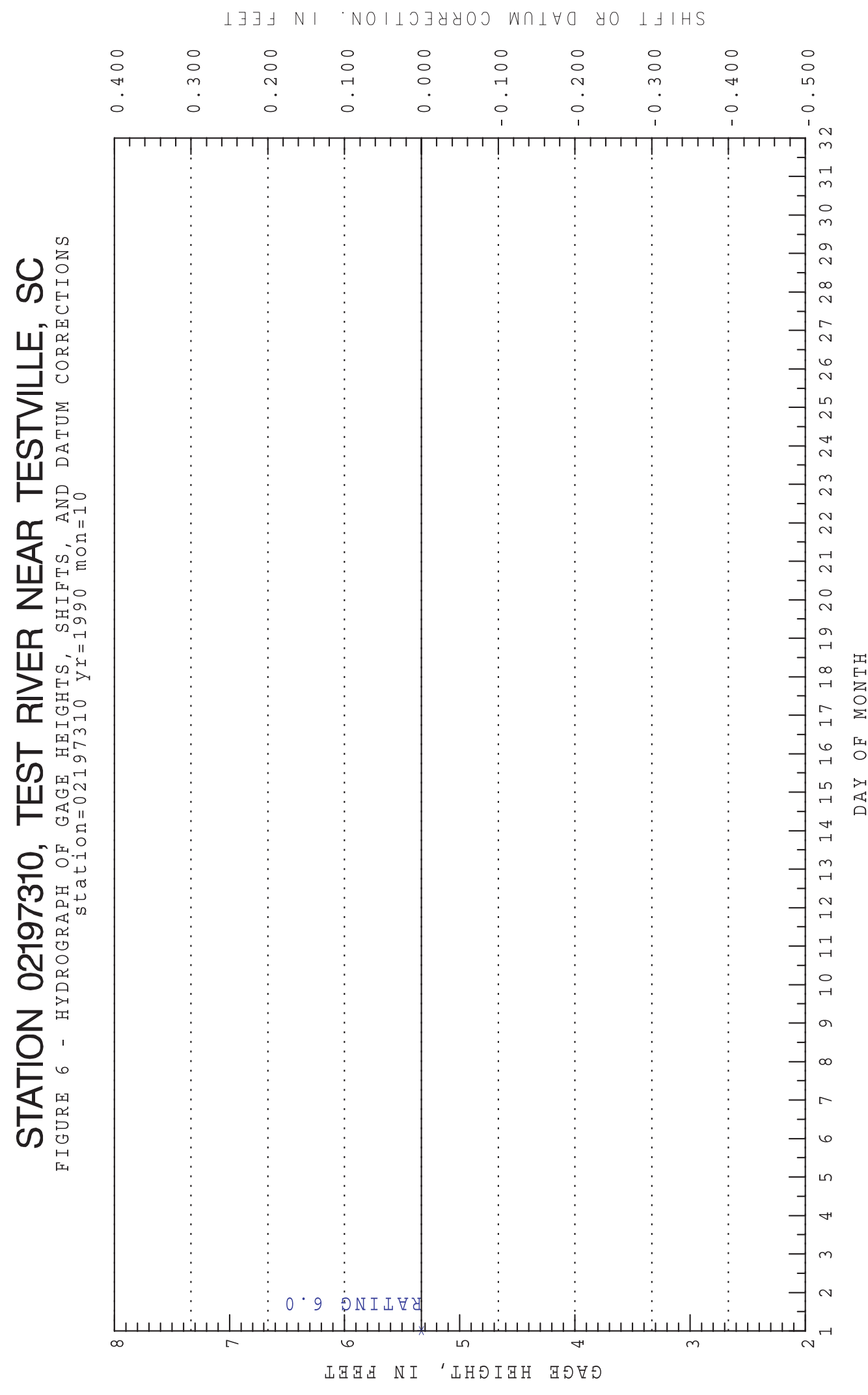

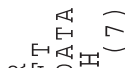

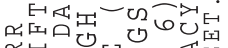

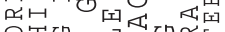

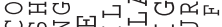

$\sum \sum 01514$

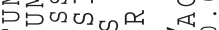

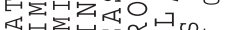

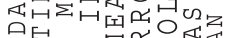

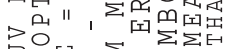

DO ${ }_{11} \sum_{i=1} \sum E$

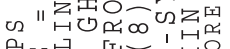

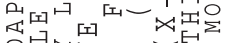

बण 엄

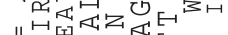

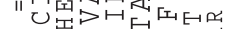

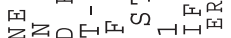

四四的

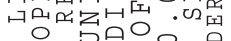

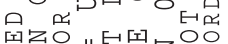

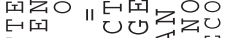

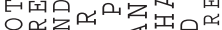

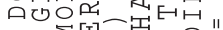

되 和 는

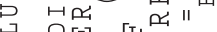

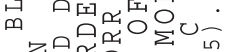

z되잉

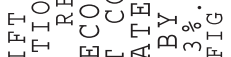

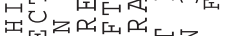

利员

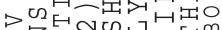

口兹

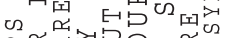

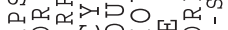

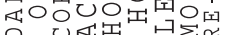

口证出昆品

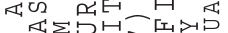

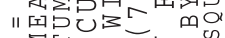

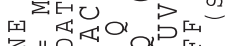

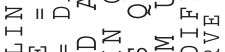

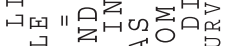

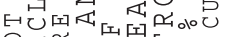

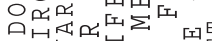

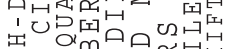

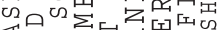

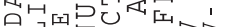

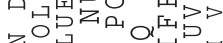

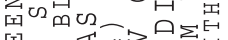

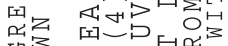

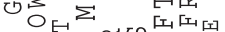

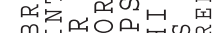

由

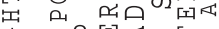

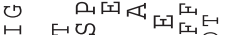

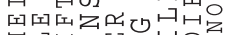

证

प्राप्य

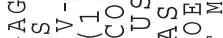

ण质利

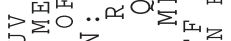

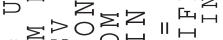

"

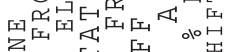

"

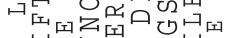

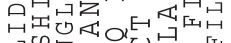

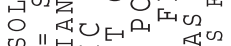

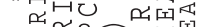

ख्या

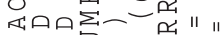

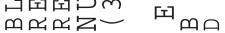

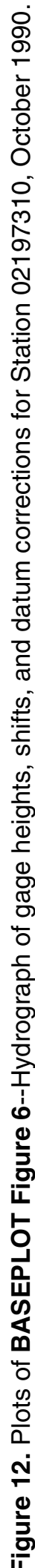




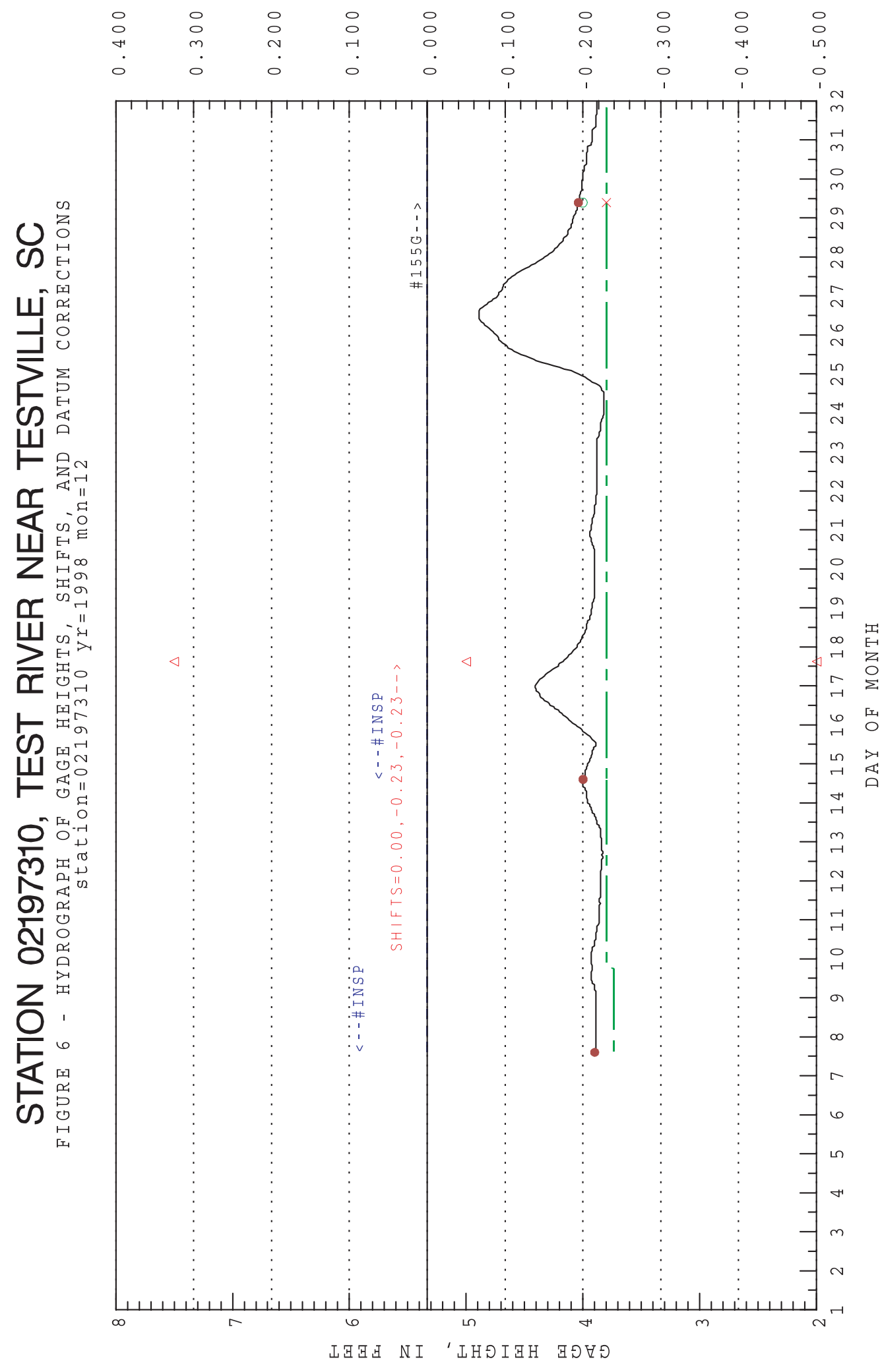

瓜

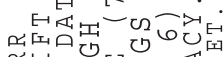

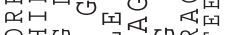

엄답

$\sum \sum 014$ पा山

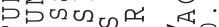

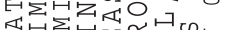

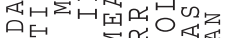

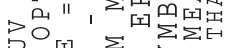

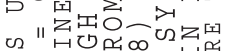

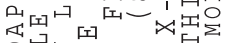

告》

स

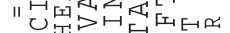

त्राय

四四的

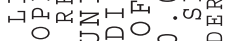

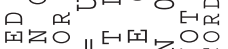

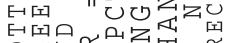

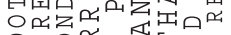

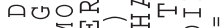

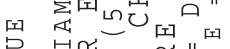

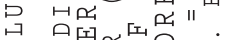

星

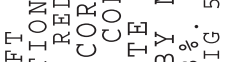

䨨

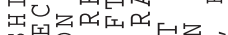

山四

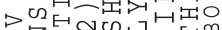

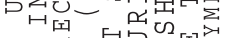

थ

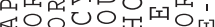

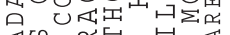

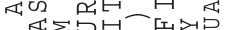

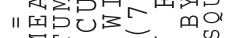

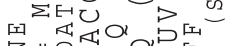

号 11 口古

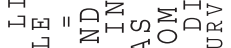

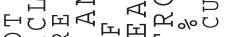

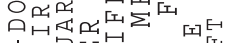

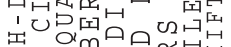

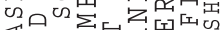

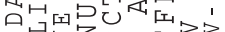

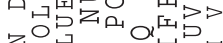

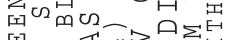

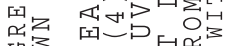

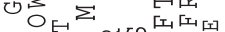

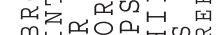

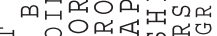

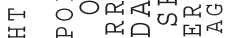

焉 口四四团

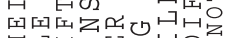

出・け・四け口

ज故出

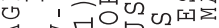

《Uत्र

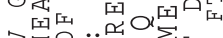

品治江 II

" 利罂

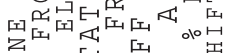

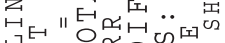

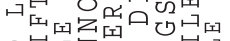

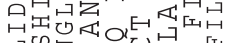

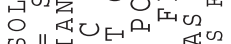

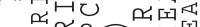

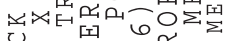

«ดค

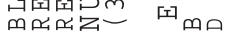

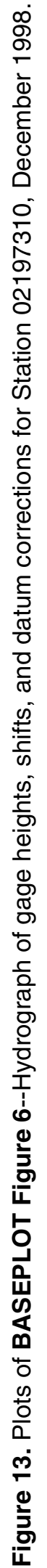




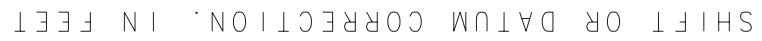

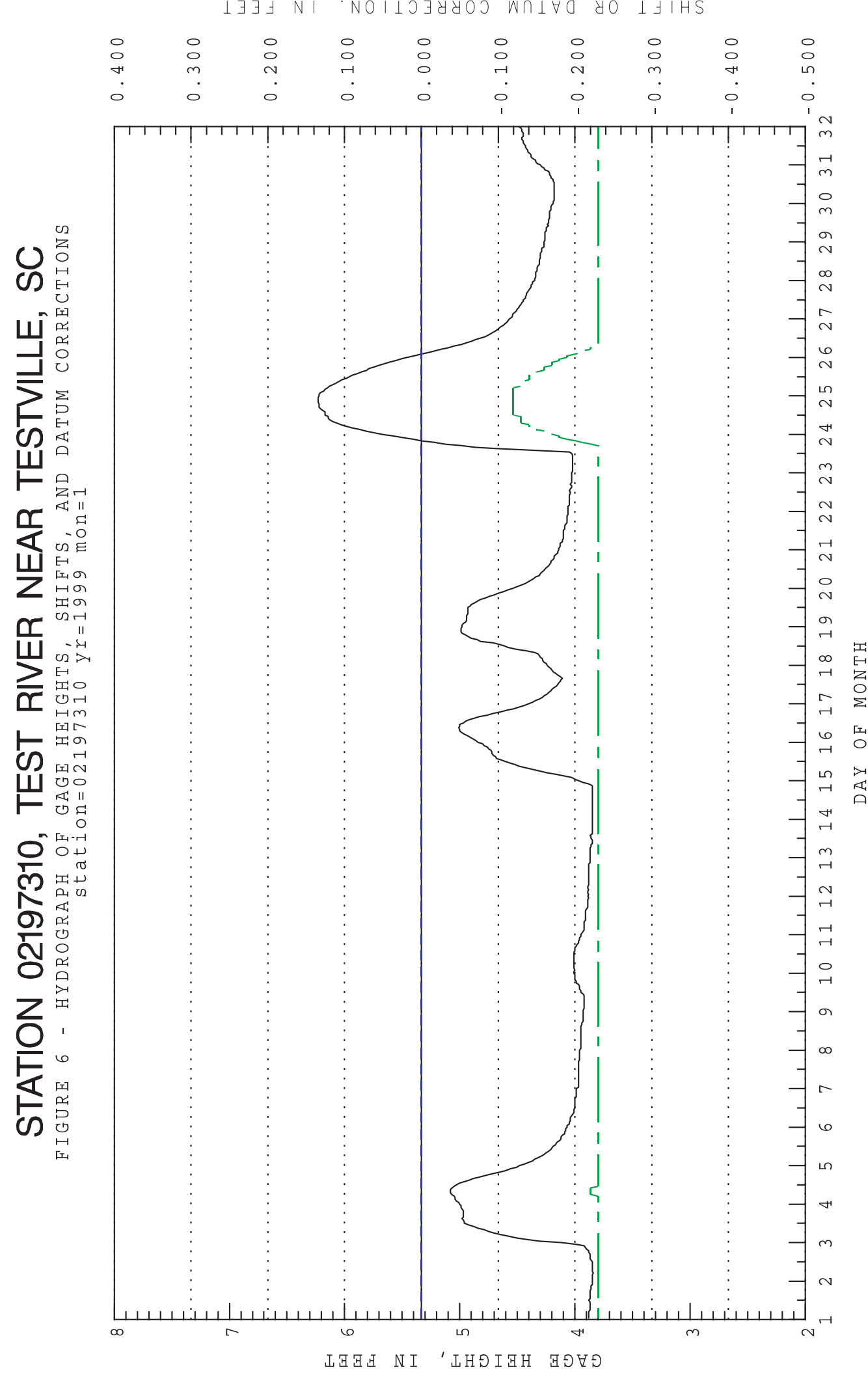

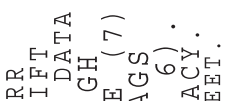

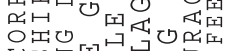

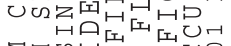

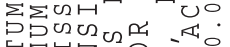

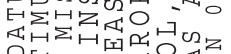

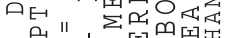

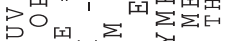

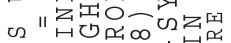

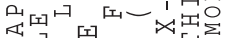

两

4

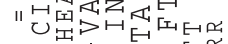

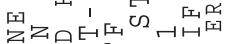

纴场出

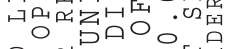

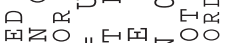

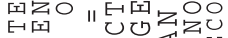

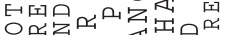

口ण叫质聙"

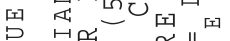

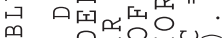

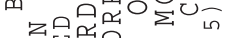

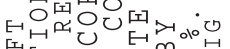

出

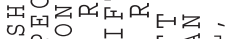

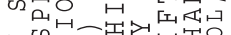

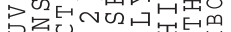

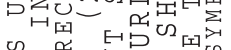

थक्य

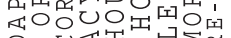

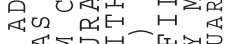

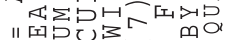

펄

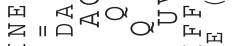

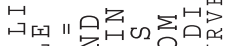

Е昌四质质

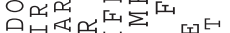

光四饮岳

要

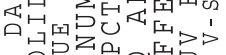

不品

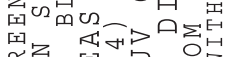

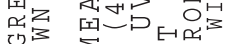

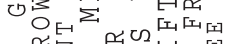

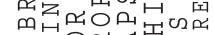

E

岁叫利㕕听

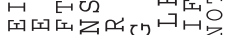

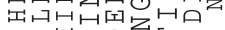

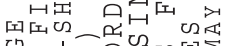

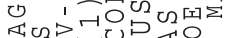

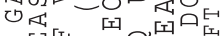

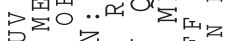

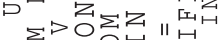

" $\sum_{0}$

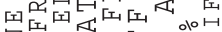

然 "

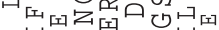

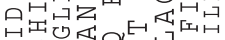

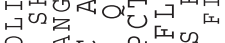

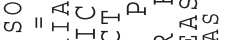

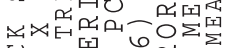

䟚

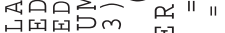

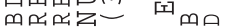




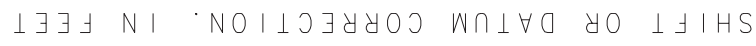

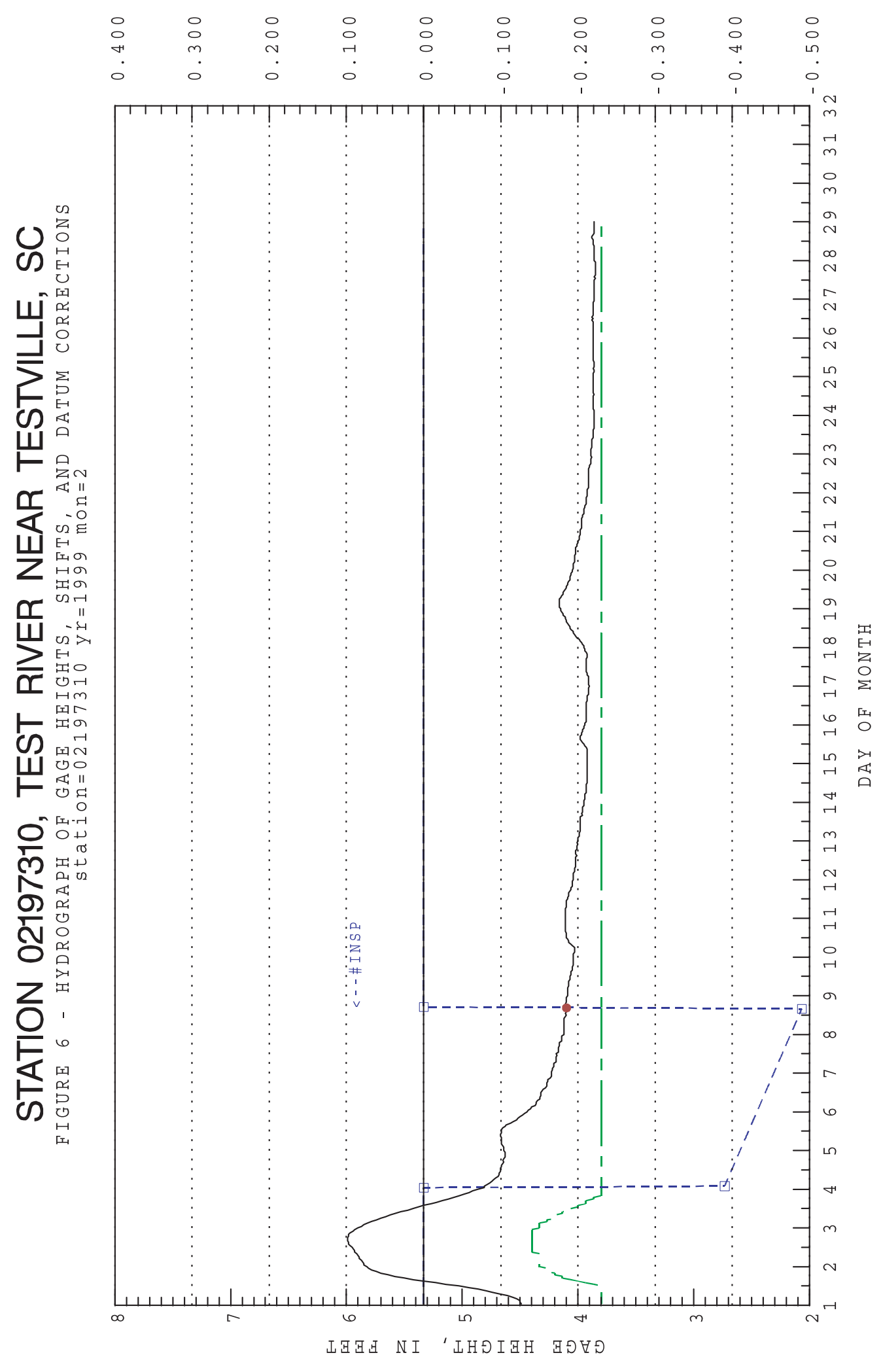

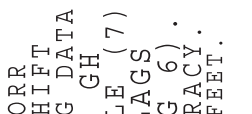

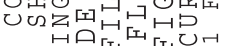

$\sum \sum \pi \sum^{2}$

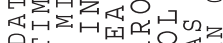

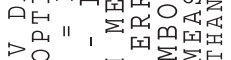

范

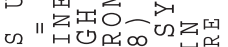

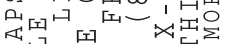

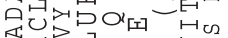

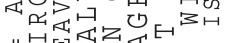

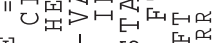

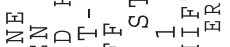

뵈되대

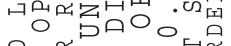

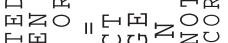

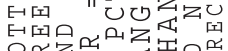

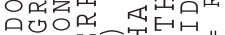

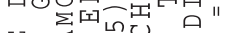

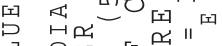

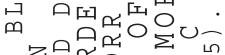

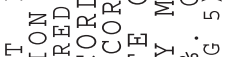

至

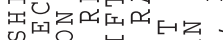

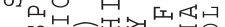

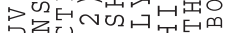

国

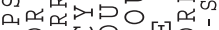

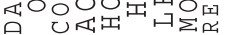

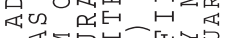

II 结已

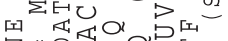

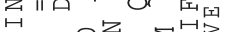

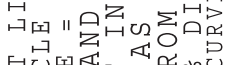

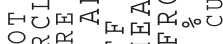

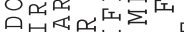

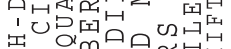

क $2 \sum^{\infty}$

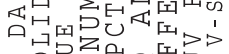

彻品

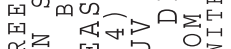

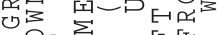

톨

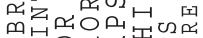

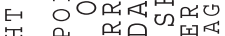

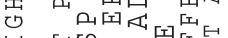

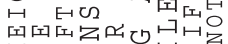

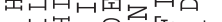

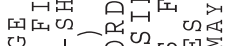

《纣式包口

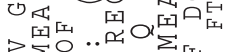

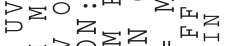

" $>0$ ○一由

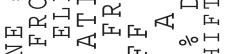

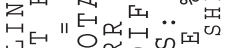

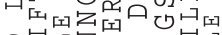

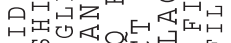

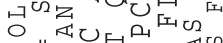

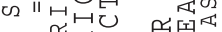

ख्य

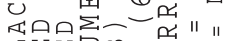

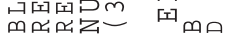

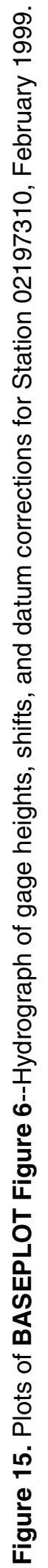




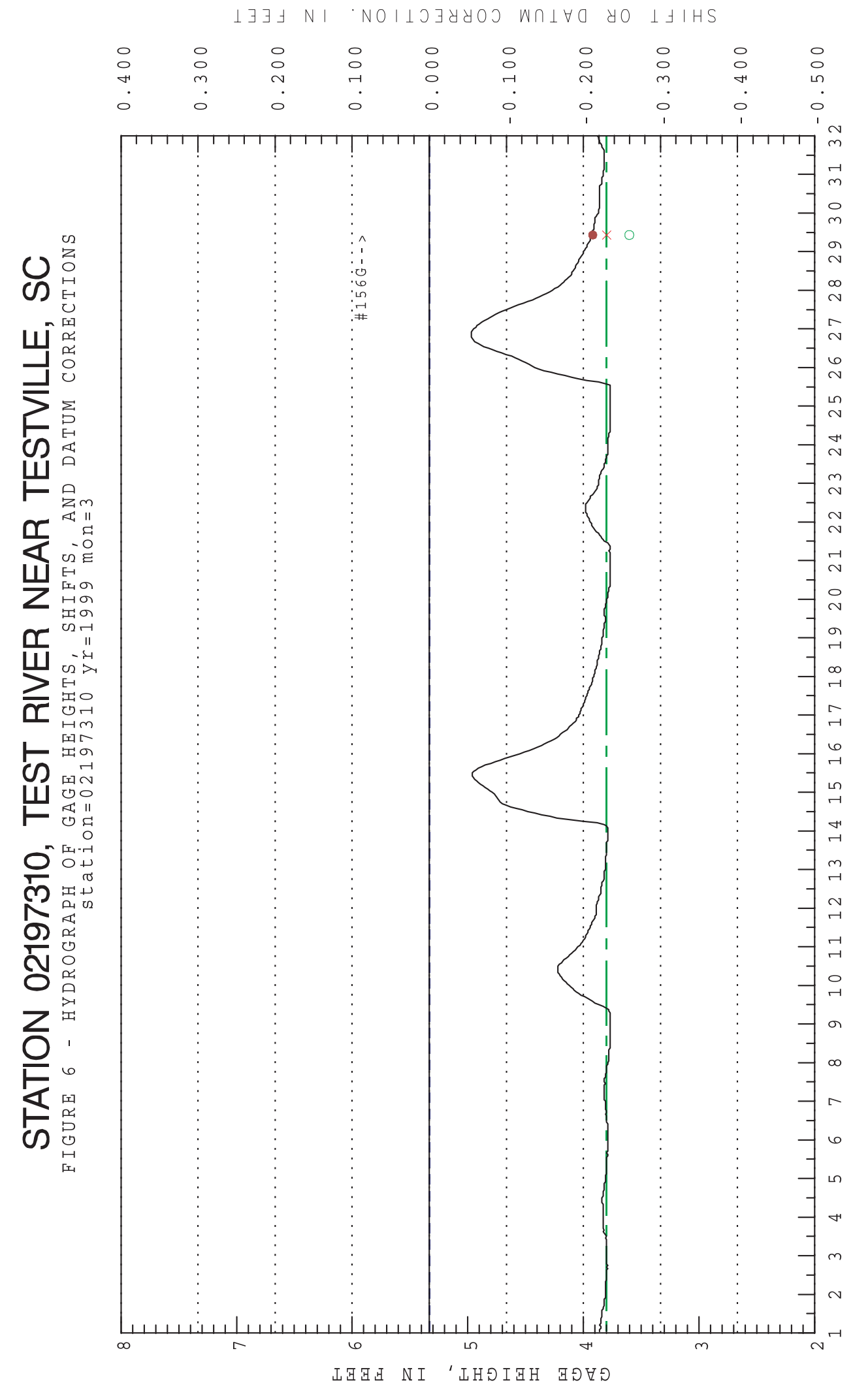

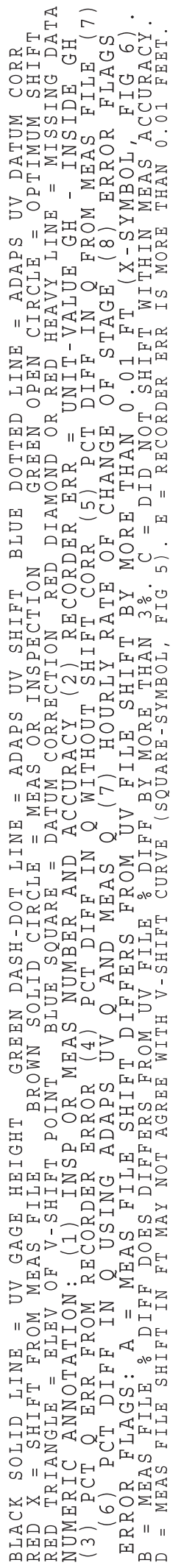

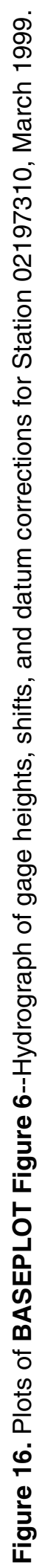




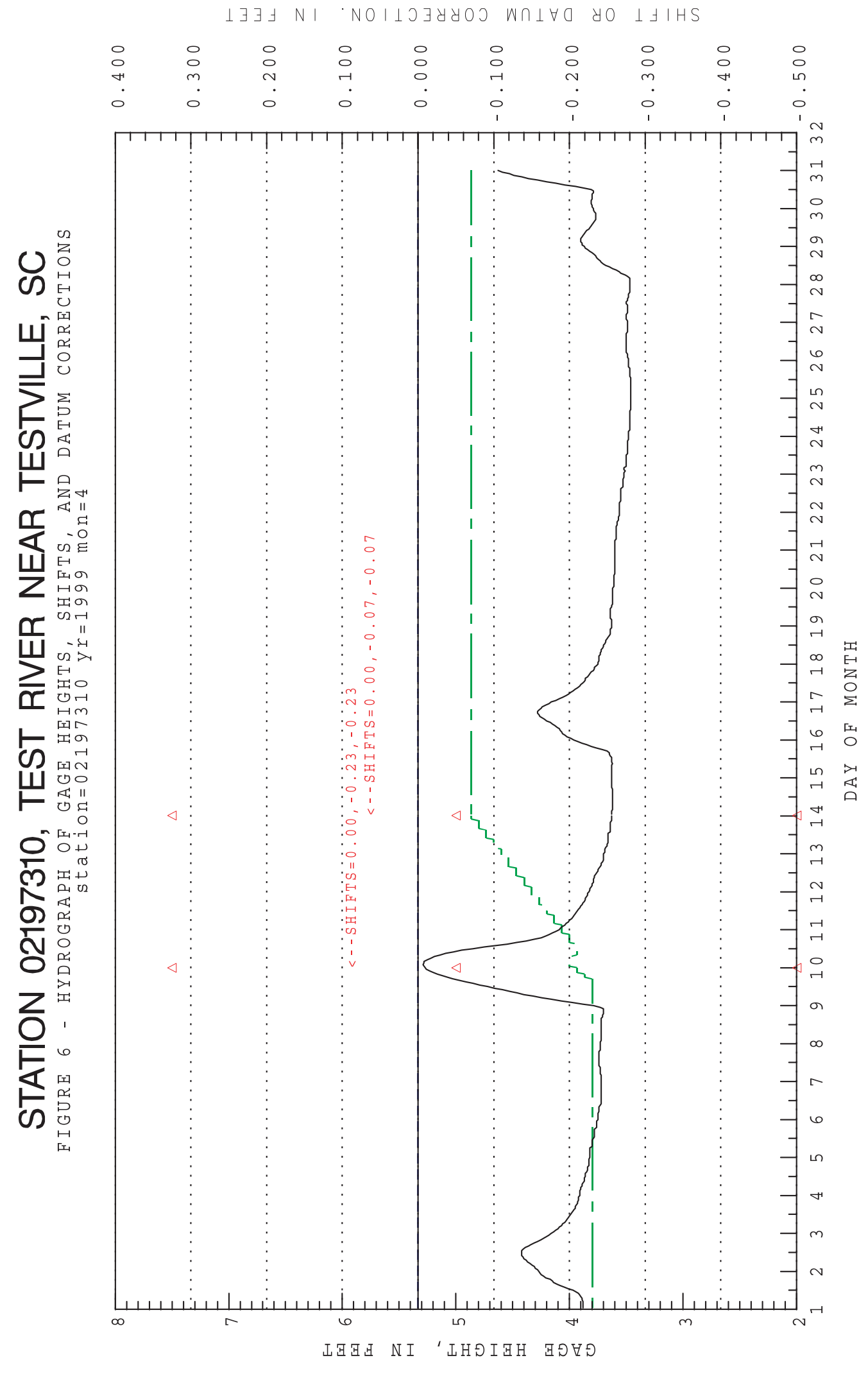

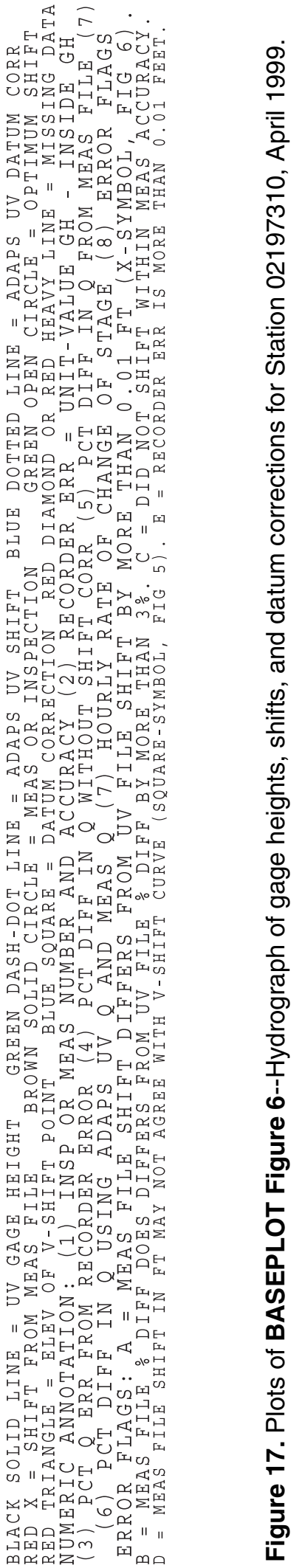




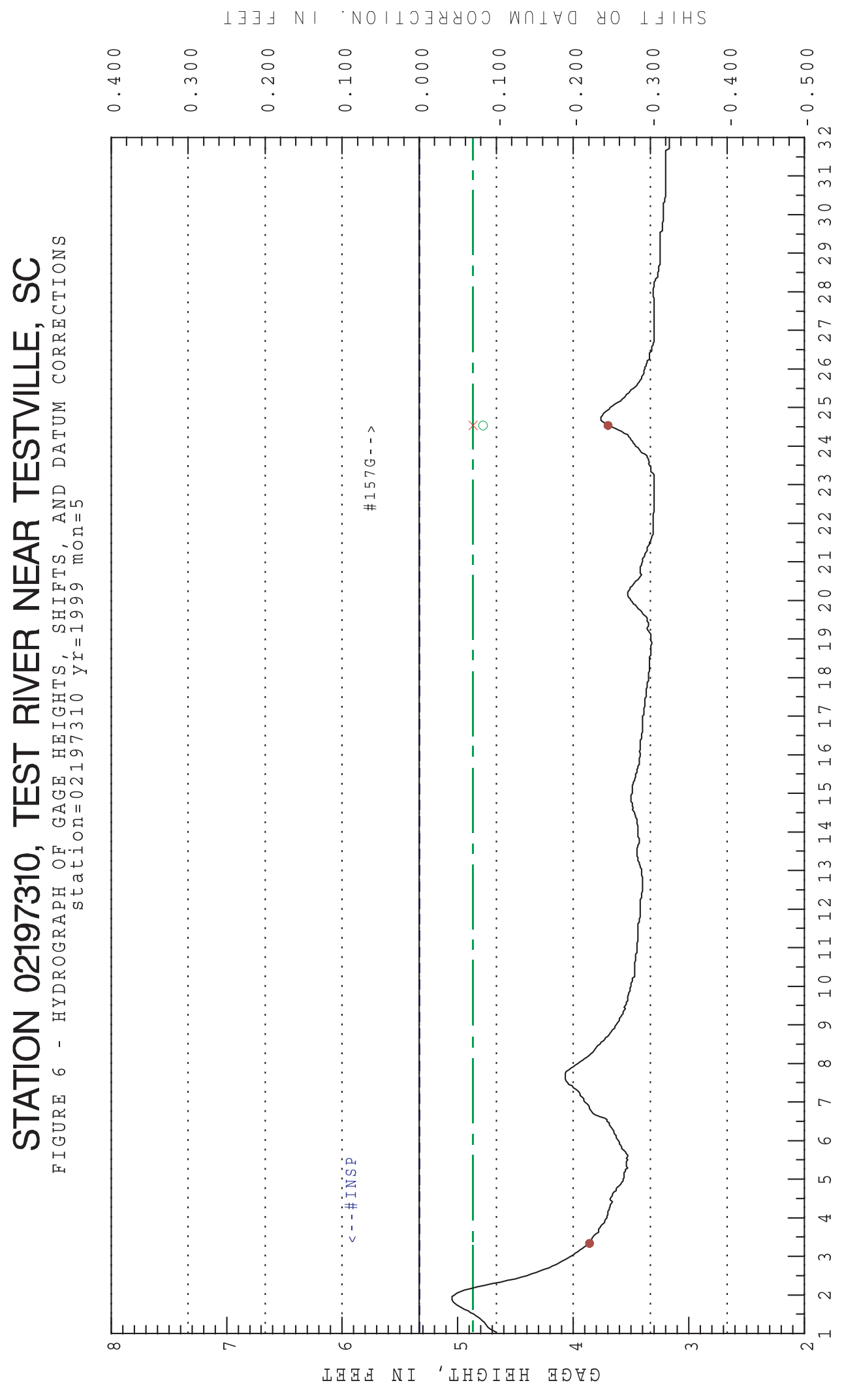

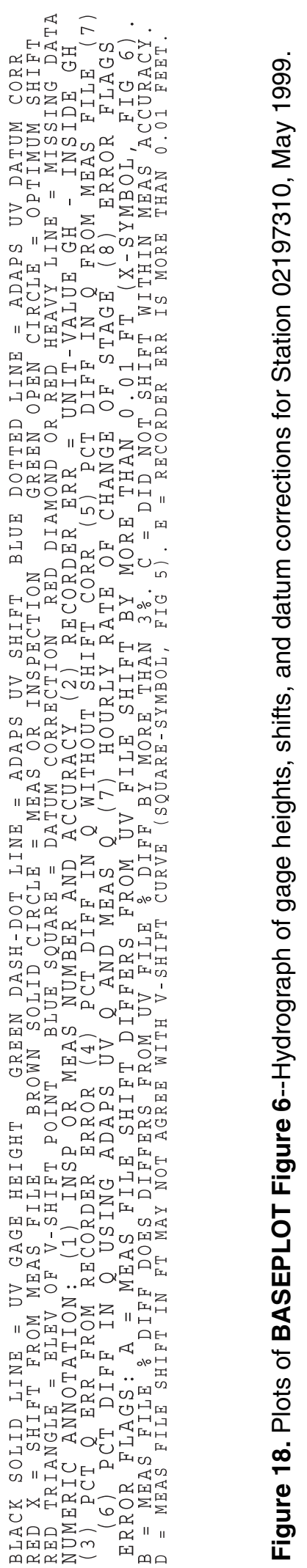




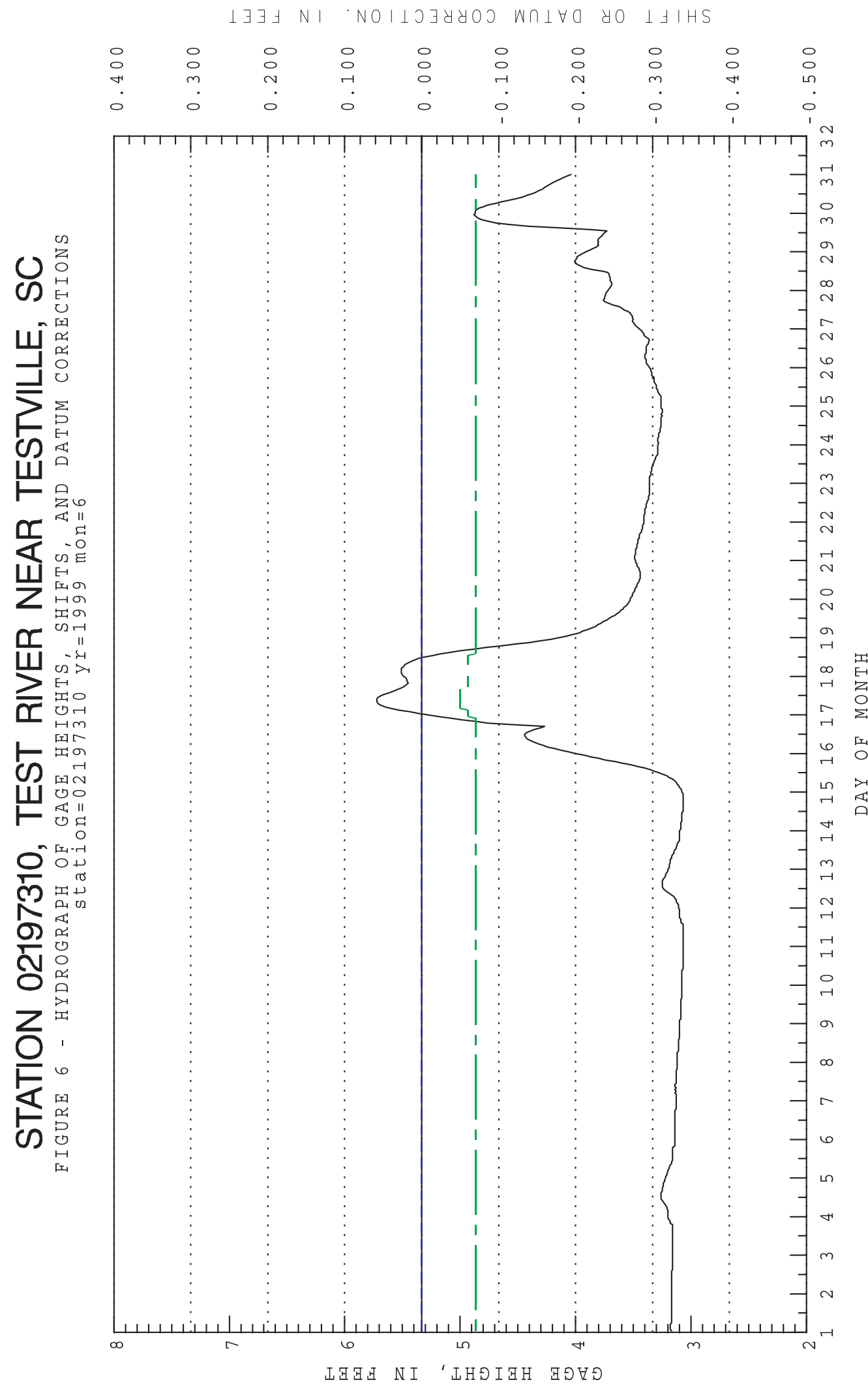

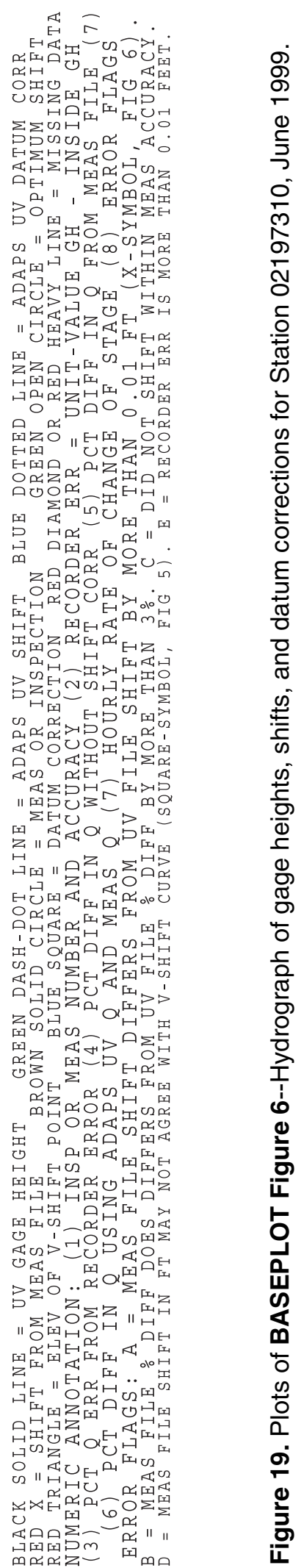




\section{$\perp \exists \exists \exists \mathrm{NI} \cdot \mathrm{NOI} \perp J \exists y+O J \quad W \cap \forall O \quad y O \perp \exists I H S$}

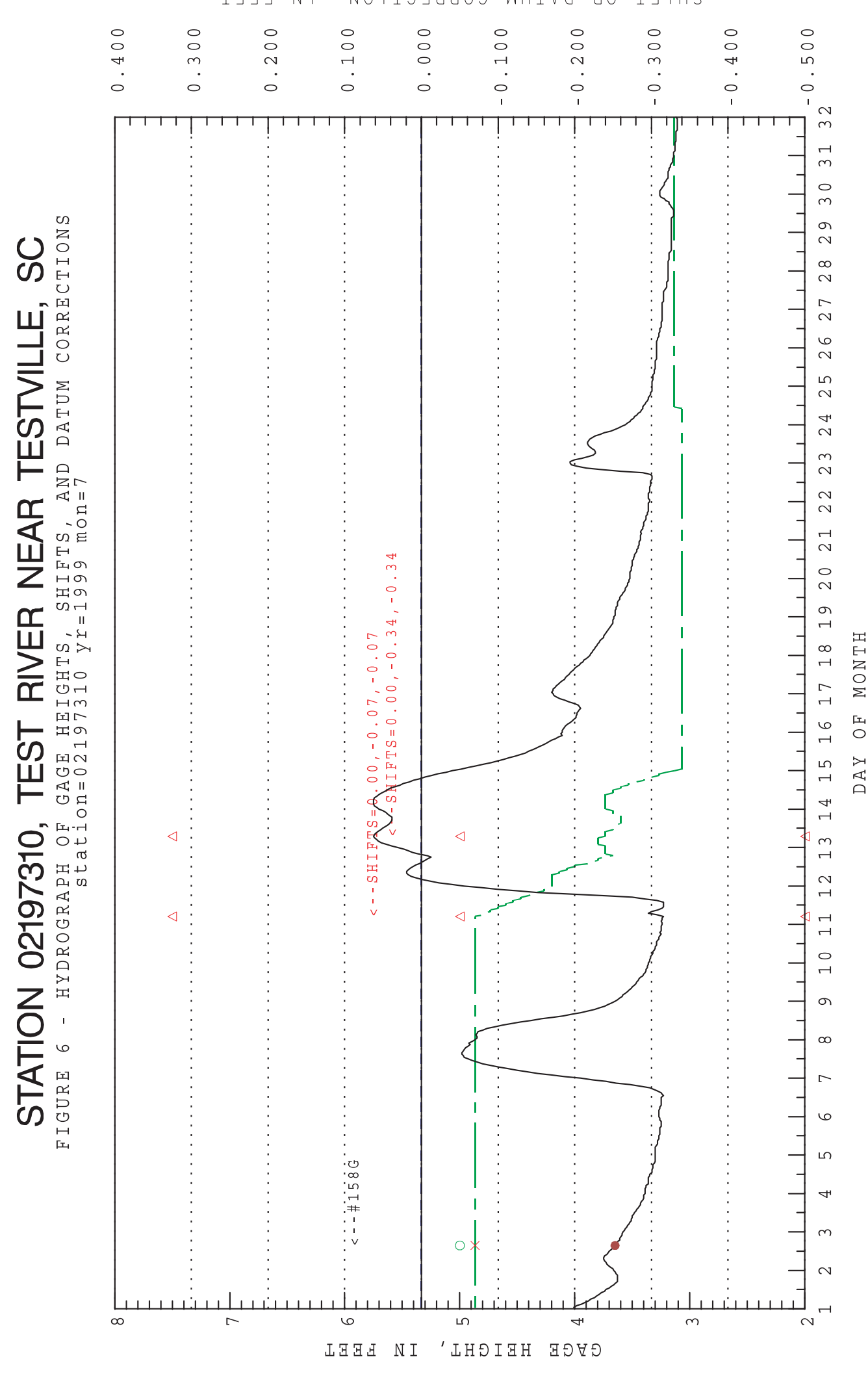

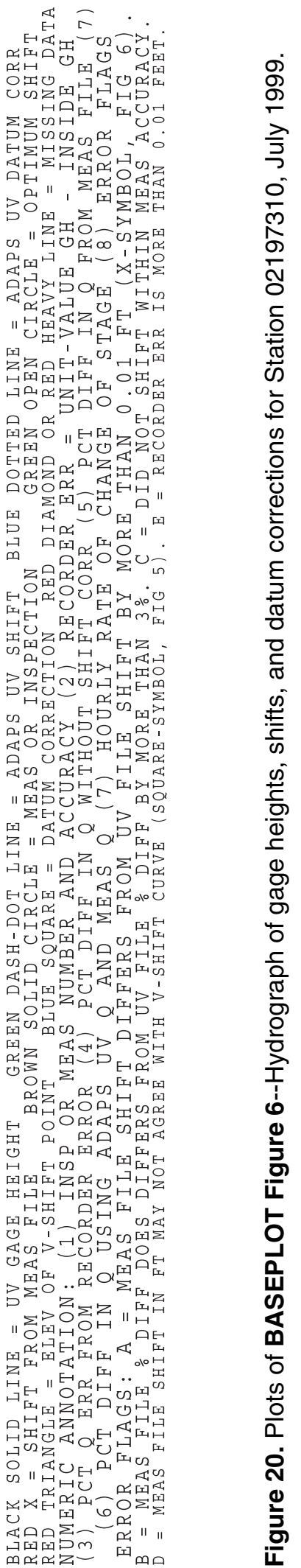




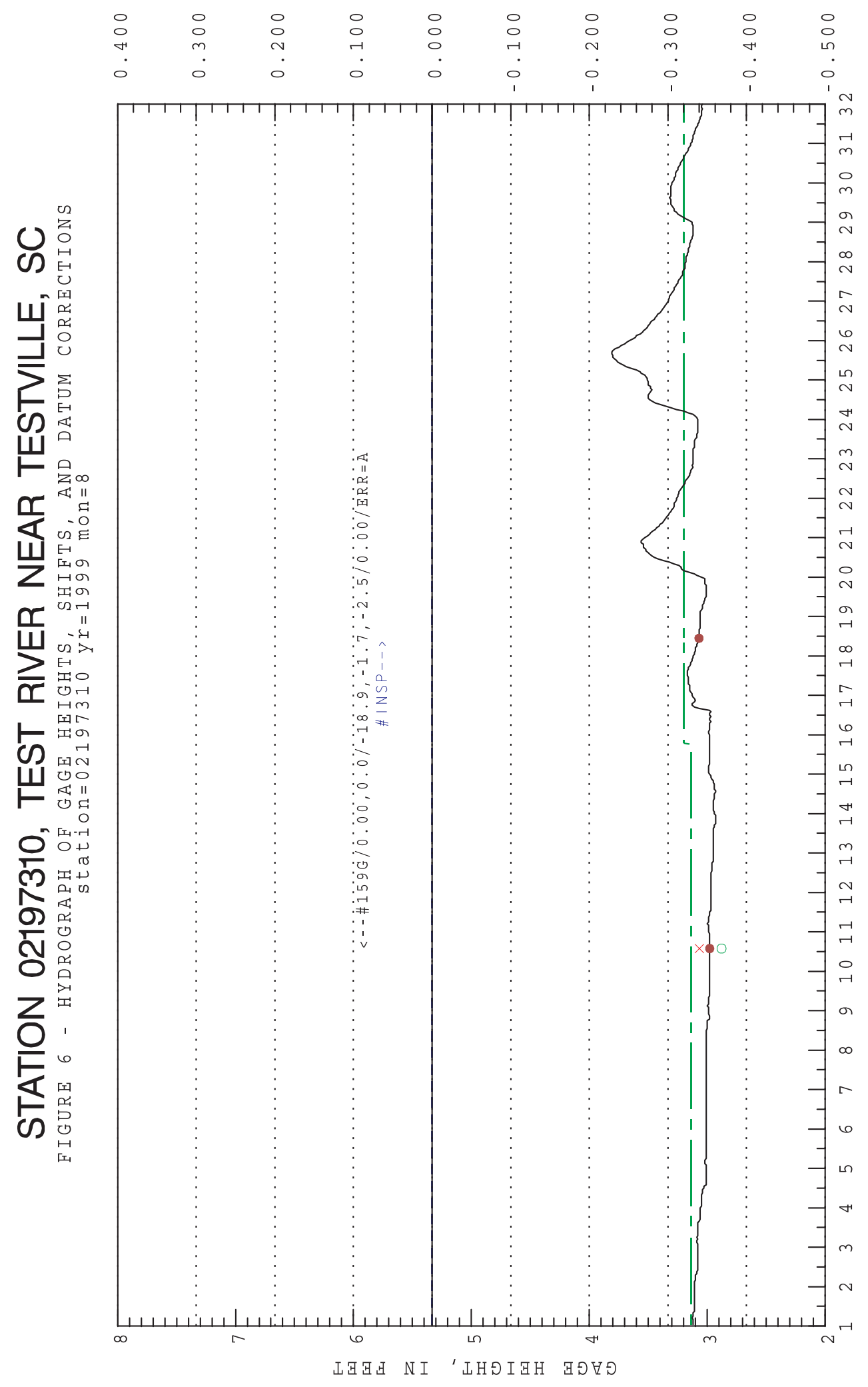

E

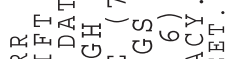

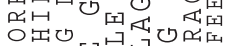

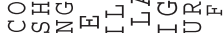

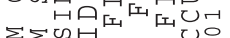

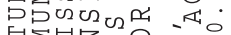

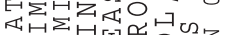

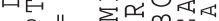

$>0,1, \sum \sum \sum_{1}^{n}$

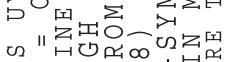

2 210000

出

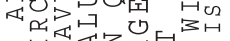

"

त्राय

四四的

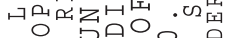

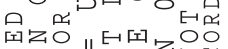

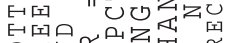

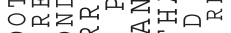

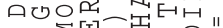

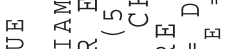

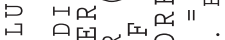

星

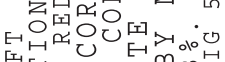

䨨

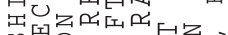

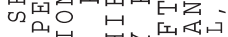

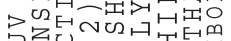

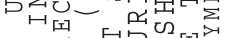

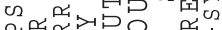

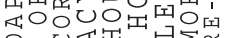

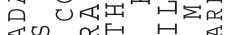

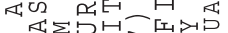

11 또의의

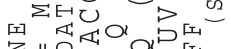

茁 110 只

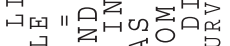

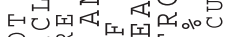

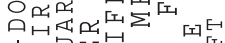

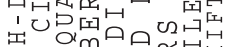

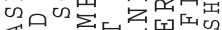

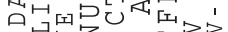

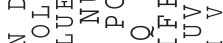

되

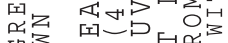

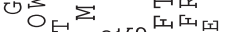

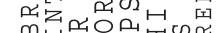

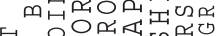

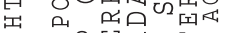

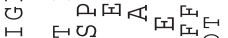

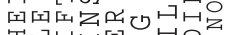

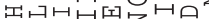

ज故出

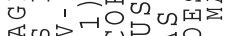

《Uत्र

प्ञ⿰氵工千

品治江 11 出

" 利罂

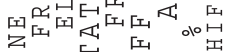

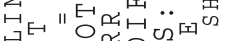

ज的出口饵的

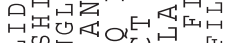

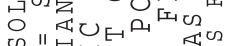

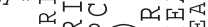

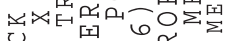

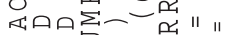

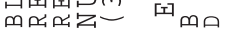

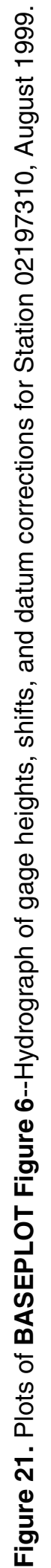


$\perp \exists \exists \exists N \mid \cdot N O I \perp J \exists y y O J N \perp \forall O \quad y O \perp \exists I H S$

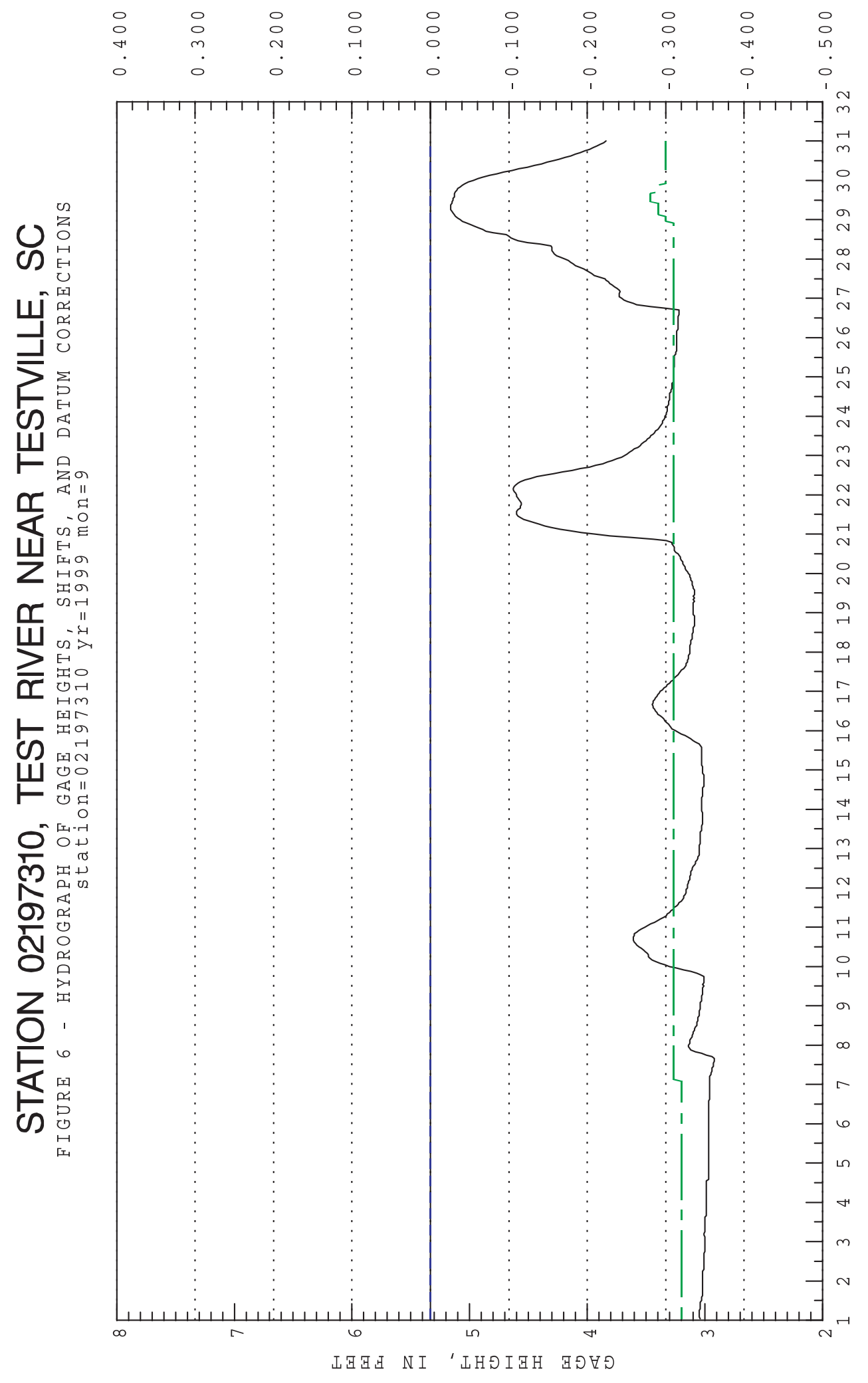

昏

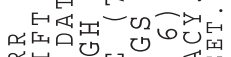

里

연멉

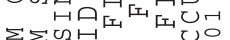

放哟州

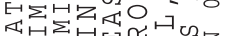

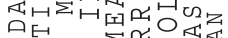

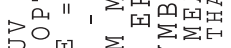

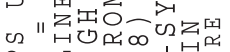

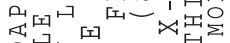

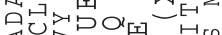

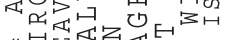

"U

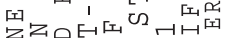

四四的

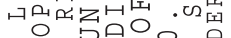

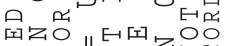

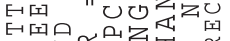

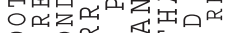

口णО人

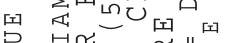

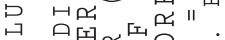

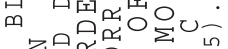

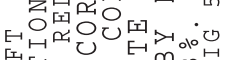

䨨

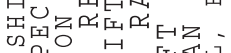

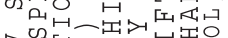

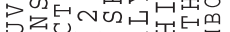

P

थ

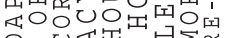

侹出是棌

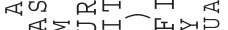

"I 되의

IEU

号 119 口

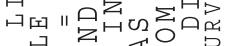

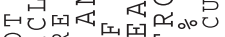

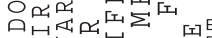

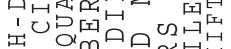

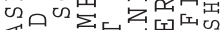

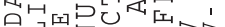

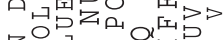

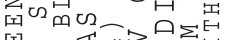

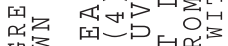

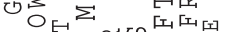

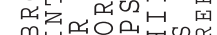

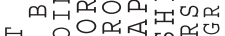

曷 品叫称

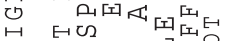

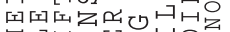

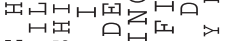

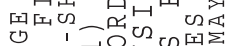

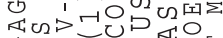

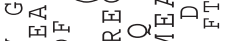

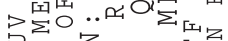

际没 11

" 利罂

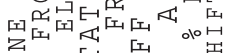

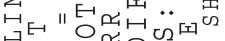

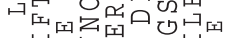

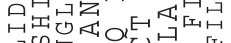

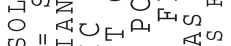

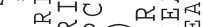

ख्या

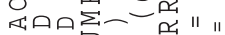

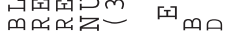

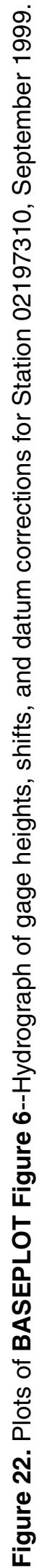




\section{$\perp \exists \exists \exists \mathrm{NI} \cdot \mathrm{NOI} \perp J \exists y y O J \mathrm{WO} \perp \forall O$ yO $\perp$ IHS}

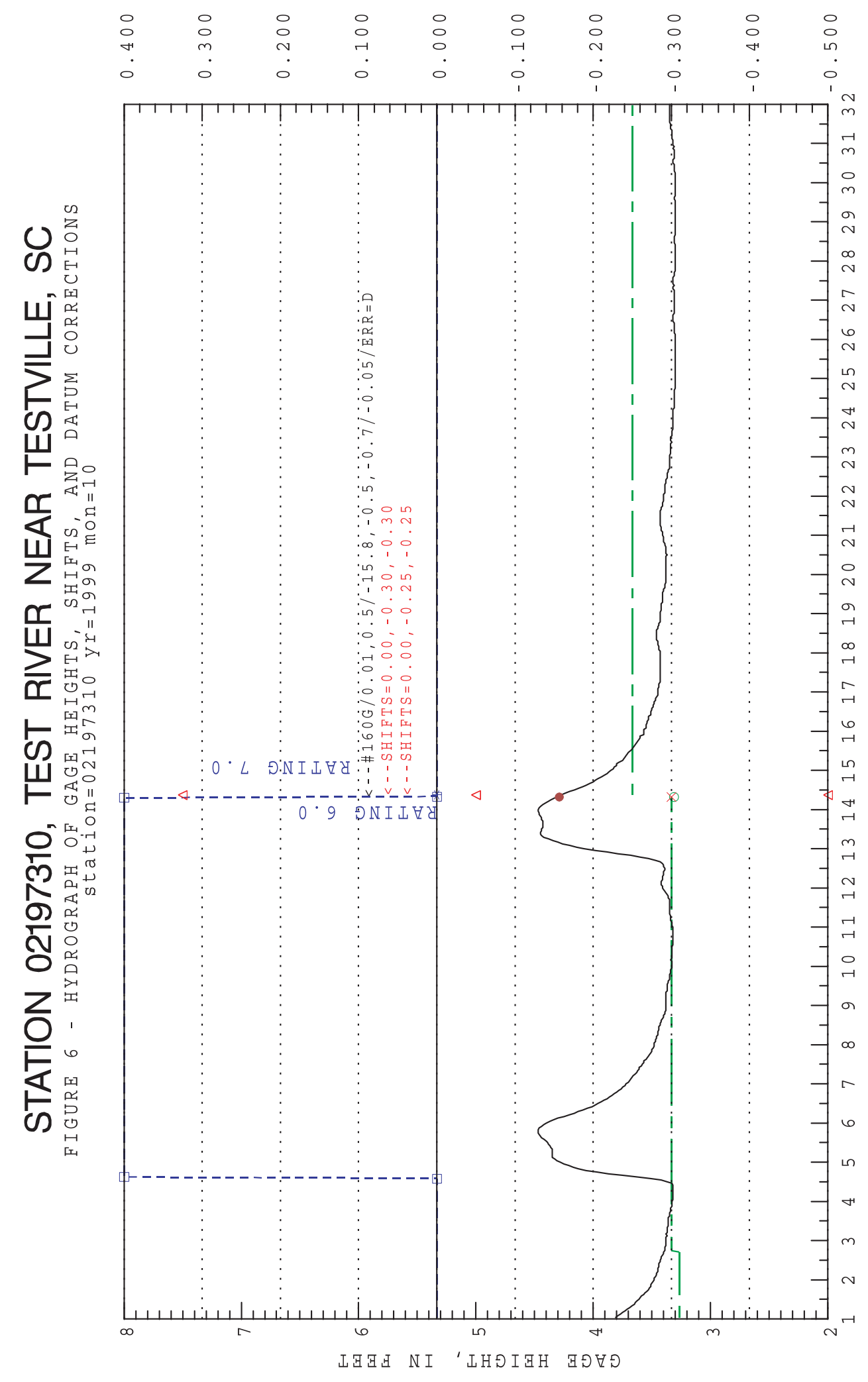

瓜

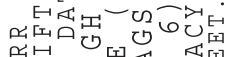

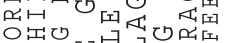

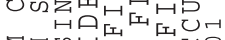

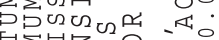

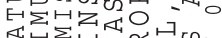

ब日, $\Sigma_{\mapsto}$

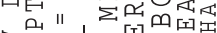

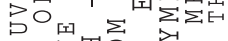

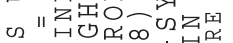

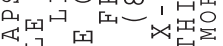

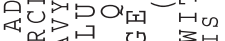

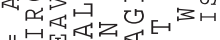

"

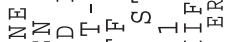

和四场

잉잉

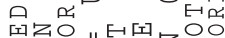

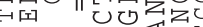

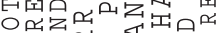

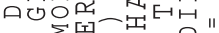

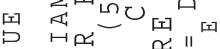

吅和品品。

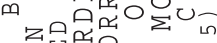

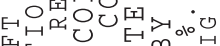

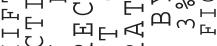

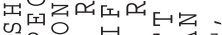

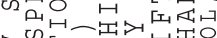

次NU・日

计

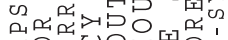

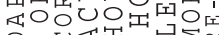

दू

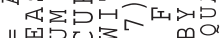

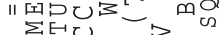

咥 II

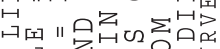

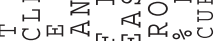

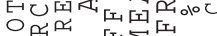

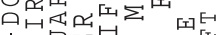

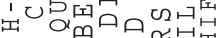

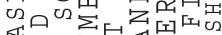

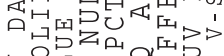

展品

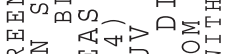

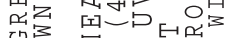

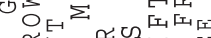

विक

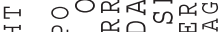

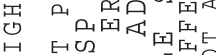

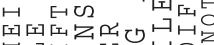

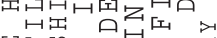

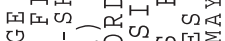

《थ口

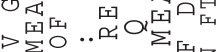

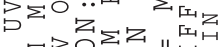

"

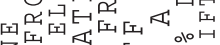

"

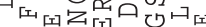

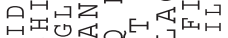

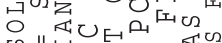

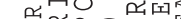

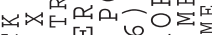

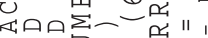

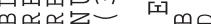

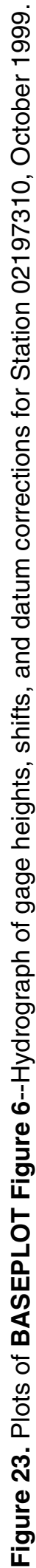




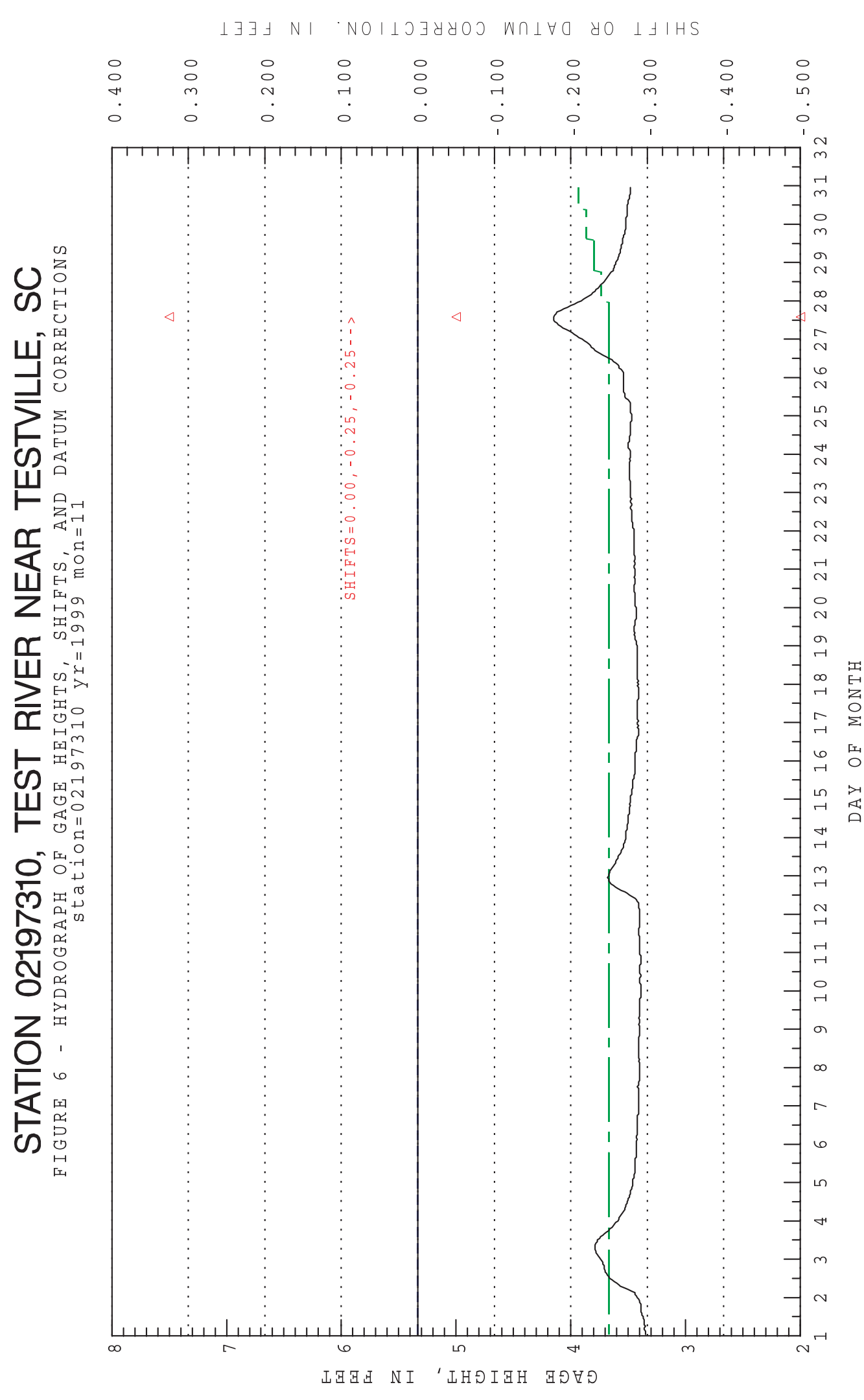

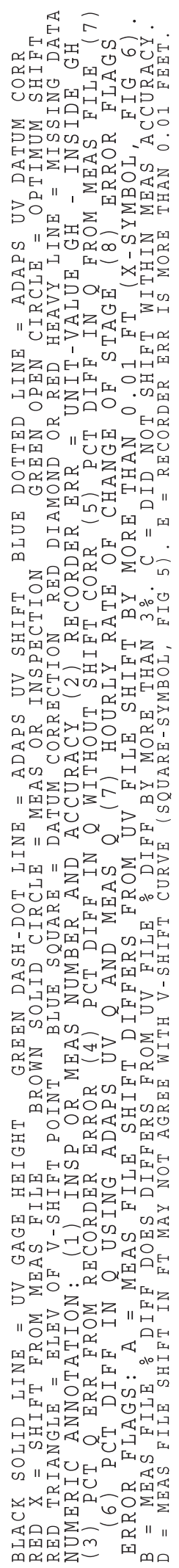



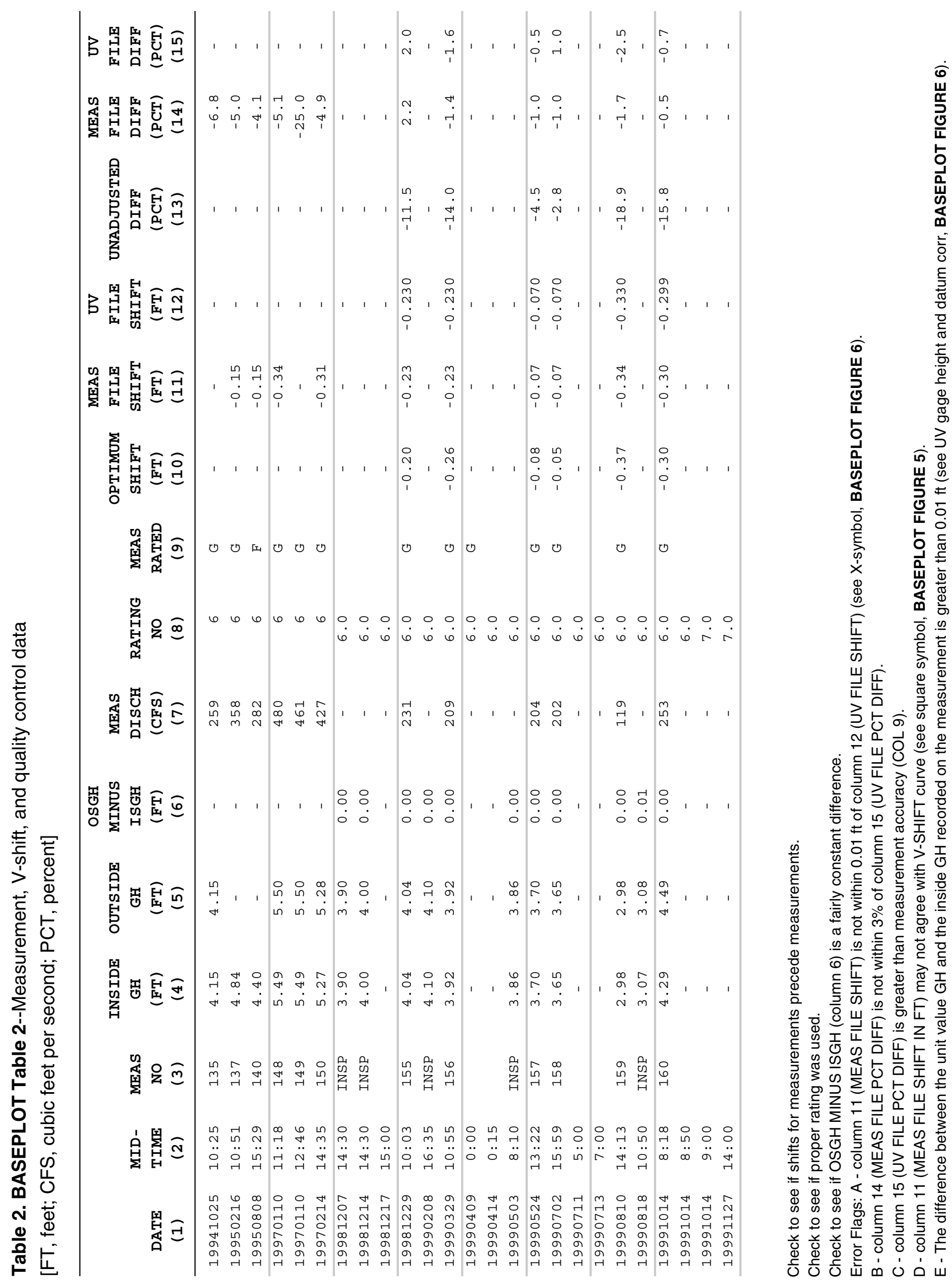


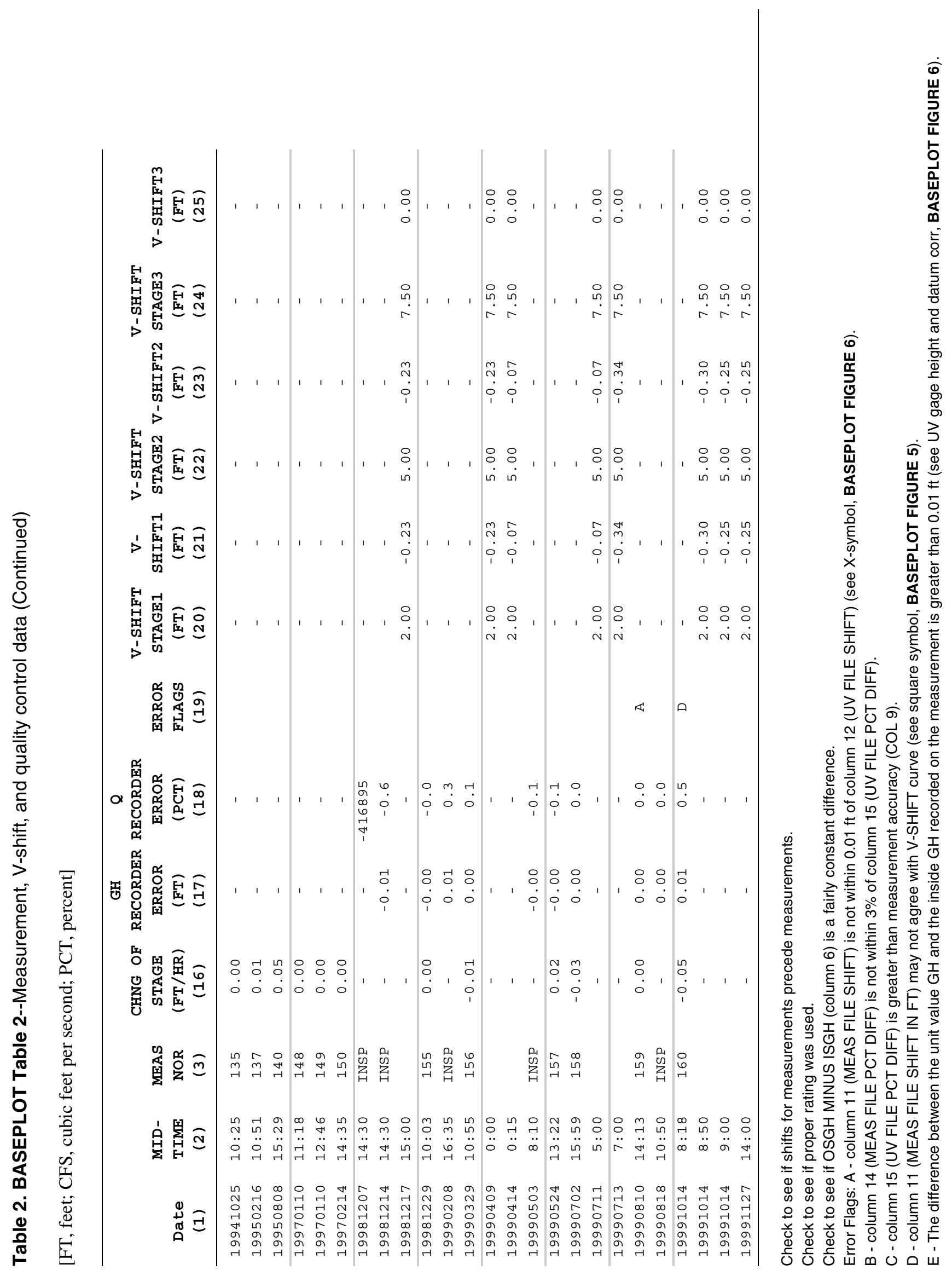




\section{2. "Was the optimum shift always used?"}

"If the "o" symbol for the optimum shift falls exactly on the "square" symbol for the measurement-file shift, the optimum shift was used. If the optimum shift is used throughout the analysis, this may mean that an attempt was not made to get as many measurements as possible on each v-shift curve."

Each v-shift curve should average as many measurements as possible, because inaccuracies of individual measurements are minimized by the averaging process. In addition, the smaller the number of v-shifts, the more analytical time is saved because there are fewer shifts to apply and explain in the station analysis. Therefore, efforts should be made to get as many measurements on one shift curve as possible.

Example Analysis: The answer is "no".

\section{3. "Do all the squares (shifts entered in the measurement file) fall within $0.01 \mathrm{ft}$ of the V-shift curves?"}

"If not, there MAY be an error somewhere in the shifting process."

WARNINGS: (1) Currently, BASEPLOT does not interpolate from one v-shift curve to another $v$-shift curve with time. Therefore, if shift curves of different shapes are applied on either side of a measurement, the square may not fall on the v-shift line, even though the shift may have been applied correctly. If the square does not fall on the $v$-shift curve for whatever reason (including the one in warning 2 below) but the answer to questions 4 and 5 below are "Yes", the reviewer is assured that the shift was probably applied properly.

(2) The program assumes that the shift is applied before the measurement. If the measurement is plotted, but no shift curve is plotted or the square does not fall on the shift curve, it may mean that the shift was applied shortly after the measurement. DO NOT CHANGE THE TIME OF THE SHIFT AND RERUN THE PRIMARY JUST TO MAKE FIGURE 5 CORRECT.

(3) If the measurement is not plotted, it may mean that the time of the measurement was not entered in the measurement file, and the measurement file should be corrected.

Note: ERR flags A-D in Figure 5 can also be reviewed in Figure 6 or Table 2. ERR flag E can be reviewed on either Figure 6 or Table 2. See questions for Table 2 for a definition of the flags.

The warnings are self-explanatory, and should be heeded to avoid unnecessarily spending time checking for errors. If the situation described in warning 2 exists, do not rerun the primary just to correct the BASEPLOT output. 
The V-shift curve in BASEPLOT Figure 5 is plotted using the V-shift data entered into the ADAPS database. The shift entered in the measurement file for a measurement is the shift selected by the hydrographer, but may not be the optimum shift and erroneously may not be the shift used for streamflow computation. The optimum shift is the shift that will adjust the stagedischarge rating to agree closely with the measurement, with a minimum residual percent difference. The selected shift entered in the measurement file should agree almost exactly with the $\mathrm{V}$-shift curve entered into ADAPS, as shown by the square plotting exactly on the V-shift curve (fig. 9). If the square does not plot on the V-shift curve and the conditions described in warnings 1 and 2 above do not exist, then there must be an error in the computation of the shift in the measurement file, the derivation of the V-shift curve, or data entry. If the square does not plot on the V-shift line and the differences described in question 4 (below) are within 3 percent, the reviewer can assume that the mathematical computation of the shifts were correctly done.

Example Analysis: The answer is "No," for measurement 160 (fig. 11).

Note: ERR flags A-D in Figure 5 can also be reviewed in Figure 6 or Table 2. ERR flag E can be reviewed on either Figure 6 or Table 2. See questions for Table 2 for a definition of the flags.

The BASEPLOT numeric quality control flags and information usable for understanding what caused the flags are included in the numeric annotation for BASEPLOT Figure 5. The following annotation is shown in Figure 11. The annotation proceeds from the top of BASEPLOT Figure 5 to the bottom of the figure in the order of increasing measurement number and time.

$$
\begin{aligned}
& <-\# 159 G /-18.9,-1.7,-2.5 / 0.00 / E R R=A \\
& <--\# 160 G /-15.8,-0.5,-0.7 /-0.05 / E R R=D
\end{aligned}
$$

The annotation is as follows:

a. The "<--" arrow points to the optimum shift of the measurement, as indicated by the circle on the plot.

b. "\#159" is the measurement number.

c "G" means that the measurement was rated "Good."

d. "-18.9" indicates that the percent difference in the measurement file between the measured discharge and the rating discharge without shifting is -18.9 percent.

e. "-1.7" indicates that the percent difference in the measurement file between the rating discharge and the discharge after shifting is -1.7 percent.

f. "-2.5" indicates that the percent difference between the measurement discharge and the unitvalue discharge at the midtime of the measurement is -2.5 percent. If the measurement-file percent difference differs from the unit-value file percent difference by more than 3 percent, Error Flag B is raised). 
g. "0.00" indicates that the hourly rate-of-change-of-stage during the discharge measurement was $0.00 \mathrm{ft} / \mathrm{hr}$; because the stage did not change during the measurement (or if it were very small, as in the "\#160" example), the computation of the unit-value file difference (-2.5 percent in the "\#159" example) is accurate.

h. "ERR=A" and "ERR=D" means that numeric quality control error flags A and D, described earlier in this report, were detected by the program. Error Flag A means that the measurement file shift, in feet, differs from the unit-value file shift by more than $0.01 \mathrm{ft}$, which cannot be verified by looking at BASEPLOT Figure 5. However, it can be seen that the " $\mathrm{X}$ " symbol for the measurement-file shift does not fall on the unit-value shift hydrograph in Figure 21 of this report.

Error Flag D for measurement number 160 means that measurement file shift does not agree with the V-shift curve, as indicated by the square symbol not falling on the V-shift line in Figure 11. Inspection of BASEPLOT Table 2 shows that the shift associated with measurement 160 was entered into the ADAPS shift file after measurement 160, rather than before. Although it is illogical to enter the shift for a measurement after the measurement rather than before it, the difference in timing is so small that no perceptible difference in discharge would be computed if a correction were made. Therefore, the user would not rerun the primary and then BASEPLOT just to correct the logic; the user should just make a note in the BASEPLOT Table 2 section of the Checklist describing the reason for the error flag, and then continue with the review.

\section{BASEPLOT Figure 6-Hydrograph of Gage Heights, Shifts, and Datum Corrections}

The reviewer checks the unit-value gage heights, the applications of shifts with time and stage, and datum corrections, and numeric quality control checks in BASEPLOT Figure 6 (figs. 12-24) as follows.

1. "Are visually obvious gage height errors from float problems, frozen wells, mud in the well, and recorder malfunctions corrected as shown by plotted datum corrections?"

"If not, datum corrections must be applied in ADAPS."

If the reviewer detects an error in the gage height hydrograph as shown by anomalous data such as flat periods, sudden spikes, or increases/decreases, and a datum correction is not plotted on the hydrograph, the error has not been corrected by a datum correction in ADAPS.

Example Analysis: The answer is "yes," because no uncorrected errors were detected.

2. "If datum corrections were made as depicted by squares and dotted lines, is the gage height line below the plotted datum corrections appropriately smoothed by the corrections?"

"If not, the datum corrections need to be corrected. WARNING: If ERR flag E is raised, check the unit-value datum correction line in BASEPLOT Figure 6 to see if the correction was made." 
Datum corrections are depicted by squares showing input datum correction points and dashed lines showing interpolated unit-value datum corrections (figs. 15 and 23). Where a datum correction is depicted, the reviewer should check the corresponding gage height hydrograph to ensure that the applied datum correction resulted in a smooth and reasonable gage height hydrograph. If extremely large datum corrections are interpolated with time, the reviewer should use the hydrographic comparisons produced by program HYDCOMP (C.L. Sanders, U.S. Geological Survey, written commun., October 2000) to ensure that the interpolation is not greatly in error.

Example Analysis: The answer is "yes."

3. "If the unit-value shift line varies uniformly with time between shift applications (depicted by triangles), do any large rises occur between the shift applications?"

"If they do occur, the shift was applied by time only, and possibly should have been applied by time and stage at or since the last significant rise."

A major function of BASEPLOT is to graphically display the data to make it easier for the reviewer to quickly evaluate the logic used in applying shifts with time and gage height. Review methods are described below.

Gage heights of the V-shift diagrams are depicted by triangles plotted on the BASEPLOT Figure 6 hydrographs. The V-shifts corresponding to the V-shift gage heights are demonstrated in the example below (fig. 13).

$$
\text { SHIFTS }=0.00,-0.23,-0.23-->
$$

The shift corresponding to the uppermost V-shift point is $0.00 \mathrm{ft}$. The shifts at the mid-point and lower point of the V-shift diagram are both $-0.23 \mathrm{ft}$. The "-->" arrow points to the time the V-shift was applied.

Lacking other evidence, shifts are usually assumed to be caused by high velocities and heavy sediment loads during large rises or floods. Therefore, if the hydrographer applied the shift by time only when floods existed between measurements, it may be more reasonable to apply the shift on the rising or falling stages of the rise.

Example Analysis: The answer is "yes." Associated with rating 6, a shift of $-0.34 \mathrm{ft}$ on July 13 , 1999 (figure 20), was varied uniformly by time to a unit-value shift of $-0.30 \mathrm{ft}$ on October 14 , 1999 (figure 23). Associated with rating 7, a unit-value shift of $-0.25 \mathrm{ft}$ was applied on October 14, 1999 (figure 23), when the ratings changed. In both cases, the shift diagrams were interpolated uniformly by time, and not attributed to floods. However, a rise of 4.6 feet occurred on September 22, 1999, and a rise of about 5.1 feet occurred on September 29, 1999 (fig. 22). Shifts had been applied on the rise of 5.3 feet on April 10, 1999 (fig. 17), and on the rise of $5.7 \mathrm{ft}$ on July 13, 1999 (fig. 20). Therefore, the rise of 5.1 feet on September 29, 1999 (fig. 22), could have caused the change in shift from $-0.34 \mathrm{ft}$ to $-0.30 \mathrm{ft}$.

An alternative would be to apply the change in shifts over the four rises that occurred between September 22, 1999, and October 14, 1999 (figs. 22 and 23). Because none of the rises seem to be unusually large and the change in shift seems small, the reviewer would probably not reverse the original decision to shift by time only. 
4. For shifts being applied during flood events, are scouring shifts (shifts becoming more positive) applied on rising stages and filling shifts (shifts becoming more negative) applied on the falling stages?"

"V-shifts are depicted by triangles at the gage heights of the V-shifts. The logic used for the timing and magnitude of these shifts may be determined by looking at rises on the stage hydrographs, the dates of the measurements plotted on the hydrographs, and the locations of the shifts depicted by triangles."

If there are large rises between the two measurements, a common practice is to apply "scouring" shifts (shifts becoming more positive) on the rising limb of large rises and to apply "filling" shifts (shifts becoming more negative) on the falling limb of large rises. Discharge in a river is not only a function of the stage as used in the stage-discharge rating, but also a function of fall (slope of the water surface) at the stage in question. On rising stages, the downstream channel and/or overbank area are relatively empty, so fall and discharge are higher than at the same stage on falling stages. On falling stages, the bulk of the flood water has filled the downstream channel and(or) overbank areas, so the fall and discharge for falling stages may be less than for rising stages at the same gage height. It is assumed (though not proven) that the higher velocities on a rising stage would cause the river bed to be lowered by scour, and that lower velocities on falling stages would allow sediment carried by preceding higher flood flow to be deposited in the downstream channel. Therefore the reviewer should check to see if the V-shifts depicted by the triangles are properly applied at the beginning and end of rising stages or falling stages, depending on whether the shifts are scouring or filling shifts. The reviewer should check to see if the shift applications are correct, and if the shift was distributed across several rises, or just during one rise.

Another method for applying shifts during rises is to apply the entire change in shift during a time when the gage height is higher than the highest gage height of the shift, where no mathematical shifting is being done. Typically, shift curves go to zero at the point of greatest curvature of the rating, where flows may be getting out of banks and becoming substantially larger than in-bank flow. In this method, it is assumed that the larger out-of-bank flows are more able to change the control by scour or making sediment deposits than lower in-bank flows.

Example Analysis: The answer is "no." A scouring shift (shift becoming more positive) was incorrectly applied on the falling stages of the rise of April 10, 1999, rather than on the rising stages (fig. 17). Also, a filling shift (shift becoming more negative) was inappropriately applied on the rising stages on July 13, 1999 (fig. 20). The record should be revised.

5. "During periods of flat gage heights and no precipitation, do small, sudden changes or gradual changes of gage height signal a period of shifting because of leaves, trash, or ice being caught on or released from a control, or because of degradation or aggradation of a sand channel?"

Sudden changes of gage height during periods of otherwise non-changing gage heights could indicate the sudden accumulation or removal of debris from the control, when a shift should be applied. Periods of increasing or decreasing gage heights during lengthy periods of no runoff and shallow, high-velocity flows could mean aggradation or degradation of sand channels and indicate where to apply shifts. Gage height changes may indicate the beginning of shifting because of 
ice forming or melting in the stream, but the formation or melting of ice should be verified by temperature and rainfall data, and by hydrographic comparison to other stations using program HYDCOMP (C.L. Sanders, U.S. Geological Survey, written commun., October 2000) or similar methodology.

Example Analysis: The answer is "no."

6. "In general, have the shifts with time or time and gage height been properly applied?"

V-shift values are depicted beside triangles plotted at the gage height points of the V-shift diagram. Measurements are depicted by the plotted "X," solid circle, open circle, and numeric data on the plot. The reviewer should inspect the numeric shift information at successive measurements, and then evaluate the shifting logic by viewing the V-shift input data indicated by triangles, and the unit-value shifts and gage heights.

Example Analysis: The answer is "no," because of the incorrect applications of a scouring shift on the falling stages of the rise of April 10, 1999, and a filling shift on the rise of July 13, 1999.

7. "Have known or assumed physical reasons for shifting been documented in the station analysis?"

"The answer should be "yes." If a physical reason is not known or postulated for shifting, it cannot be known when or how to apply the shift."

The sometimes common practice of listing the dates and times of shifts in the station analysis without explanations of physical reasons for the shifts should be discontinued.

Example Analysis: The reviewer determines if reasons were given in the Station Analysis and if they are valid.

8. "Was there continuity of discharge at the Sept. 30 - Oct. 1 boundary in spite of rating changes or carried-over shifts at the boundary?"

A check should be made at the September 30 - October 1 boundary of the water year to determine if a transition from one rating to another or shift change at the boundary causes a discontinuity in discharge.

Example analysis: The answer is "yes."

Note: ERR flags A-D in Figure 6 also can be reviewed in Figure 5 and Table 2. ERR flag E in Figure 6 also can be reviewed in Table 2. See questions for Table 2 for a definition of the flags.

The BASEPLOT numeric quality control flags and information usable for understanding what caused the flags are included in the numeric annotation for BASEPLOT Figure 5. The following annotation is shown in Figure 21. The annotation for measurements, inspections, and shifts proceeds from the top of BASEPLOT Figure 6 to the bottom of the figure, sorted by increasing time. 
In this example, BASEPLOT was run with the "short" argument (the same as leaving off the "long" argument). If the "short" argument is used, numeric annotation is made on BASEPLOT Figure 6 only if a numeric error flag is raised.

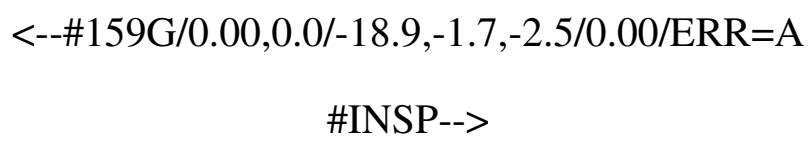

The forward slashes divide the annotation into the following categories of information:

a. Measurement number and measurement quality.

b. Gage height accuracy information, in $\mathrm{ft}$ and percent discharge error.

c. Shift differences, in percent.

d. Hourly rate-of-change-of-stage during the measurement.

e. Numeric quality control error flags.

The annotation is as follows:

a. The "<--" arrow points to the midtime of the measurement or the time of the inspection.

b. "\#159" is the measurement number and "\#INSP" indicates an inspection. For inspections, only the information listed under " $d$ " and "e" below will appear.

c. "G" means that the measurement was rated "Good."

d. " 0.00 " is the gage height error, or the difference between the inside gage height of the measurement or inspection and the unit-value gage height at the mid-time of the measurement or time of the shift. If this difference is larger than $0.01 \mathrm{ft}$, Error Flag E is raised.

e. " 0.0 " is the percent error in discharge resulting from the recorder error " 0.00 ." This error should be less than 3 percent, unless the stage-discharge rating is very flat.

f. "-18.9" indicates that the percent difference between the measured discharge and the rating discharge without shifting is -18.9 percent.

g. "-1.7" indicates that the percent difference between the rating discharge and the discharge after shifting, entered in the measurement file, is -1.7 percent.

h. "-2.5" indicates that the percent difference between the measurement discharge and the unit-value discharge at the midtime of the measurement is -2.5 percent. (Note: if the measurement-file percent difference differs from the unit-value file percent difference is more than 3 percent, Error Flag B is raised.)

i. " 0.00 " indicates that the hourly rate-of-change-of-stage during the discharge measurement was $0.00 \mathrm{ft} / \mathrm{hr}$. Because the stage did not change during the measurement or if it were very small, the computation of the unit-value file difference ( -2.5 percent in the example) is accurate. 
j. "ERR=A" means that numeric quality control error flag A, described earlier in this report were detected by the program. Error Flag A means that the measurement-file shift, in feet, differs from the unit-value file shift by more than $0.01 \mathrm{ft}$. In Figure 21 , note that the " $\mathrm{X}$ " symbol for the measurement-file shift does not fall on the unit-value shift hydrograph.

Notes: (a) Items f-j below are the same as items d-h documented for BASEPLOT Figure 5.

(b) Items d and e did not appear for the inspection (\#INSP) because Error Flag E was not raised for the inspection.

\section{BASEPLOT Table 1-Percent Differences Between Measurements in Prior 4 Years and the Current Ratings}

BASEPLOT Table 1 compares the rating(s) being analyzed in the current period of review with measurements made in the 4 years prior to the period being reviewed and/or that have higher discharges than the highest discharge measured during the period being reviewed. In the example station, from August 1, 1998, to November 30, 1999, the highest measured discharge was 253 cubic feet per second ( $\left.\mathrm{ft}^{3} / \mathrm{s}\right)$. Therefore, the program retrieved all the discharge measurements for the 1994-97 water years that are higher than $253 \mathrm{ft}^{3} / \mathrm{s}$, and compared all ratings used in the 1999 water year to these measurements by means of BASEPLOT Figure 1 and BASEPLOT Table 1. The purpose of the comparison is to determine if enough measurements have been made to define the upper end of the stage-discharge rating and to indicate whether or not the upper end of the current ratings should be redrawn. In particular, BASEPLOT Table 1 is useful to determine the exact percent difference between these measurements and the current rating(s), if it is determined visually from BASEPLOT Figure 1 that the measurements do not agree with the current ratings. Contents of BASEPLOT Table 1 are:

Column 1. DATE - Date of discharge measurement.

Column 2. MEAS NUMBER - Measurement number

Column 3. RATING NUMBER - Current stage-discharge rating number. Note that this is not the rating number originally associated with the measurement. It is the number of a rating used in the current period being reviewed.

Column 4. INSIDE GAGE HEIGHT - The inside gage height of the discharge measurement, in feet.

Column 5. MEAS DISCHARGE - Measured discharge, in cubic feet per second.

Column 6. RATING DISCHARGE - The discharge computed using the rating listed in Column 3, in cubic feet per second.

Column 7. MEAS RATED - Accuracy rating of the discharge measurement.

Column 8. PERCENT DIFFERENCE - The percent difference between the measured discharge (Column 5) and the current-rating discharge (Column 6).

If BASEPLOT Figure 1 indicates that some of these high-flow measurements do not agree with current rating(s), the reviewer can inspect this table to determine the degree of disagreement. 
At least some of these measurements should agree with the current rating(s), and there should be enough measurements during the current period and prior 4-year period to adequately define the upper end of the rating. If several of the most recent consecutive measurements have positive or negative percent differences, a new high-end stage-discharge rating may need to be redrawn.

BASEPLOT Table 1 is discussed below.

\section{1. "Are percent differences consistently positive or negative?"}

"If so, a new high-flow rating should be drawn."

If the most recent consecutive percent differences are consistently positive or negative and the differences average 3 percent or more, the upper end of the rating in use does not agree with the latest measurements. For these conditions, the reviewer should check to see if the shifts applied for these measurements in past years should be carried over to the current year, and if a new highflow rating should be redrawn.

Shift diagrams should be used only for the highly variable low-flow end of the rating and for temporary shifts of the less variable high-flow end of the rating. Do not use shift diagrams to define semi-permanent high flow ratings. New high-flow ratings are more easily remembered and carried over from one year to the next than high-flow shift curves.

Example Analysis: The answer is "yes." All of the differences are consistently negative.

Computed discharges for the current water year are probably correct because shifts were applied to the upper end of the rating, so they do not need to be revised. However, a new high-flow rating should be drawn for next year's records.

\section{BASEPLOT Table 2-Measurement, Inspection, V-shift, and Quality Control Data}

BASEPLOT Table 2 contains measurement, inspection, and shift data, and all the numeric quality control checks previously described. The table has four principal uses:

1. The tabular numeric quality control checks can be scanned without viewing the plots.

2. A comparison of inside and outside gage heights is made.

3. Numeric quality control values that are overwritten on the plots can be determined from this table.

4. Comparison of exact time of measurements and shifts can be made without having to mentally collate the measurement and shift data.

5. BASEPLOT Table 2 shows if bias exists after shifts have been applied. If percent differences are consistently positive or negative after shifting, the computed flows are biased.

Some of the numeric quality control checks in BASEPLOT Table 2 are repeated in BASEPLOT Figures 5 and 6 for convenience in comparing the checks to shift diagrams and to timing of measurements, shifts, and unit-value gage heights. Those quality control checks need to be reviewed only once. A detailed description of the contents of the BASEPLOT Table 2 follows. 
Column 1. DATE - date of measurement or shift, in YYYMMDD.

Column 2. TIME - Mid-time of measurement or shift, in HHMM.

Column 3. MEAS NO - Measurement number.

Column 4. INSIDE GH - Inside gage height of discharge measurement or inspection, in feet.

Column 5. OUTSIDE GH - Outside gage height of discharge measurement or inspection, in feet.

Column 6. OSGH MINUS ISGH - Outside gage height minus inside gage height, in feet.

Column 7. MEAS DISCH - Measurement discharge, in cubic feet per second.

Column 8. RATING NUMBER - Stage-discharge rating number.

Column 9. MEAS RATED - Accuracy rating of the discharge measurement.

Column 10. OPTIMUM SHIFT - Optimum shift, in feet.

The optimum shift is the shift, in feet, necessary to make the rating discharge agree with the measured discharge.

Column 11. MEAS FILE SHIFT - Shift, in feet, selected by the hydrographer and entered in the measurement file.

Column 12. UV FILE SHIFT - Unit-value file shift, in feet.

The unit-value shift is computed by subtracting the ADAPS unit-value gage height from the shifted unit-value gage height. The shifted unit-value gage height in BASEPLOT is computed by applying the unit-value discharge from ADAPS at the mid-time of the measurement to the current stage-discharge rating.

Column 13. UNADJUSTED DIFF - The unadjusted difference, in percent, between the measured discharge and rating discharge.

Column 14. MEAS FILE DIFF - The difference, in percent, between the measured discharge and the discharge from the stage-discharge rating table after application of the shift as entered in the measurement file.

Column 15. UV FILE DIFF - The difference, in percent, between the measured discharge and the unit-value discharge interpolated at the mid-time of the measurement.

Column 16. CHNG OF STAGE - Rate of change of stage in $\mathrm{ft} / \mathrm{hr}$, as determined from the begin and end times of the measurement, and the change of stage during the measurement. Error Flag B may be raised erroneously if the hourly rate of change of stage is large, as described after question 3 below and previously. Therefore, the hourly rate of change of stage is presented in column 16. For example, if Error Flag B is raised, and the hourly rate of change of stage is less than $0.1 \mathrm{ft} / \mathrm{hr}$, the flag is probably valid. 
Column 17. GH RECORDER ERROR - Difference between the inside gage height of the measurement and the unit-value gage height at the mid-time of the measurement or the time of the inspection, in feet.

Column 18. Q RECORDER ERROR - Percent error in discharge resulting from the recorder error in Column 17.

Column 19. ERROR FLAGS - Numeric quality control error flags A-E, as described below for question 3 and previously.

Columns 20-21, 22-23, and 24-25. V-shift STAGE1, V-shift1; V-shift STAGE2, V-shift2; and V-shift STAGE3, V-shift3 - The stages and V-shifts for each V-shift curve.

A discussion of the questions on BASEPLOT Table 2 follows:

1. "In column 6, are the differences between the inside and outside gage heights consistent with time?"

"If not, a person could have been entering erroneous gage heights into the database. Also, it could indicate settlement of one of the gages, water in the float, and so forth."

If the differences are not consistent with time, the reviewer should investigate why.

Example Analysis: The answer is "yes."

2. "Are the percent differences in discharge after shifting, as tabulated in columns 14 and 15 , consistently positive or negative from one measurement to the next?"

"If the percent differences are consistently positive or negative from one measurement to the next, and average roughly 3\% or more, the unit-value discharges are biased, and the v-shift curves should be re-worked to balance the individual optimum shifts, even if the differences are within the accuracy of the measurements. Such a bias could greatly affect the computation of intervening flows between two stations fairly close together on large rivers."

Individual $\mathrm{v}$-shift curves should average as many measurements as possible if the average percent differences are greater than about 3 percent and are consistently positive or negative. Inaccuracies of individual measurements are minimized by the averaging process.

Example Analysis: The answer is "no", because all the high flow measurements are consistently negative, indicating that the high-flow rating needs to be re-drawn. However, shifts were made to the high-flow rating, so computed discharges are probably correct for this water year.

3. If ERR flags were raised in Figures 5 or 6 or Table 2, have the flags been investigated?

Note: ERR flags A-D in Column 19 also can be reviewed in Figures 5 and 6. ERR flag E also can be reviewed in Figure 6 . The flags are:

(A) Measurement-file shift in feet (Column 11) differs from the unit-value shift in feet (Column 12) by more than 0.01 feet (the $X$-symbol should fall on the unit-value shift line in figure 6 ). 
(B) The measurement-file percent difference in percent (Column 14) after shifting differs from the percent difference using the unit-value discharge and the measured discharge (Column 15) by more than $3 \%$.

WARNINGS: (a) The two differences may not agree exactly, because the unit-value discharge is taken at the mid-time of the measurement, ignoring the fact that the discharge may not have changed uniformly with time during the measurement or with stationing across the cross section. IF THE DISAGREEMENT IS MORE THAN ABOUT 3 PERCENT AND THERE IS CONSIDERABLE CHANGE OF STAGE DURING THE MEASUREMENT, THEN IGNORE THE QUALITY CONTROL CHECK OF FLAGB.

(b) Also, if the rating is extremely flat, the difference may be more than 3 percent.

(C) Did not shift within the accuracy of the discharge measurement (the unit-value file difference (Column 15) is greater than the measurement accuracy (Column 9)).

(D) The measurement file shift, in feet, MAY differ from the V-shift curve by more than 0.01 feet (the square-symbol should fall on the V-shift line in Figure 5; ALSO, SEE THE WARNINGS ISSUED IN QUESTION 3 FOR FIGURE 5).

(E) The recorder error (Column 17, the unit-value height minus the measurement inside gage height) is more than 0.01 feet (see unit-value gage-height line at the time of the measurement and the datum corrections in Figure 6).

Error Flags A-E are described in the above note and in the section titled "Numeric quality control error flags A-E" of this report. The user can evaluate Error flags A-C and E in BASEPLOT Table 2. Error Flags A-C can be evaluated in BASEPLOT Figures 5 and 6. Error Flag D can be evaluated in BASEPLOT Figure 5, and Error Flag E can be evaluated in BASEPLOT Figure 6. The user can evaluate the flags on the BASEPLOT figures or in BASEPLOT Table 2, but must acknowledge for question 3 that the evaluation has been made. The user must also make notes in the comment columns and on the back of the form, if necessary, describing whether or not the flags were valid, or what actions were taken to correct the detected errors.

Example analysis: Error Flag A was raised for measurement 159, indicating the measurement file shift in column 11 was not within $0.01 \mathrm{ft}$ of the unit-value file shift in column 12 . The difference is $0.01 \mathrm{ft}$. The measurement-file percent difference in column 14 is -1.7 percent, and the unit-value file percent difference in column 14 is -2.5 percent. Therefore, the user will note that $0.01 \mathrm{ft}$ difference in shifting had very little effect on the final adjusted discharge, and no changes in the computed record are warranted. Because the hourly rate of change of stage in column $16 \mathrm{was} 0.0 \mathrm{ft} / \mathrm{hr}$, the unit-value percent difference in column 15 is accurate.

Error Flag D was raised for measurement 160, indicating that the measurement-file shift may differ from the V-shift curve by more than $0.01 \mathrm{ft}$, as shown in BASEPLOT Figure 5. However, BASEPLOT Table 2 shows that the V-shift associated with measurement 160 was applied after measurement 160, rather than before the measurement. Although this is not logical, computed flows will not be changed if the shift is moved before the measurement. Therefore, the user will note the reason that the flag will be ignored, and will NOT rerun the primary just to eliminate the flag from BASEPLOT output. 


\section{SUMMARY}

The checking and reviewing of daily records of streamflow is traditionally accomplished by hand-plotting and collating tables of measurements, datum corrections, and shift corrections on daily value or unitvalue hydrographs; reviewing hand-plotted shift curves; and reviewing hand- or computer-drawn stagedischarge ratings. The process is very time consuming, difficult to standardize, and subject to errors in computation, data entry, and logic. The presentation of flow data on the internet requires more timeefficient and accurate computation of daily flow records.

Program BASEPLOT was designed to make checking and review of primary flow records more efficient and less costly; improve quality control; achieve some uniformity of checking and review techniques; and provide a tool for teaching streamflow computation techniques to inexperienced hydrographers.

By using data already stored in the ADAPS database, the BASEPLOT program produces tables of quality control checks and produces plots of rating curves and discharge measurements; variable shift (V-shift) diagrams; and V-shifts converted to stage-discharge plots. In addition, the program plots unit-value hydrographs showing unit-value stage, shifts, and datum corrections; input shifts, datum corrections, and effective dates; discharge measurements; effective dates for rating tables; and numeric quality control checks. Checklist/tutorial forms are provided for reviewers to ensure completeness and standardization of the review process.

\section{REFERENCES}

National Water Information System, 1997, Automated data processing system, ADAPS user's manual: U.S. Geological Survey, [about 400] p.

Kennedy, E.J., 1983, Computations of continuous records of streamflow: U.S. Geological Survey Techniques of Water-Resources Investigations, Book 5, chap. A13, 53 p.

Kennedy, E.J., 1984, Discharge ratings at gaging stations: U.S. Geological Survey Techniques of WaterResources Investigations, Book 3, chap. A10, 59 p.

Rantz, S.E., and others, 1982, Measurement and computation of streamflow; Volume 1. Computation of discharge, Volume 2: U.S. Geological Survey Water-Supply Paper 2175, 631 p.

SAS Institute, Inc., 1993, SAS language: Reference, version 6, (1st ed.): Cary, N.C., 1042 p. 


\section{APPENDIX}

Review Checklist for Computer Program BASEPLOT 


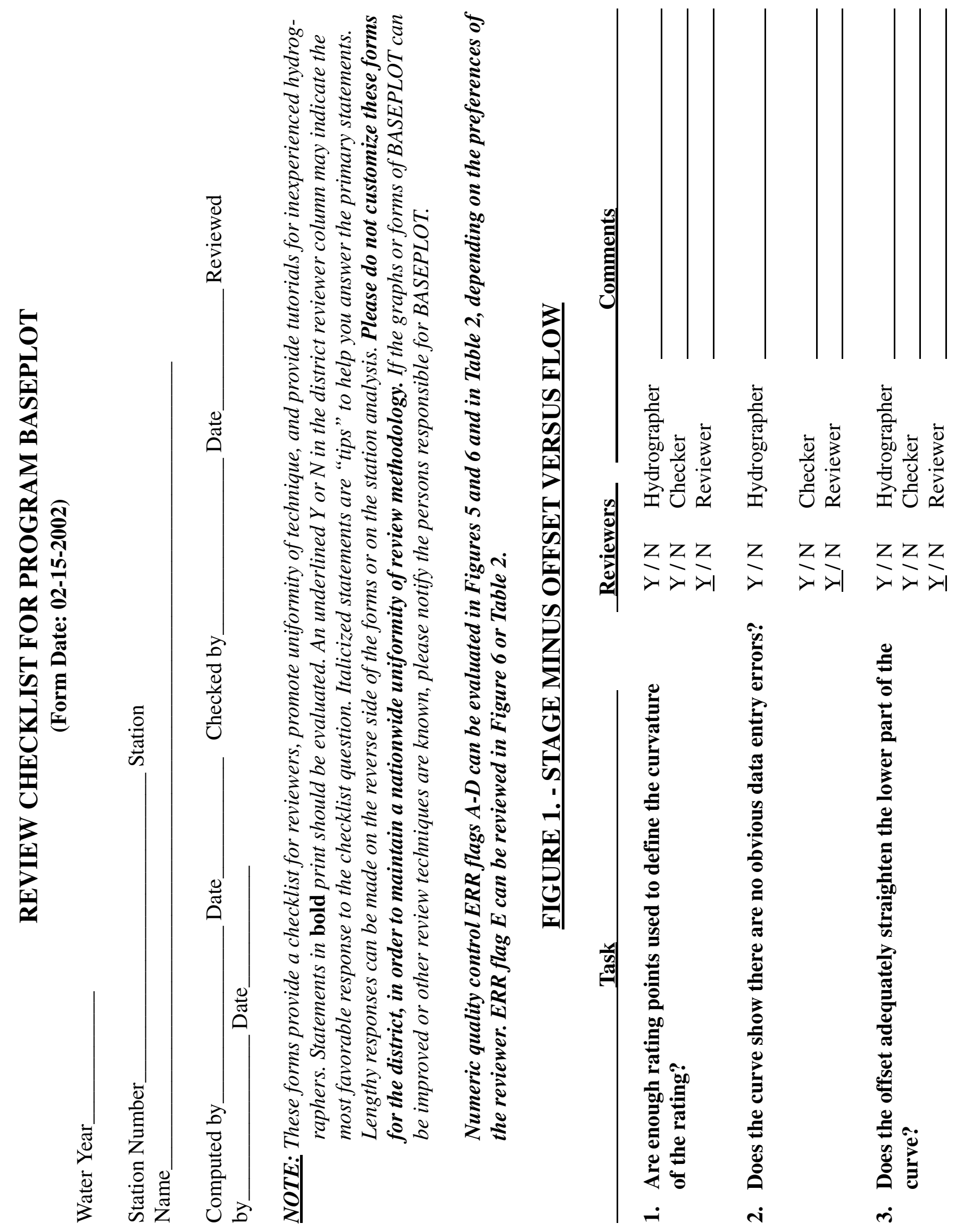




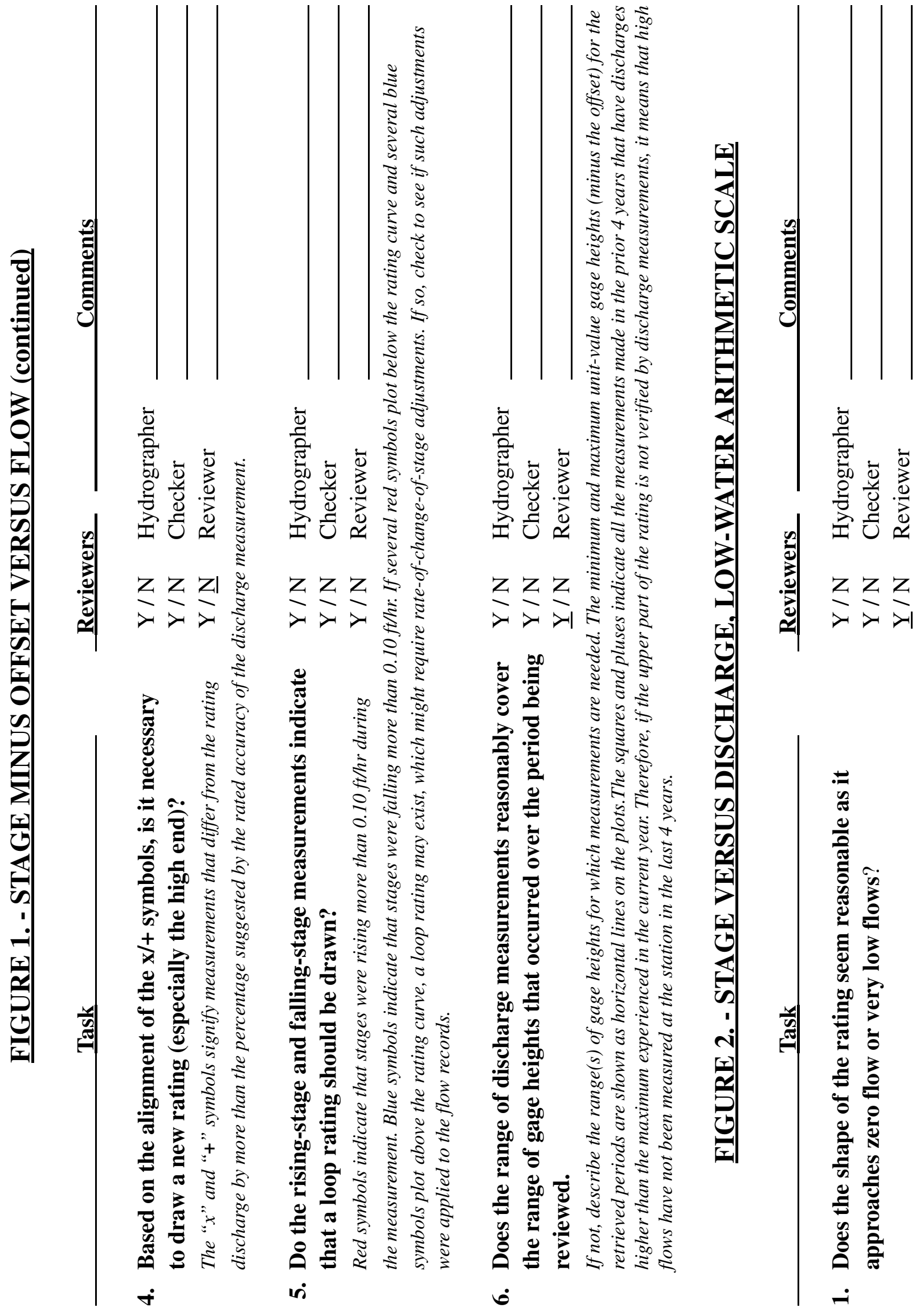




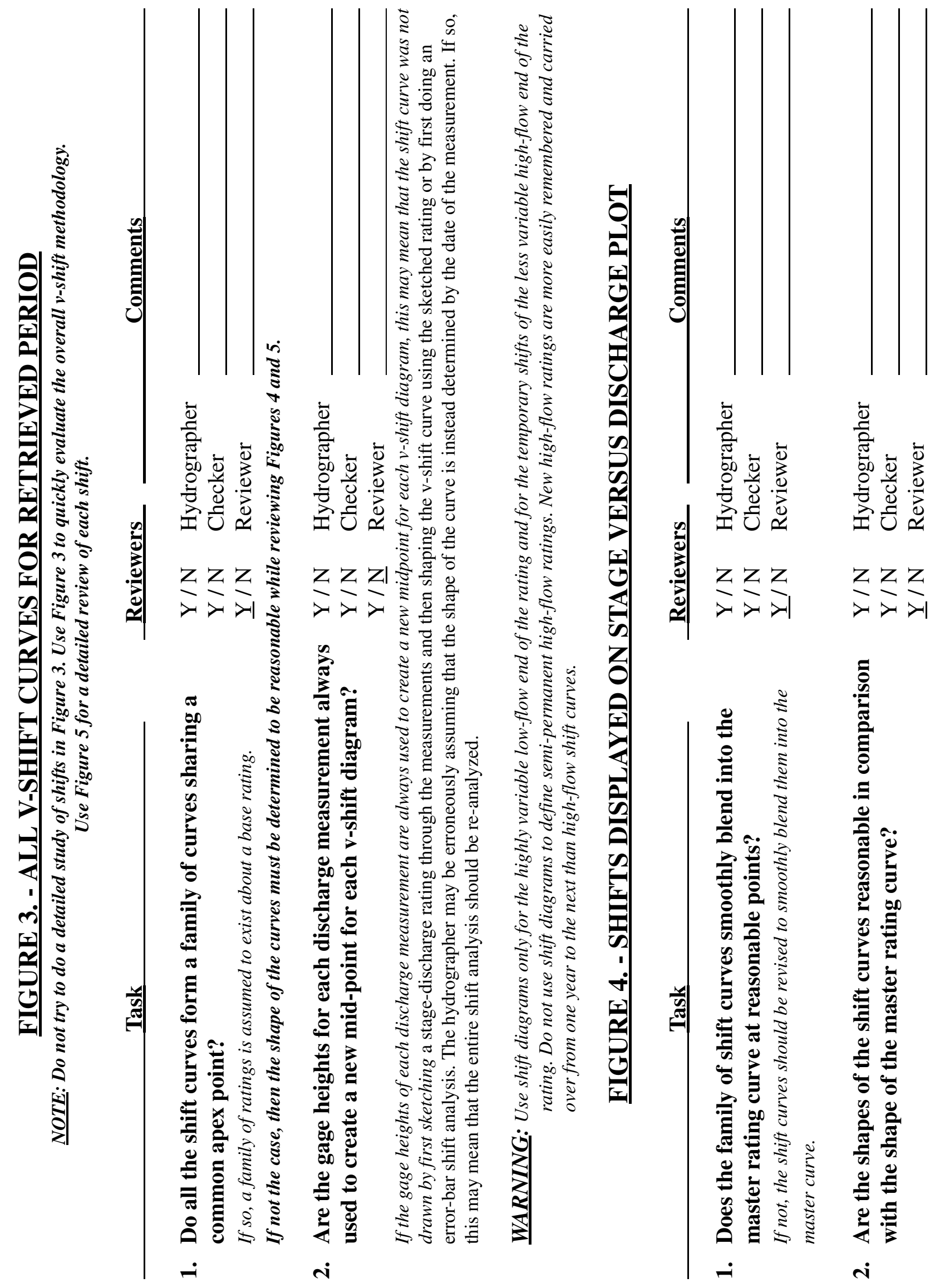




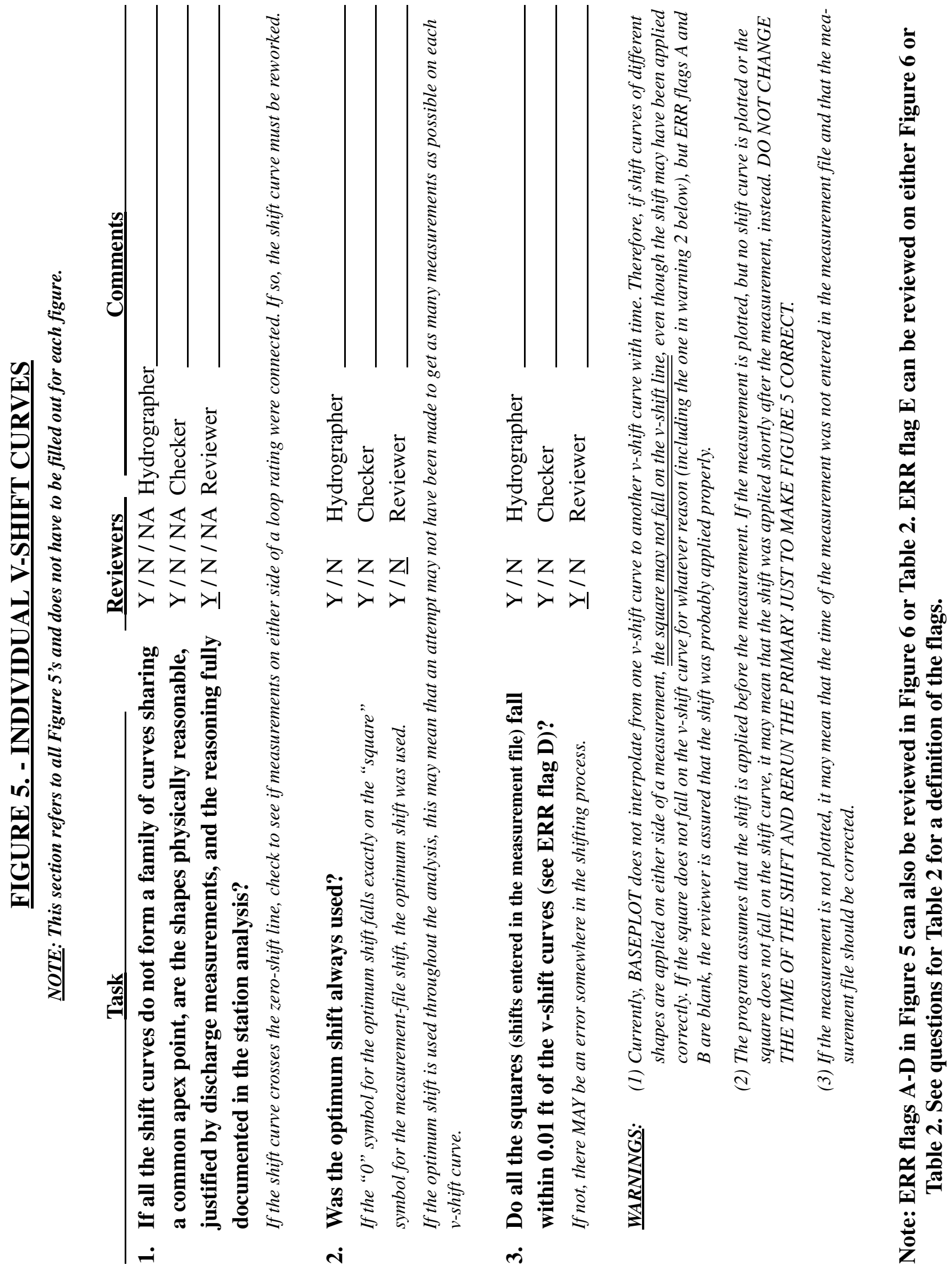




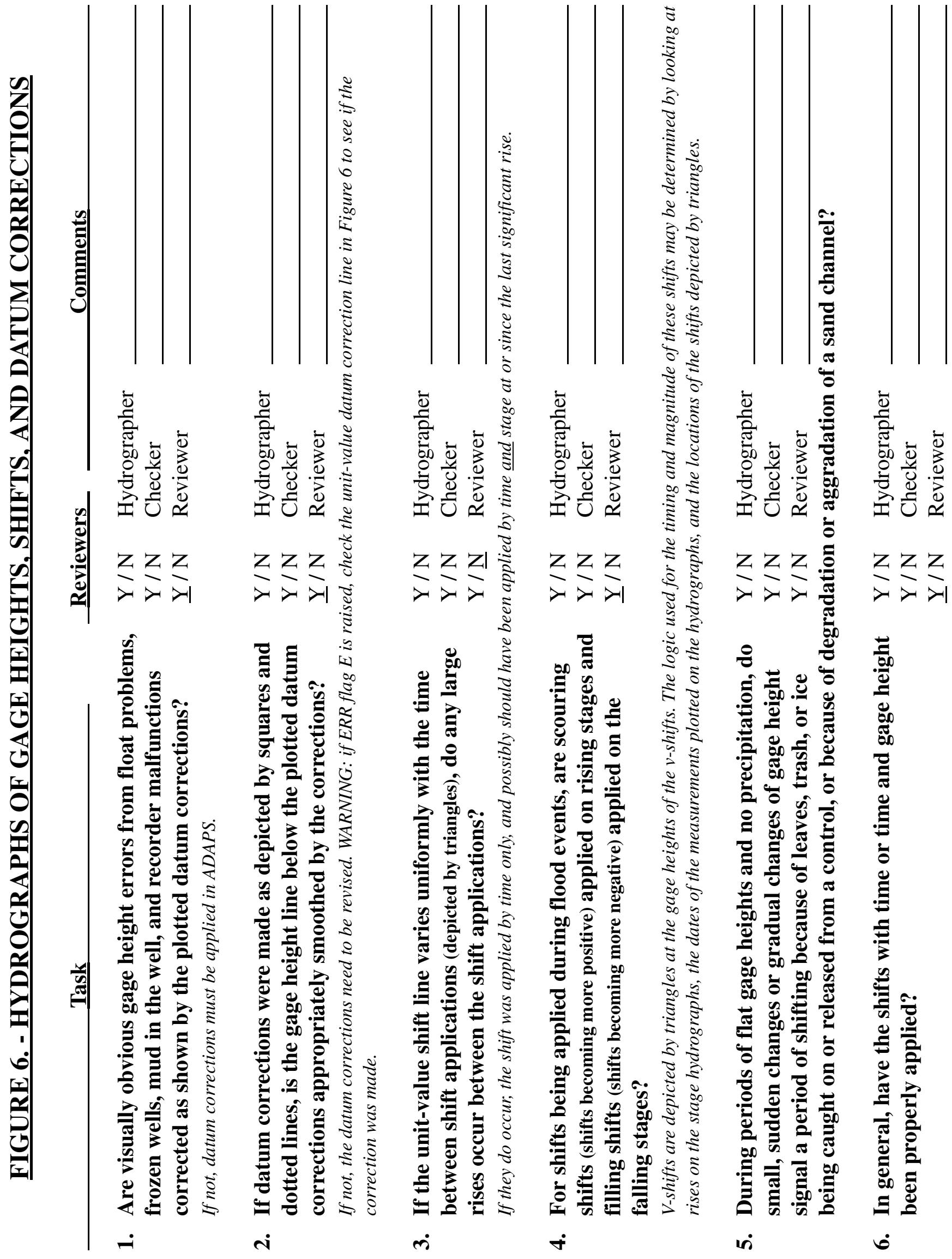




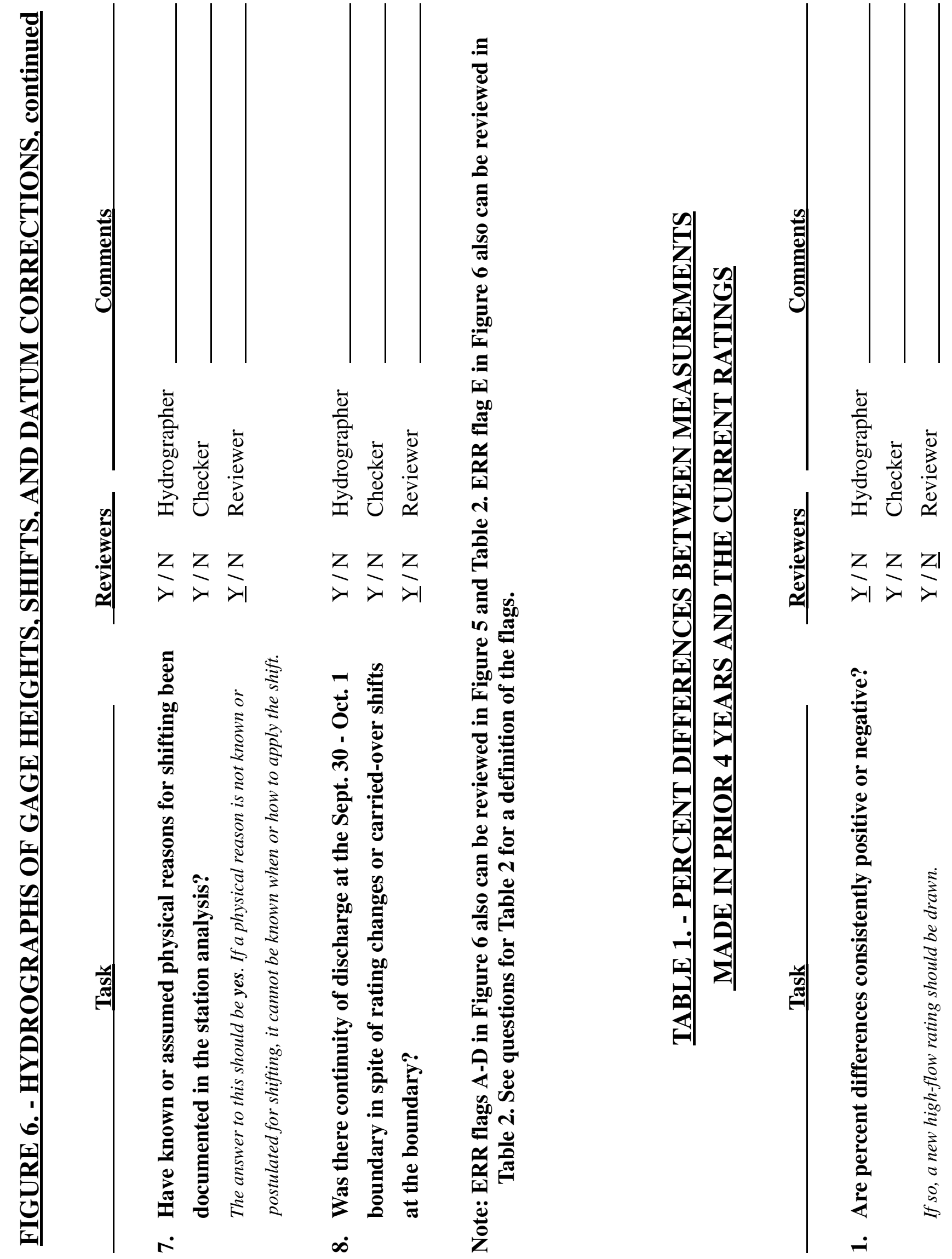




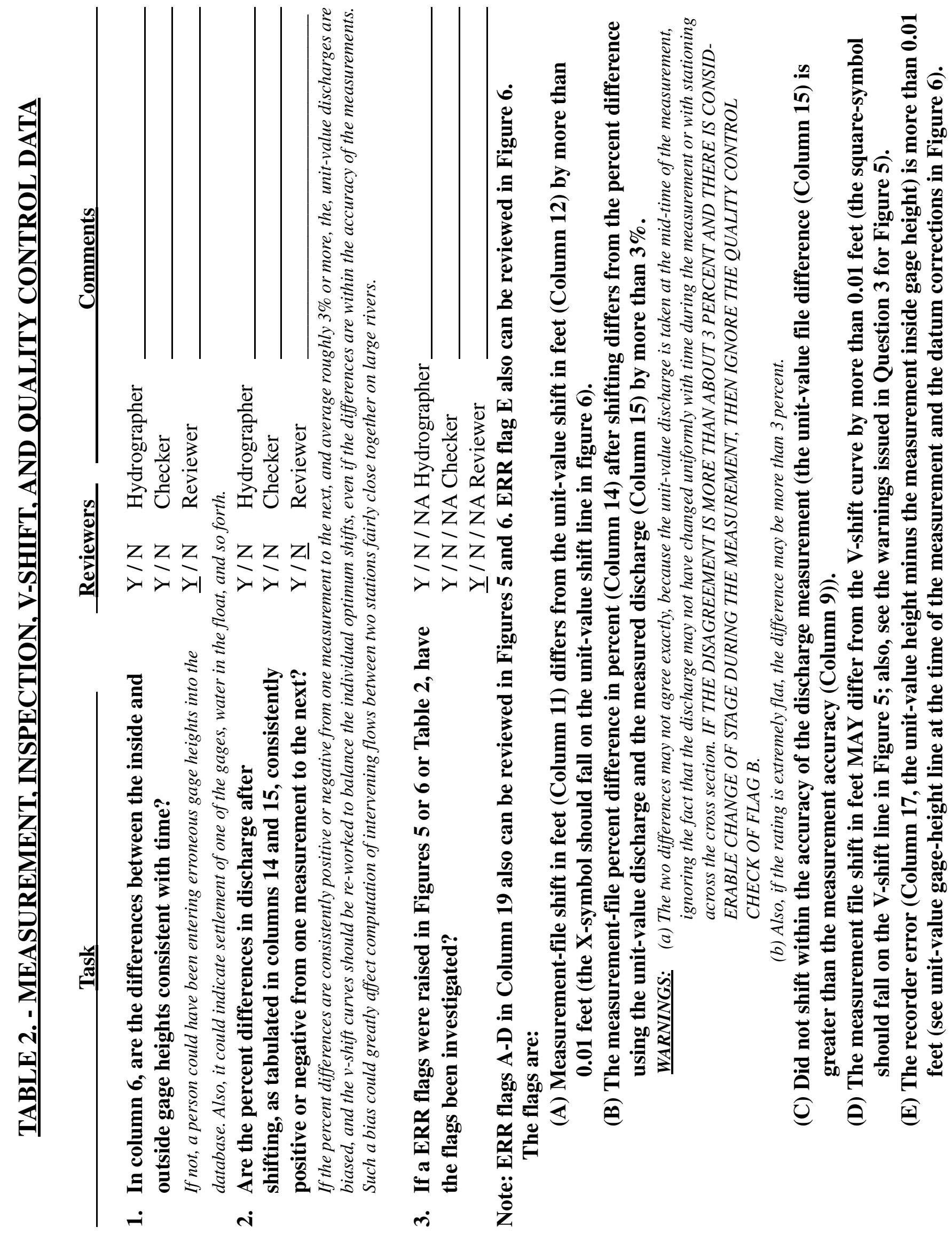




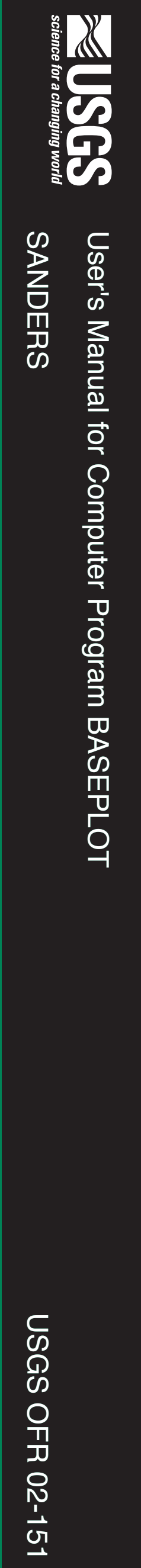

